\title{
Estudo de uma conceituação geométrica para os logaritmos
}

\author{
Fernando Pavan Guido
}

DiSSERTAÇÃO APRESENTADA AO

Instituto DE MATEMÁTICA E ESTATÍSTICA DA

UNIVERSidAdE DE SÃo PAUlO NO

Programa de Mestrado Profissional em

ENSINO DE MATEMÁTICA

Programa: Mestrado Profissional em Ensino de Matemática

Orientadora: Profa. Dra. Iole de Freitas Druck 


\section{Estudo de uma conceituação geométrica para os logaritmos}

Dissertação apresentada ao Programa de Mestrado Profissional em Ensino de Matemática no Instituto de Matemática e Estatística da Universidade de São Paulo para obtenção do título de Mestre em Ciências. Esta versão contém as correções e alterações sugeridas pela Comissão Julgadora durante defesa pública ocorrida em $26 / 04 / 2017$. 
A essência da matemática reside em sua liberdade.

Então criou Cantor seu paraíso e trouxe a luz. Todo o restante... é obra do homem. 


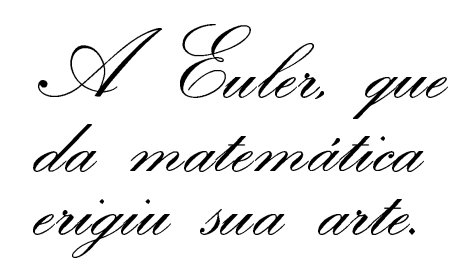




\section{Agradecimentos}

Agradeço à minha noiva por estar ao meu lado, sempre me apoiando, mesmo nos momentos críticos pelo qual passei ao longo de mais essa caminhada e por sempre compartilhar meus (nossos) devaneios. Te amo.

À minha mãe que passou a acreditar em mim e compreender minhas convicções e ao meu pai, que mesmo tendo partido tão cedo, foi o responsável por toda a base do meu conhecimento e caráter. Após duros anos sem entender, percebi, que se hoje consigo voar, foram pelas noites em claro que passou me contando histórias de planetas com pessoas engraçadas, raposas, asteroides, cowboys domadores de tufões e tudo o mais do qual nem o céu era o limite. Sei que se estivesse aqui hoje ficaria orgulhoso de mim.

Aos colegas que fiz ao longo do curso e aos que já conhecia antes. Em especial, Ana Olivia, André, Caio, Cintia, Claudio, Douglas, Lili, Marília, Monica, Paçoca, Rodrigo, Ronaldo, Tadeu, Vinicius e Will que de algum modo fizeram parte dessa etapa

Aos professores Antonio Carlos Brolezzi, Cláudia Cueva Candido, Claudio Possani, Cristina Cerri, Cesar Polcino, Marcos Magalhães, Oscar João Abdounur e Rosa Maria Barreiro Chaves por fazer parte direta ou indiretamente do meu enriquecimento acadêmico, profissional e cultural. E à professora Ana Paula pelas contribuições, apoio e maravilhosas aulas.

Aos professores Ruy César Pietropaolo, Bárbara Corominas Valério, Lucília Daruiz Borsari e Rogério Ferreira da Fonseca por terem aceitado participar da minha banca de qualificação, sei que seus apontamentos serão extremamente valiosos para o engrandecimento deste trabalho. Em especial, gostaria de expressar meus eternos agradecimentos ao professor Rogério (meu orientador na graduação). Ninguém melhor do que você pra dividir essa vitória comigo.

E por fim, à minha querida orientadora, prof. Iole de Freitas Druck. Não apenas por suas ótimas aulas ou magistrais orientações nesse trabalho, mas, muito mais importante, pelos momentos de conversa, pelo ombro amigo e por toda ajuda (mesmo antes de ser aluno). Foi muito tranquilo e engrandecedor trabalhar contigo. Muito obrigado.

Obrigado a todos. 


\section{Resumo}

GUIDO, F. P. Estudo de uma conceituação geométrica para os logaritmos. 2017. 118 f. Dissertação (Mestrado) - Instituto de Matemática e Estatística, Universidade de São Paulo, São Paulo, 2017.

Este trabalho tem como objetivo principal contribuir para o aperfeiçoamento do professor de matemática seja ele em formação ou em atuação. Buscamos oferecer um material que possa servir de referência técnica, histórica e epistemológica para o estudo do Logaritmo Natural. Discutimos aqui o conceito de Conhecimento Especializado do Conteúdo, cunhado por pesquisadores da Universidade de Michigan e liderados por Deborah Ball. Em seu artigo Content Knowledge for Teaching: What Makes It Special? (2008), eles levantam a questão "Qual matemática o professor deve conhecer para dar cabo do trabalho de ensinar?", dado que o conhecimento matemático necessário para o docente difere do conhecimento matemático requerido em outras profissões. Fazemos aqui uma análise crítica da abordagem utilizada para o tema em alguns livros didáticos de Ensino Médio, descrevemos de modo detalhado a construção da Função Logarítmica como realmente ocorreu no século XVII, ou seja, por meio de áreas de regiões sob a curva $x y=1$, e definimos a função exponencial como a inversa dela, enfoque esse com caráter fortemente geométrico e que deu origem à noção de integral definida. Mostramos também a estreita relação existente entre as Progressões Aritméticas, Geométricas, Trigonometria e o próprio tema principal. Obtemos ainda a formalização do número irracional e tanto pelo método tradicional usado em livros de Cálculo e Análise como a decorrente da teoria apresentada. Por fim, apresentamos algumas situações curiosas que envolvem direta ou indiretamente essa constante e que podem ser trabalhadas com alunos da Educação Básica.

Palavras-chave: Logaritmo Natural, Número e, Hipérbole, Conhecimento Especializado do Conteúdo. 


\section{Abstract}

GUIDO, F. P. Study of a geometric conceptuation for logarithms. 2017. 118 f. Dissertação (Mestrado) - Instituto de Matemática e Estatística, Universidade de São Paulo, São Paulo, 2017.

The main objective of this work is to contribute to the improvement of the mathematics teacher, whether in training or acting. We seek to offer a material that can serve as a technical, historical and epistemological reference for the study of the Natural Logarithm. We discuss here the concept of Specialized Content Knowledge, coined by University of Michigan researchers and led by Deborah Ball. In your article Content Knowledge for Teaching: What Makes It Special? (2008), they raise the question "What mathematics does the teacher need to know for teaching?", since the mathematical knowledge required for the teacher differs from the mathematical knowledge required in other professions. Here we present a critical analysis of the approach used for the subject in some high school textbooks. We describe in detail the construction of the Logarithmic Function as actually occurred in the seventeenth century, that is, through areas of regions under the curve $x y=1$, and we define the exponential function as the inverse of it, a focus with a strongly geometric character that gave rise to the notion of definite integral. We also show the close relationship between Arithmetic, Geometric, Trigonometry and the main theme itself. We also obtain the formalization of the irrational number $e$, both by the traditional method used in Calculus and Analysis books and by the theory presented. Finally, we present some curious situations that directly or indirectly involve this constant and that can be worked with Basic Education students.

Keywords: Natural Logarithm, Number e, Hyperbole, Specialized Knowledge of Content. 


\section{Sumário}

Lista de Figuras $\quad$ xi

1 Introdução $\quad 1$

2 Justificativa e embasamento teórico $\quad 5$

2.1 Análise crítica de abordagens em alguns livros didáticos . . . . . . . . . 5

2.2 Sobre o conceito de conhecimento especializado de conteúdos para a docência 9

3 Contextualização Histórica $\quad 19$

3.1 Os logaritmos . . . . . . . . . . . . . . . . . . . 19

3.2 Progressões e logaritmos . . . . . . . . . . . . . . . . . . . . . . . . . . . . . . . . . . . . .

3.3 Interpolação linear . . . . . . . . . . . . . . . . . . . . . . . 22

3.4 Juros Compostos e um limite curioso . . . . . . . . . . . . . . . . 27

4 Logaritmos, hipérboles e a área de uma faixa de hipérbole 33

4.1 Logaritmos e a hipérbole . . . . . . . . . . . . . . . . . . 33

4.2 Equação reduzida da Hipérbole na Geometria Analítica . . . . . . . . . . . . 35

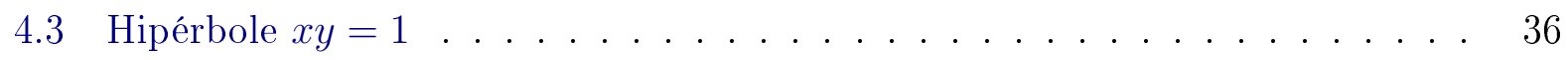

4.4 Faixa da Hipérbole $x y=1 \ldots \ldots \ldots \ldots$

5 Principais propriedades dos logaritmos, bases e definições 45

5.1 Faixas da hipérbole $x y=1$ : propriedade fundamental . . . . . . . . 45

5.2 Definição de Logaritmo via área da hipérbole $x y=1 \ldots \ldots$. . . . . . 50

5.3 Propriedade das Funções Logarítmicas . . . . . . . . . . . . . . . 52

6 O número $e \quad \mathbf{5 9}$

6.1 Número $e$ via área de uma faixa da hipérbole $x y=1 \ldots \ldots$. . . . . . 59

6.2 Limite exponencial fundamental . . . . . . . . . . . . . . . 64

7 Logaritmos e exponenciais $\quad 73$

7.1 Limite exponencial fundamental via área da hipérbole . . . . . . . . . . . 77

7.2 Logaritmos e exponenciais em outras bases . . . . . . . . . . . . . 79

7.3 Logaritmos em outras bases por um viés geométrico . . . . . . . . . . 80 
7.4 Logaritmo natural e sua inversa . . . . . . . . . . . . . . . 82

7.5 Aplicações envolvendo $\ln x$ e $e^{x}$ na modelagem de fenômenos . . . . . . . . 85

8 Problemas interessantes e curiosidades envolvendo $e \quad 89$

8.1 Problema do moleiro e do burro . . . . . . . . . . . . . . . . . . . . 89

8.2 Problema do amigo secreto (Permutação Caótica) . . . . . . . . . . . . . . . . 90

8.3 Matematizando as sensações . . . . . . . . . . . . . . . . 93

8.4 Problema do paraquedista . . . . . . . . . . . . . . 94

9 Considerações finais $\quad 97$

$\begin{array}{ll}\text { Referências Bibliográficas } & 99\end{array}$ 


\section{Lista de Figuras}

2.1 Domínio do conhecimento matemático para ensinar (Ball et al., 2008, p. 403,

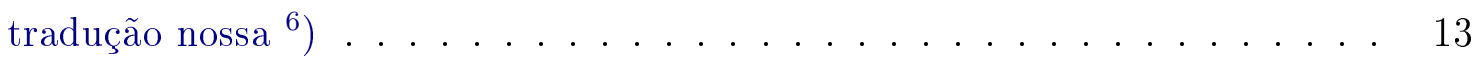

2.2 Exemplo 1: subtração. . . . . . . . . . . . . . . . . 15

2.3 Exemplo 2: subtração. . . . . . . . . . . . . . . . . . . . . 16

2.4 Exemplo 3: subtração. . . . . . . . . . . . . . . . . 16

4.1 Gráfico de Hipérbole. . . . . . . . . . . . . . . . . . . 34

4.2 Características da Hipérbole. . . . . . . . . . . . . . . . 35

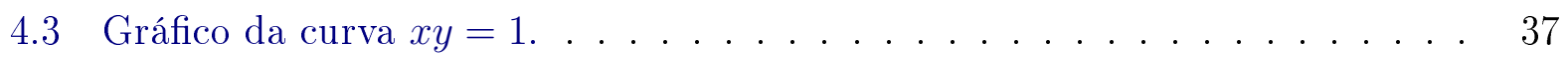

4.4 Ramo positivo da curva $x y=1 \ldots \ldots \ldots \ldots$. . . . . . . . . 40

4.5 Faixa de Hipérbole. . . . . . . . . . . . . . . . . . . . . 40

4.6 Aproximação por falta com três retângulos de $H_{1}^{4} \ldots \ldots$. . . . . . . . . . 41

4.7 Aproximação por excesso com três retângulos de $H_{1}^{4}$. . . . . . . . . . . 42

4.8 Aproximação por falta com seis retângulos de $H_{1}^{4}$. . . . . . . . . . . . . . 42

4.9 Aproximação por excesso com seis retângulos de $H_{1}^{4}$. . . . . . . . . . . 43

5.1 Propriedade Fundamental. . . . . . . . . . . . . . . . 45

5.2 Propriedade Fundamental três retângulos. . . . . . . . . . . . . . . 46

5.3 Propriedade soma de logaritmos. . . . . . . . . . . . . . . . 48

5.4 Definição Logaritmo. . . . . . . . . . . . . . . . . . . . . 51

$5.5 \quad$ Gráfico $f(x)=\operatorname{sen} x \ldots \ldots \ldots \ldots \ldots \ldots$

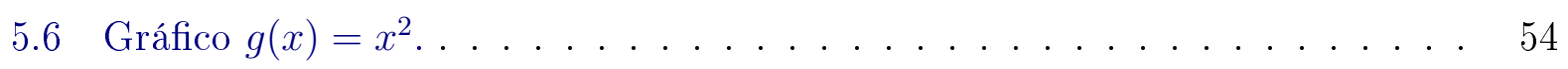

5.7 Gráfico $h(x)=x^{3} \ldots \ldots \ldots \ldots \ldots \ldots \ldots$

6.1 Aproximação LOG(2) por sobra com 4 retângulos. . . . . . . . . . . . . 60

6.2 Aproximação LOG(3) por falta com 8 retângulos. . . . . . . . . . . . . . 60

6.3 Subdivisão com valor das áreas igual a uma constante. . . . . . . . . . . 61

6.4 Subdivisão com valor das áreas igual a uma constante e abscissas em P.G. $\quad$ • 62

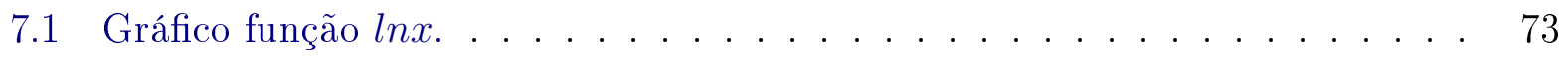

7.2 Gráfico Inversa. . . . . . . . . . . . . . . . . . 74

7.3 Hipérbole da desigualdade exponencial fundamental. . . . . . . . . . . . 77

7.4 Hipérbole da desigualdade exponencial fundamental. . . . . . . . . . . . 78 
7.5 Feixe de gráficos. . . . . . . . . . . . . . . . . . . 79

7.6 Feixe de gráficos $2 \ldots \ldots \ldots \ldots \ldots \ldots$. . . . . . . . . . . . . . . . . . . .

7.7 Gráficos das hipérboles $H(2)_{a}^{b}$ e $H_{a}^{b} \ldots \ldots \ldots \ldots \ldots$. . . . . . . . . . . . . . . . . . . . . . .

7.8 Gráfico de $y=a^{x}$ para $a>1 \ldots \ldots \ldots$. . . . . . . . . 83

8.1 Gráfico Paraquedas. . . . . . . . . . . . . . . . 96 


\section{Capítulo 1}

\section{Introdução}

O estudo dos logaritmos, assunto que desempenhou papel primordial em tempos passados, enfrenta hoje um grande desinteresse por parte dos alunos, principalmente os da Educação Básica que, não vendo a importância que o assunto desempenhou em gerações passadas, recebem esse ensino como algo sem utilidade e permeado de contextos e exemplos que em nada estimulam o aprender. Conforme Elon Lages Lima, os logaritmos tiveram três séculos de valorização, isso por facilitar operações complicadas, porém atualmente não se dá importância a esses estudos pela facilidade das calculadoras (Lima, 2009, p. VII). Por que deveríamos gastar dispendioso tempo com manipulações algébricas, tediosos cálculos ou ainda complicadas tabelas, quando para isso dispomos de máquinas que rapidamente resolvem tais problemas?

Outro ponto que causa forte estranheza nos estudantes é o momento no qual é introduzido o logaritmo de base $e$ ou, simplesmente, logaritmo natural. Por que deveríamos aceitar que existe um número mais natural do que 10 (base da nossa numeração) para compor a base de um logaritmo? E mais ainda, se buscamos algo que seja "natural", por que aceitar um número irracional como 2,71828... (conhecido como $e$ ) que nem sequer conseguimos registrar em sua totalidade no sistema decimal?

Talvez apenas aqueles que optarem por um curso de exatas e cursarem pelo menos um semestre de Cálculo, recebam uma resposta convincente e só então percebam de forma plena a importância e beleza do famoso logaritmo em sua base natural. Muito provavelmente, nesses estudos serão introduzidas ideias básicas para o entendimento de

[...] crescimento populacional, desintegração radiativa, velocidade de reações químicas, circuitos elétricos e muitos outros fenômenos da Física, Química, Biologia, Geologia e virtualmente qualquer ciência que utiliza métodos quantitativos [...] (Simmons, 1987, p. 351).

A experiência, como docente e aluno, possibilitou-me observar que alguns materiais didáticos, como livros e apostilas, trazem outro entrave de graves consequências, além dos obstáculos acima apresentados. A maneira como é definida, pela inversa da função exponencial, requer que sejam estudadas anteriormente todas as suas propriedades, e que se dê sentido para expressões do tipo $a^{x}$ sendo $a$ positivo quando $x$ é um número irracional, fato que, apesar de extremamente comum, é normalmente omitido aos alunos com a finalidade de "facilitar o ensino". É possível notar que em geral, nos exemplos iniciais apresentamos $a=2,3,5$ ou 10. Entretanto, ao passar para o estudo dos logaritmos, descobrimos que essas bases não são tão importantes em comparação ao chamado logaritmo de base natural, ou seja, o logaritmo cuja base é o número irracional $e$. Tal abordagem acaba por reforçar ainda mais a repulsa pelo número $e$ nos alunos, devido ao modo artificial como esse número é introduzido 
em substituição aos corriqueiros 2, 3, 5 e 10. Notamos ainda que existe certa "preferência" dos alunos da Educação Básica por exercícios em que predominam o uso de técnicas de manipulação e uso de "regras" em detrimento dos que necessitam uma maior compreensão conceitual ou da competência em aplicá-lo em situações contextualizadas.

Por outro lado, é preciso notar que a abordagem dada aos logaritmos nos cursos de Licenciaturas e de formação continuada em geral, não se ligam à abordagem utilizada no Ensino Médio. Os logaritmos aparecem no curso de cálculo diferencial e integral definidos como $\ln x=\int_{1}^{x} \frac{1}{t} d t$, que evidentemente, extrapola o nível básico, ainda que, historicamente tenha ocorrido de forma inversa. Ou seja, a concepção de logaritmo como área é que precedeu a noção de integral na História da Matemática, sendo a primeira ideia que deu origem à última.

Por fim, uma questão que julgo de extrema importância, diz respeito à quais sejam os conhecimentos sobre logaritmos cujo domínio possa permitir ao professor uma maior autonomia e capacidade na tomada de decisões e elaboração de suas aulas, no sentido de dispor de recursos para fornecer motivações, tanto do ponto de vista histórico como de aplicações, além de poder articular a temática com outros campos da Matemática ou outras áreas do conhecimento. Enfim, melhor adequar suas aulas sobre o tema aos seus alunos, e consequentemente favorecer seu aprendizado.

Partindo dessas observações nosso objetivo com este trabalho é apresentar um texto amplo e abrangente sobre logaritmos e exponenciais que possa ser utilizado em atividades de formação inicial ou continuada de professores. Esta dissertação busca um resgate histórico e epistemológico da noção de logaritmos como área abaixo da curva de equação $x y=1$. Apresenta ainda resposta à questões como: o porquê dessa abordagem, para que foi criada e como se desenvolveu. Tal abordagem para os logaritmos não é muito difundida na Educação Básica ou mesmo em cursos de Licenciatura em Matemática, ainda que tenha sido a primeira registrada na História da Matemática. Ela se apoia fortemente em conceitos geométricos, enquanto a abordagem mais utilizada nos livros didáticos possui caráter quase que exclusivamente algébrico. Posteriormente formalizamos aqui muitos dos conceitos usualmente apresentados por meio do cálculo e da análise real.

Do ponto de vista dos conhecimentos pedagógicos voltados ao ensino dos logaritmos e exponenciais, tecemos críticas às abordagens adotadas por alguns livros didáticos utilizados no Ensino Médio e aprovados no PNLD 2015. Apontamos eventuais falhas na apresentação de conceitos e a falta de clareza no tratamento dado a alguns temas relativos ao assunto, principalmente sobre o logaritmo natural e a base $e$ para as exponenciais. Tomando por base o artigo Content Knowledge for Teaching: What Makes It Special? de Deborah Ball, Mark Thames e Geoffrey Phelps (2008), buscamos identificar os conhecimentos especializados sobre logaritmos e exponenciais que possam ampliar o repertório dos professores, por meio de sugestões de diferentes abordagens de alguns tópicos do tema, potencialmente úteis na elaboração e proposição de atividades a seus alunos em sala de aula na busca de favorecer a atribuição de significado sobre o assunto em foco.

Desse modo, no capítulo 2 fazemos um levantamento de como os livros Matemática: Ensino Médio de Kátia Smole e Maria Ignes Diniz, publicado pela editora Saraiva, Matemática ciência e aplicações de Gelson Iezzi... [et al], publicado pela editora atual e Matemática de Manoel Paiva, publicado pela editora Moderna definem os logaritmos, e destacamos alguns pontos que podem deixar dúvidas nos alunos na construção de seus conhecimentos sobre o tema. 
Posteriormente, fazemos uma revisão teórica sobre o conceito de conhecimento especializado dos conteúdos, proposto por Ball, Thames e Phelps no artigo anteriormente citado.

A seguir, no capítulo 3, trazemos um levantamento histórico acerca das principais ideias que envolveram o desenvolvimento dos logaritmos, incluindo suas ligações com as progressões, juros compostos e interpolação linear.

Nos capítulos 4 e 5 apresentamos a construção dos logaritmos e suas propriedades utilizando área de figuras planas e geometria analítica. Especificamente, discutimos procedimentos para o cálculo da área abaixo da curva de equação $x y=1$.

No capítulo 6 mostramos um pouco da teoria concernente ao número irracional e, para no capítulo 7, apresentarmos a ligação entre os logaritmos e a exponencial.

O capítulo 8 contém algumas sugestões curiosidades e indicações de assuntos relacionados aos temas abordados.

Por fim, no capítulo 9, colocamos algumas considerações finais obtidas a partir do desenvolvimento dessa dissertação.

Antes porém que você inicie sua leitura, gostaria de tecer algumas palavras sobre o texto que irá encontrar.

Na medida do possível, ele foi escrito de modo a conversar com o leitor, pois sabemos ser a essência da matemática ideias e não símbolos desprovidos de significados, isto é, noções em vez de apenas notações. No entanto, não podemos esquecer que a linguagem utilizada para expressar a maior parte dos fatos científicos é a matemática, devido à sua precisão incomparável e por eliminar as ambiguidades naturais da linguagem corrente. Além disso, evitamos considerar qualquer fato ou passagem matemática como trivial, trazendo em vários momentos os pré-requisitos necessários para uma boa compreensão. Procuramos detalhar os raciocínios feitos nos trechos mais técnicos e quando achamos que fugisse do contexto do trabalho, indicamos boas fontes de consulta. Por outro lado, também sabemos que Matemática não se aprende simplesmente ouvindo, por mais organizadas e concisas que sejam essas informações ou por mais que se compreenda todo o exposto. Em geral, para uma apropriação significativa dos conteúdos específicos, é necessário repassar as informações ouvidas, estudando do seu próprio jeito. De igual modo, merecem ser tratadas as informações contidas em um texto matemático. A simples leitura linear certamente ajudará na compreensão dos fatos, mas é provável que não seja suficiente, sendo necessário, sempre que possível, uma pausa pra refletir sobre o que foi lido. Muitas vezes isso demanda uma produção do leitor, seja uma figura, um gráfico, um diagrama, cálculo ou simplesmente refazendo o passo a passo de uma demonstração. Em um primeiro contato com o trabalho, caso queira uma leitura mais fluente, pode-se omitir os tópicos 4.2, 4.3, 5.3 e 6.2 (de caráter mais técnico) bastando que se aceite os resultados ali mostrados. Entretanto, são tópicos de extrema importância na construção e comprovação do tema, e em algum momento merecem ser lidos. Não esperamos um leitor passivo, que apenas receba informações, mas ao contrário, que a todo o momento levante questões e, sempre que julgar apropriado, vá além desse texto, quiçá de nossas sugestões e referências.

A título de motivação, trouxemos vários apontamentos históricos e epistemológicos, porém, não se deve confundir a história e desenvolvimento das ciências com um simples conjunto de fatos, contos e anedotas. Seria importante que eles viessem permeados de contextos, sejam eles políticos, sociais ou mesmos pessoais, caso contrário passaríamos a interpretar a história por um viés pseudoimparcial, totalmente livre de influências externas, o que sabemos não 
ser verdade. No entanto, se fossemos apresentar tal rigor historiográfico, poderíamos por vezes nos distanciar do foco principal do trabalho, qual seja, a apresentação de uma teoria para os logaritmos em particular de base e. Dessa forma, a fim de alcançar algum ganho didático e tornar o texto dinâmico e menos carregado, nem sempre explicitamos os contextos por completo. Acredito que o leitor que fará uso do texto, pode e deve ir além também nesse aspecto, e para tais momentos em que sentir a necessidade de extrapolar essa leitura, indicamos Miguel e Roque usado em nossas referências.

Espero que esse trabalho lhe agregue conhecimento seja em sua formação inicial ou continuada e que satisfaça sua curiosidade pelo tema. Em especial, gostaria que ele tivesse um papel significativo no exercício da docência em matemática, trazendo novas informações, provocando questionamentos, e principalmente, tornando-o crítico de sua própria prática pedagógica. Por fim, espero que você encontre nessa leitura tanto prazer quanto tive ao escrevê-lo. 


\section{Capítulo 2}

\section{Justificativa e embasamento teórico}

Neste capítulo, trazemos alguns dos motivos que serviram de inspiração, justificativa e embasamento teórico para a pesquisa. Na seção 2.1 apresentamos o modo como o tema logaritmos é apresentado nos livros selecionados, dando especial atenção à forma como é introduzido o logaritmo natural e consequentemente o número irracional $e$. A partir disso, tecemos algumas críticas e apontamos eventuais falhas que as obras apresentam. Se por um lado, analisamos um pequeno número de obras, por outro, podemos afirmar que elas refletem em grande parte o modo como é abordado o tema na Educação Básica, uma vez que todas foram aprovadas no PNLD de 2015. Na seção 2.2, defendemos a ideia de que além de dominar a teoria concernente à sua disciplina, o professor deve ter um conhecimento teórico pedagógico vasto e sua prática constantemente auto avaliada. Buscamos no artigo Those Who Understand: Knowledge Growth in Teaching (2008) o conceito de conhecimentos especializados dos conteúdos que servirá como aporte para justificar a importância e necessidade da formação continuada na carreira docente, de modo a permitir ao professor uma ampliação do seu repertório sobre ideias conexas com o tema dos logaritmos e suas abordagens possíveis e uma maior capacidade de estabelecer articulações entre tópicos do conteúdo, possibilitando que ele tome decisões mais autônomas sobre atividades adequadas para trabalhar com seus alunos.

\subsection{Análise crítica de abordagens em alguns livros didá- ticos}

É muito comum no tratamento dado aos logaritmos em sala de aula defini-los de um modo a depender do estudo anterior da exponencial. Essa definição, inclusive, é a mais encontrada nos livros didáticos. Vamos ver como os livros citados na introdução definem os logaritmos:

Logaritmo de um número positivo $b$ em uma base $a, a>0$ e a $\neq 1$, é o expoente da potência à qual se deve elevar a para se obter $b$.

Se $b>0, a>0$ e $a \neq 1$, então $\log _{a} b=x \Leftrightarrow a^{x}=b$. (Smole e Diniz, 2013, p. 190)

Sendo a e $b$ números reais e positivos, com $a \neq 1$, chama-se logaritmo de $b$ na base a o expoente $x$ ao qual se deve elevar a base a de modo que a potência a $a^{x}$ seja igual a $b$. $\log _{a} b=x \Leftrightarrow a^{x}=b$ (Iezzi et al., 2014, p. 225).

Sendo a e $b$ números reais e positivos, com $b \neq 1$, chama-se logaritmo de a na base $b$ o expoente $x$ tal que $b^{x}=a$. $\log _{b} a=x \Leftrightarrow b^{x}=a$ (Paiva, 2013, p. 231).

Essa forma de definir os logaritmos, entretanto, traz consigo algumas dificuldades que posteriormente deixarão lacunas quase que intransponíveis no aprendizado dos alunos. 
O primeiro inconveniente nessa abordagem como já dito, é o fato dela depender do estudo anterior da teoria da exponenciação. Porém muito mais do que isso, é primordial [...] que se saiba o significado de $a^{y}$ quando y é irracional, e que se provem regras como $a^{y} \cdot a^{z}=a^{y+z}$ para, $y, z, \in \mathbb{R}^{+}$quaisquer. (Lima, 2009, p. VIII). Corroborando com esse fato, Simmons defende dizendo:

Se o expoente $c$ for um número irracional, então aparecem as dificuldades que os estudantes podem não notar se não as mencionarmos. Por exemplo, o que significa a expressão $2^{\sqrt{2}}$ ? É claro que não faz sentido multiplicar 2 por ele mesmo $\sqrt{2}$ vezes (Simmons, 1987, p. 352).

Outro inconveniente nessa definição é que tratamos todas as bases de forma igual, não permitindo apresentar de modo natural o número $e$ como uma base especial. Na definição de logaritmo como expoente, o número e aparece artificialmente. (Lima, 2009, p. IX)

Em relação ao número irracional e, o livro Matemática: Ensino Médio (Smole e Diniz, 2013) não faz qualquer menção a ele no capítulo destinado à apresentação dos conjuntos numéricos "Unidade 1 (Conjuntos numéricos e intervalos na reta real)", em particular nos tópicos " 5. Os números irracionais" e "6. Os números reais" que, como os próprios nomes deixam claro abordam os conjuntos do qual o número $e$ faz parte. Já na "Unidade 7 (Função exponencial, equação exponencial e inequação exponencial)", apenas na seção "CONEX $\tilde{A} O$ " (de título Matemática - Ciência da natureza: Cálculo do "tempo de vida" da radioatividade de uma substância) pode-se ler o seguinte trecho, no qual é possível observar que todas as constantes envolvidas na descrição da função são definidas, menos o número $e$ :

Esse decaimento é calculado matematicamente pela função exponencial $N(t)=$ $N_{0} e^{-\lambda t}$, onde $\lambda$ é a constante de decaimento nuclear, uma característica do núcleo do elemento químico em questão; $N_{0}$ é o número de núcleos radioativos em um instante inicial $\left(t_{0}\right) ; N$ é o número de núcleos remanescentes em um instante posterior $t$ (Smole e Diniz, 2013, p. 186).

Finalmente, apenas no final da "Unidade 8 (Logaritmo e função logarítmica)", na seção PROBLEMAS E EXERCÍCIOS o número $e$ volta a aparecer. Aqui também sem qualquer explicação, e sem uma discussão anterior sobre logaritmo de base $e$ ou sua notação usual $l n$, o exercício pede que se use $\ln 2=0,7$ sem que a conexão desta informação com o enunciado fique clara para o aluno:

(UFPB) O movimento de uma bola de golfe é influenciado tanto pela força gravitacional como também pela resistência do ar. Essa força retardadora atua no sentido oposto ao da velocidade da bola. Em um estudo realizado durante uma partida de golfe, observou-se que, quando foi considerada a força de resistência do ar, a distância horizontal $d(t)$, em metros, percorrida por uma bola em função do tempo $t$. em segundos, a partir do instante em que a bola foi lançada $(t=0)$, era dada por $d(t)=50\left(1-e^{-0,1 t}\right)$. Use $\ln 2=0,7$. A partir dessas informações, conclui-se que, para que a bola percorra uma distância na horizontal de $25 \mathrm{~m}$, o tempo gasto, a partir do instante do lançamento, é de:
a) $5,0 \mathrm{~s}$
b) $6,6 \mathrm{~s}$
c) $7,0 \mathrm{~s}$
d) $8,5 \mathrm{~s}$
e) $10 \mathrm{~s}$

(Smole e Diniz, 2013, p. 201).

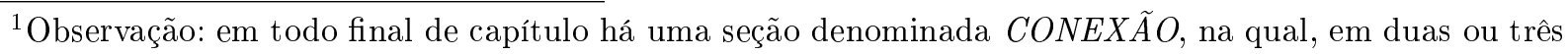
páginas, as autoras apresentam alguma contextualização para o conteúdo recém abordado.
} 
Já o livro Matemática do autor Paiva, é possível observar que tanto na seção "13. Conjuntos numéricos" do "Capítulo 1 (Uma introdução à linguagem dos conjuntos)" quanto no "Capítulo 10 (Função exponencial)" não há nenhuma menção a respeito de sua existência.

No "Capítulo 11 (Função logarítmica)", em EXERCÍCIOS COMPLEMENTARES, há uma seção de nome ANÁLISE DA RESOLUÇÃO que apresenta o seguinte exercício:

Um aluno resolveu o exercício conforme a reprodução a seguir. Um erro foi cometido. Apontem o erro e refaçam a resolução no caderno, corrigindo-a.

\section{EXERCÍCIO}

Quando as válvulas da artéria aorta se fecham, a pressão $\mathrm{P}$, em mmHg (milímetro de mercúrio), no interior dessa artéria, durante o fechamento, pode ser expressa em função do tempo t, em segundo, por meio da equação $P=95 \cdot e^{-0,49 t}$. Após o fechamento das válvulas, em quanto tempo a pressão atingirá $70 \mathrm{mmHg}$ ?

Nota: O número e, conhecido como número de Neper ou de Euler, é um número irracional que vale aproximadamente 2,7 . Na calculadora científica, o logaritmo de base $e$, isto é, $\log _{e}$, corresponde à tecla ln. (Paiva, 2013, p. 251)

Podemos notar aqui, que há certa preocupação em mencionar ao aluno o que significa a vogal $e$ que aparece no meio da fórmula, entretanto, as informações apresentadas não são suficientes para esclarecer todos os pormenores que o envolvem. Talvez a Nota dê conta de relembrar um estudante que tenha de fato aprendido sobre o conjunto dos irracionais e em particular sobre o número $e$. Entretanto, ao levar em consideração que o capítulo destinado a tal não o faz, somos obrigados a acreditar que o autor espera do aluno que já tenha aprendido no Ensino Fundamental II e que ainda se lembre do que foi visto, porém essa apresentação não é feita nessa fase, em geral.

Por fim, em relação à apresentação do número e na obra Matemática ciência e aplicações de Iezzi et al. (2014), existe um tópico chamado O número e contido na seção Função exponencial presente no "Capítulo 7 (Função Exponencial)" que traz, de modo resumido (o equivalente a uma página), algumas informações acerca desse número irracional. Ele introduz e partindo do seguinte comentário:

Um importante número irracional em Matemática é o número $e=2,718281828459 \ldots$.. Para introduzi-lo, vamos considerar a expressão $(1+x)^{\frac{1}{x}}$, definida em $\mathbb{R}^{*}$, e estudar os valores que ela assume quando $x$ se aproxima de zero:

\begin{tabular}{|c|c|c|c|c|c|}
\hline$x$ & 0,1 & 0,01 & 0,001 & 0,0001 & 0,00001 \\
\hline$(1+x)^{\frac{1}{x}}$ & 2,594 & 2,705 & 2,717 & 2,7182 & 2,7183 \\
\hline
\end{tabular}

Na tabela podemos notar que, à medida que $x$ se aproxima de zero, a expressão $(1+x)^{\frac{1}{x}}$ fica mais próxima do número $e \cong 2,7183$.

Considerando valores negativos de $x$, porém cada vez mais próximos de zero (por exemplo, $x=-0,1 ; x=-0,01 ; x=-0,001$, etc.), a expressão também fica cada vez mais próxima de $e \cong 2,7183$.. Calcule você mesmo com o auxílio de uma calculadora científica.

Dizemos então que o limite de $(1+x)^{\frac{1}{x}}$, quando $x$ tende a zero, é igual ao número e. Representamos esse fato por $\lim _{x \rightarrow 0}(1+x)^{\frac{1}{x}}=e$ (Iezzi et al., 2014, p. 199).

Ainda nessa obra, segue uma pequena contextualização histórica e alguns comentários sobre a forma como as calculadoras científicas trazem as teclas $e^{x}$ e $l n$. Pra finalizar a sessão, é definida $f: \mathbb{R} \rightarrow \mathbb{R}_{+}^{*}$ por $f(x)=e^{x}$ e apresentado um gráfico contendo destacados os pares ordenados $(-1,0,36),(0,1)$ e $(1, e)$. 
No "Capítulo 8 (Função Logarítmica)", na seção chamada Sistemas de Logaritmos, encontramos o seguinte comentário:

Existem dois sistemas de logaritmos que são os mais utilizados em matemática:

(a) O sistema de logaritmos decimais, de base 10, desenvolvido por Henry Briggs, a partir dos trabalhos de Napier. Briggs foi também quem publicou a primeira tábua dos logaritmos de 1 a 1000, em 1617. Como vimos, indicamos com $\log _{10} x$, ou simplesmente $\log x$, o logaritmo decimal de $x$.

(b) O sistema de logaritmos neperianos, de base $e$. O nome neperiano deriva de Napier. Os trabalhos de Napier envolviam, de forma não explícita, o que hoje conhecemos como número $e$. Com o desenvolvimento do cálculo infinitesimal, um século depois reconheceu-se a importância desse número. Representamos o logaritmo neperiano de $x \operatorname{com} \log _{e} x$ ou $\ln x$. Assim, por exemplo, $\ln 3=\log _{e} 3 ; \ln ^{4}=\log _{e} e^{4}=4$ etc. É comum referir-se ao logaritmo neperiano de $x$ como o logaritmo natural de $x(x>0)$ (Iezzi et al., 2014, p. 230).

Segue uma pequena explanação sobre como usar as teclas " $L O G$ " e " $L N$ " contidas nas calculadoras científicas. Por fim, é interessante notar que existe um número considerável de exercícios sobre exponenciais e logaritmos que utilizam o número e como base.

Um terceiro inconveniente faz menção à função $L$ que será definida no Capítulo 5 e [...] é a dificuldade de se estabelecerem certas desigualdades fundamentais, como por exemplo, $L(1+$ $x)<x$ (válida para logaritmos de base e), que é óbvia na definição geométrica (Lima, 2009, p. IX) e se mostrará importantíssimo para a compreensão do limite exponencial fundamental, isto é, $\lim _{n \rightarrow \infty}\left(1+\frac{1}{n}\right)^{n}$.

Enfim, são muitos entraves que devem ser tratados com essa definição, e como aponta Lima:

Tais preliminares envolvem dificuldades técnicas que conduzem ao seguinte dilema: ou passar por cima dessas dificuldades, fazendo de conta que elas não existem o que deixa a desejar do ponto de vista de honestidade científica ou esgotar a paciência do aluno (ou leitor) com longos detalhes rebarbativos (Lima, 2009, p. VIII).

Entretanto, devemos dizer que o autor foi um tanto "pessimista" ao apontar apenas essas duas possibilidades. Esperamos com esse trabalho trazer ao professor subsídios para que possa analisar seu material didático com um olhar crítico e encontrar outras possibilidades para contornar o "dilema". Dessa forma, estará mais bem capacitado a decidir sobre o que é conveniente utilizar em sala de aula e o que julga interessante complementar, extrapolando o "básico" com a apresentação de fatos matemáticos, curiosidades históricas, contextos que chamem atenção, ou o que mais julgar necessário, a fim de favorecer aos seus alunos uma maior atribuição de significados para os conceitos e procedimentos referentes aos logaritmos.

E justamente para seguir por esse "terceiro caminho", direcionamos essa escrita para o aprimoramento de professores, não somente em formação, mas também os que já exercem a docência, partindo da premissa que a formação contínua é necessária ao professor e fundamental para aprimorar sua ação crítica e problematizadora. 


\subsection{Sobre o conceito de conhecimento especializado de conteúdos para a docência}

Conforme o Programa de formação de professores alfabetizadores publicado em 2001 pelo MEC, a profissão professor é complexa, pois demanda muito mais que aplicações de meios para ensinar. Não se pode tornar o exercício do magistério simplesmente como aplicação e manejo de um conjunto de técnicas, pois a atuação é complexa e singular (MEC, 2001, p. 13). Apesar daquele programa governamental ser direcionado ao professor alfabetizador dos anos iniciais do ensino fundamental I, suas justificativas e pretensões podem, e devem, ser estendidas a todos os professores, uma vez que o documento faz uma análise da profissão como um todo. A referência principal é a formação contínua, que permite refletir sobre a própria prática e é exatamente o que propomos nesse trabalho.

A reflexão sobre a prática é a "marca registrada" de um modelo de formação profissional que se pretende problematizadora. A velha máxima ação-reflexão-ação é o que há de mais representativo de uma metodologia centrada na reflexão sobre a prática e na aquisição de conhecimentos que contribuam para imprimir cada vez mais qualidade à atuação do professor (MEC, 2001, p. 28).

A construção do saber docente tem que ser entendida como um processo permanente. Iniciando na graduação, vai se desenvolvendo continuamente com a prática e os cursos de aperfeiçoamento. O ensino (no nosso caso de matemática) é um processo complexo. O professor, além de dominar o conhecimento matemático, precisa conhecer a pedagogia e a didática relacionadas ao conteúdo; saber transformar a matemática em atividades que ajudem na aprendizagem: conhecer o sistema de ensino de onde trabalha, em especial o currículo nele previsto para a sua área; utilizar vários métodos de avaliação, levar em consideração os contextos sociais, culturais e políticos em que está inserido; e por fim, conhecer intimamente seus alunos e a própria comunidade em que se encontra.

Os autores Ball, Thames e Phelps (2008), baseando-se nas ideias do pesquisador Lee S. Shulman, propõem um trabalho norteador para questões relativas à formação, ensino e em particular, à ligação entre teoria e prática. A seguir, trazemos alguns apontamentos sobre suas contribuições teóricas a respeito da importância dos conhecimentos profissionais necessários ao professor de Matemática no exercício do ensino dessa disciplina na escola.

Os autores citados definem que os conhecimentos necessários a um professor de Matemática, consistem em aprender o objeto de ensino, para aprender a ensiná-lo, de modo que consiga refletir sua prática e ganhar autonomia para se aperfeiçoar a partir da análise de sua experiência. Seria um entrelace entre conhecimento específico (a Matemática) e os conhecimentos pedagógicos (ensino e aprendizagem de um modo geral). Por Ball et al. (2008):

Os autores e seus colegas usaram estudos de prática de ensino para analisar as demandas matemáticas para o ensino e, baseados nas análises, desenvolveram um conjunto de hipóteses testáveis sobre a natureza do conhecimento matemático para o ensinar. Em uma linha relacionada de trabalho, o segundo projeto desenvolveu medidas de pesquisa do conhecimento de conteúdo para o ensino de matemática. As medidas previam uma maneira de investigar a natureza, o papel, e a importância dos diferentes tipos de conhecimento matemático para o ensino. (Ball et al., 
2008, p. 28, tradução nossa) ${ }^{2}$.

A formação inicial deve abarcar uma formação voltada para a prática, ou seja, para o trabalho de ensino que exercerá, e não somente ficar no plano teórico. É imprescindível que, para além de conhecer a teoria e a própria Matemática, o professor consiga trabalhar com experimentações, trazendo sua formação à realidade prática do seu trabalho como educador. Certamente ter um conhecimento específico apurado ajuda muito o professor a desenvolver suas aulas, porém o conhecimento pedagógico é essencial no desenrolar da mesma. Ball et al. (2008), trazem justamente esse acréscimo ao trabalho de Shulman realizado na década de 80 acerca dos conhecimentos especializados relevantes para o exercício da docência na Educação Básica. Ele notou que os processos para seleção e avaliação dos professores e as pesquisas não se preocupavam com questões como a fonte de analogias, metáforas, exemplos, forma de representar os conteúdos, bem como potencialidades de cada representação ou mesmo a preparação do docente em realizar conexões entre o conteúdo ensinado e a vida do aluno em outras disciplinas ou mesmo fora da escola. Essa falta de ênfase em questões tidas como primordiais para a profissão foi chamada por Shulman de "paradigma perdido" (SHULMAN, 1986 apud BALL et al, 2008, p. 390). Desse modo, Shulman pretendia contornar essa perda, formulando uma base de conhecimentos que norteasse os saberes necessários ao docente.

O autor cunhou o termo conhecimento pedagógico do conteúdo (pedagogical content knowledge) na literatura, em especial no artigo - hoje clássico - Those Who Understand: Knowledge Growth in Teaching (1986), designando um tipo de conhecimento voltado ao profissional docente. Seria um misto entre conhecimento pedagógico e um conhecimento específico envolvendo sua disciplina de atuação. Shulman aponta que o saber do docente deve abarcar as sete categorias descritas no que ele chamou de "principais categorias de conhecimento dos professores". A seguir apresentamos as sete categorias cujo quadro original pode ser encontrado em (SHULMAN, 1986 apud BALL et al, 2008, p. 391). ${ }^{3}$

- Conhecimento pedagógico geral, com especial referência aos princípios e estratégias gerais de gestão e organização da sala de aula que parecem ir além do conteúdo tratado.

- Conhecimento das características dos aprendizes.

\footnotetext{
${ }^{2}$ The authors and their colleagues used studies of teaching practice to analyze the mathematical demands of teaching and, based on these analyses, developed a set of testable hypotheses about the nature of mathematical knowledge for teaching. In a related line of work, the second project developed survey measures of content knowledge for teaching mathematics. The measures provided a way to investigate the nature, the role, and the importance of different types of mathematical knowledge for teaching.
}

\section{Shulman's Major Categories of Teacher Knowledge}

- General pedagogical knowledge, with special reference to those broad principles and strategies of classroom management and organization that appear to transcend subject matter

- Knowledge of learners and their characteristics

- Knowledge of educational contexts, ranging from workings of the group or classroom, the governance and financing of school districts, to the character of communities and cultures

- Knowledge of educational ends, purposes, and values, and their philosophical and historical grounds

- Content knowledge

- Curriculum knowledge, with particular grasp of the materials and programs that serve as "tools of the trade" for teachers

- Pedagogical content knowledge, that special amalgam of content and pedagogy that is uniquely the province of teachers, their own special form of professional understanding 
- Conhecimento dos contextos educacionais, desde o funcionamento do grupo ou sala de aula, passando pela governança e financiamento das diretorias de ensino até o conhecimento das características das comunidades e culturas locais.

- Conhecimento das finalidades educacionais, seus propósitos e valores, além de suas bases filosóficas e históricas.

- Conhecimento do conteúdo.

- Conhecimento do currículo, com especial compreensão dos materiais e programas que podem servir como "moeda de troca" ao professor.

- Conhecimento pedagógico do conteúdo, ou seja, aquele amálgama especial de conteúdo e pedagogia que é exclusivo do domínio do professor, a sua própria forma especial de conhecimento profissional.

Na época, a preocupação de Shulman, como dito, era nortear as concepções inerentes à formação do professor, bem como categorizar suas competências e características próprias. Os quatro primeiros itens tratam de categorias mais generalistas presentes na formação docente da época e não se constituiam no principal interesse do autor, ainda que tivessem seu espaço reservado nos estudos realizados. O foco de Shulman era a maneira como se tratava o conhecimento do conteúdo, pois, como aponta, o mero conhecimento do conteúdo se mostra tão inútil do ponto de vista pedagógico quanto uma habilidade livre de conteúdo (SHULMAN, 1986 apud BALL et al, 2008, p. 391, tradução nossa) ${ }^{4}$. O autor se refere aos três últimos itens, como o elemento que faltava nas pesquisas relacionadas ao ensino. Em poucas palavras, poderíamos destacar o seguinte:

O conhecimento do conteúdo diz respeito ao assunto que será ensinado e à sua organização, sendo enfatizado que o professor deve ser capaz de ponderar o peso que receberá cada tópico a ser ensinado, podendo, dessa forma, entender o porquê de um específico ser central para a disciplina, enquanto outro receber atenção periférica.

O conhecimento do currículo se refere a toda a gama de programas concebidos para o ensino de determinado tópico nos diferentes níveis educacionais. Além disso, duas outras dimensões curriculares são destacadas pelo autor. O que ele chama de conhecimento do currículo lateral e conhecimento do currículo vertical. O primeiro se refere ao currículo que os alunos estão percorrendo nas outras disciplinas, em paralelo com a sua; e o segundo, à familiaridade com os temas e questões que foram ou serão ensinados ao longo dos anos em sua própria área de ensino.

Por fim, o conhecimento pedagógico do conteúdo, sem dúvida o que mais influenciou novos estudos, compreende as formas mais úteis de representação das ideias, as melhores analogias, ilustrações e exemplos, isto é, a melhor maneira para tornar o assunto compreensível aos estudantes. Inclui também o entendimento do que torna a aprendizagem de cada assunto mais fácil ou difícil, na dependência das concepções e da bagagem de conhecimentos nas diferentes idades. Esse conhecimento se mostrou essencial em pesquisas de campo realizadas, a partir da observação que, algumas vezes, a representação de ideias chave usando metáforas e diagramas foram mais eficientes e poderosas para a aprendizagem do que outras, tecnicamente corretas, mas que em nada ajudaram na compreensão do assunto.

As ideias propostas por Shulman e seus colaboradores, influenciaram toda uma geração de pesquisadores e educadores, como mostra Ball et al. (2008, p. 392), ele foi citado em mais de

\footnotetext{
${ }^{4}$ Mere content knowledge is likely to be as useless pedagogically as content-free skill.
} 
1.200 artigos e revistas especializadas, mantendo uma média de 50 citações por ano desde 1990. Também é possível notar a versatilidade das ideias propostas ao perceber que, 125 revistas de áreas como direito, enfermagem e até comércio utilizaram elas como referencial teórico. Tudo isso vem apenas corroborar a certeza de que essas teorias transcenderam a área da educação.

Ainda no ano de 1990, a pesquisadora Ball cunhou o termo "conhecimento sobre a matemática" contrastando com a ideia de "conhecimento de matemática" (Ball et al., 2008, p. 393). Mais recentemente, aliado à evolução pela qual as ciências cognitivas passavam, outras questões surgiram, entre elas: "Como as ideias propostas de conhecimento pedagógico do conteúdo foram incorporados na prática?" e "O que ainda pode ser desenvolvido?". Nessa época já era consenso entre especialistas da educação que o professor certamente deveria dominar o conteúdo a ser ensinado, mas, que apenas esse conhecimento não é suficiente para o ensino. Obviamente saber o conteúdo matemático é parte indissociável da formação do professor, mas saber operar os diversos conhecimentos matemáticos não garante saber ensiná-los, ou mesmo, conhecer ferramentas, não anula a necessidade de saber como essas atuam no processo de ensino-aprendizagem.

A fim de aprimorar o trabalho já estabelecido por Shulman, os autores decidem investigar a prática real de atuação em sala de aula, com foco na observação, levantamento e análise de duas questões básicas, consideradas por Shulman distintas: sua maneira de ensinar matemática e a matemática por eles utilizada nesse ensino. Baseando-se nessas pesquisas que reportavam a prática do ensino de matemática, Ball et al puderam identificar dois subdomínios do conhecimento pedagógico do conteúdo e propuseram um novo conhecimento voltado à prática, o chamado conhecimento especializado dos conteúdos (specialized content knowledge).

A partir da noção de conhecimento pedagógico do conteúdo, proposto por Shulman, Ball et al, desenvolvem o conceito de conhecimento matemático para ensinar (mathematical knowledge for teaching $(M K T)$ ), com o objetivo de detalhar e aprofundar mais as ideias apresentadas pelo autor, especificamente para a Matemática. Isso porque, mesmo que elas tivessem sido amplamente debatidas nos meios acadêmicos, perceberam que os estudiosos do ensino de diferentes áreas do conhecimento as entendiam de distintas maneiras, por serem amplas e gerais. Mais ainda, em suas pesquisas se depararam com a constatação de que muitos professores assumiam os conhecimentos pedagógicos de conteúdo como relativamente óbvios, sendo pouco explorados em sua prática escolar. Na visão dos autores, o conhecimento matemático para ensinar é entendido como [...] o conhecimento matemático necessário para levar a cabo o trabalho de ensinar matemática (Ball et al., 2008, p. 395, tradução nossa) ${ }^{5}$. Apontam ainda que o diferencial entre esse tipo de conhecimento e o domínio de conteúdos matemáticos é, ser, o primeiro, específico para que o professor possa realizar suas atividades diárias de ensino, enquanto o segundo é geral para todas as profissões que demandam base matemática.

As pesquisas realizadas por Ball et al, partem da observação dos professores em ação, para a partir disso, em conjunto com eles, delinear o que se possa chamar de conhecimento necessário para ensinar matemática. Assim propuseram um aprofundamento e uma reorganização das categorias de Shulman sintetizada no seguinte diagrama:

\footnotetext{
${ }^{5}$... the mathematical knowledge needed to carry out the work of teaching mathematics.
} 


\section{DOMÍNIOS DO CONHECIMENTO MATEMÁTICO PARA ENSINAR}

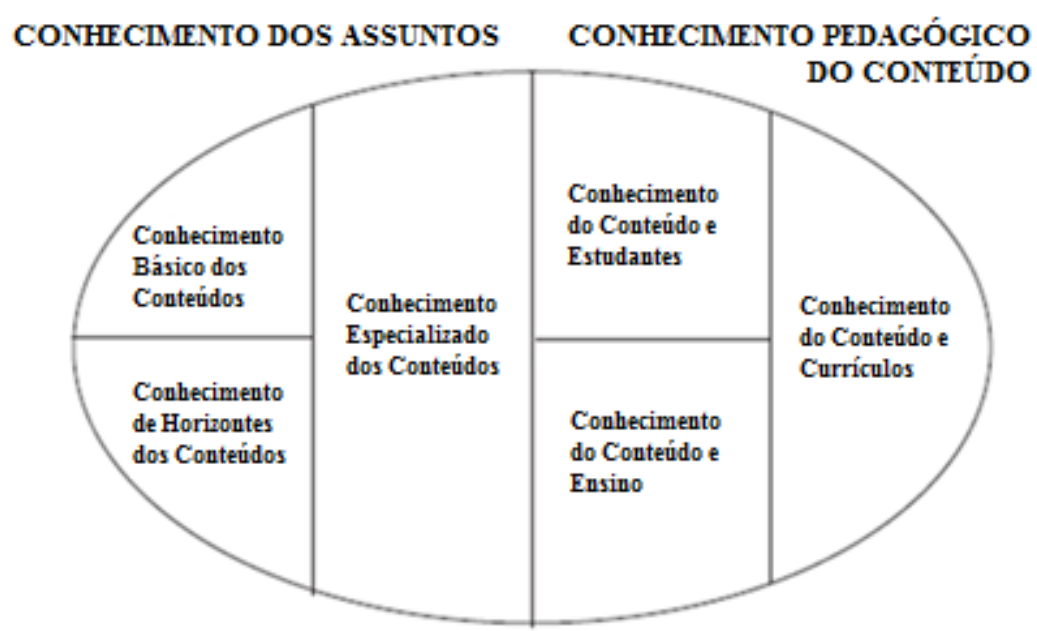

Figura 2.1: Domínio do conhecimento matemático para ensinar (Ball et al., 2008, p. 403, tradução nossa ${ }^{6}$ )

Os autores reorganizaram as sete categorias de Shulman em dois grandes blocos que juntos integram os domínios do conhecimento matemático para ensinar.

O primeiro desses blocos chamado conhecimento dos assuntos subdivide o anteriormente chamado conhecimento do conteúdo (quinta categoria de Shulman) em duas novas, o conhecimento básico dos conteúdos e o conhecimento de horizonte dos conteúdos. Acrescentam também a esse bloco uma nova categoria chamada conhecimento especializado dos conteúdos.

O segundo bloco, de nome conhecimento pedagógico do conteúdo traz o conhecimento do conteúdo e estudantes e o conhecimento do conteúdo e ensino, que além de enfatizar melhor as características do conhecimento pedagógico do conteúdo proposto por Shulman, ainda resgatam um pouco da importância de suas quatro primeiras categorias.

Por fim, os autores mantêm o chamado conhecimento do currículo, passando agora a chamar conhecimento do conteúdo e currículos fechando, portanto esse bloco. A fim de compreender melhor essa subdivisão, apresentamos a seguir um resumo da abrangência de cada um dos seis componentes discriminados na figura:

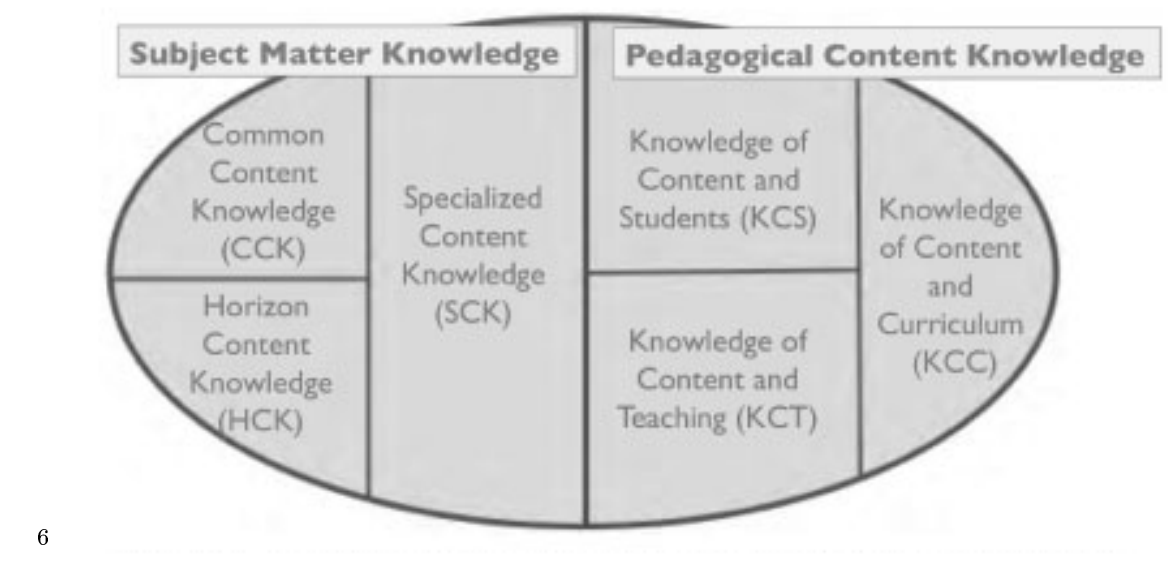


Conhecimento Básico dos Conteúdos (CCK): São os conhecimentos e habilidades necessários em contextos gerais, ou seja, são conhecimentos de conceitos e procedimentos matemáticos em si, não necessariamente voltados para o Ensino. Por exemplo, o conhecimento do algoritmo da subtração. Com esse conhecimento, é possível detectar um erro numa conta, reconhecer uma definição imprecisa, entre outros aspectos, bastando, portanto, saber executá-lo.

Conhecimento de Horizonte dos Conteúdos (HCK): É um conhecimento envolvendo uma interconexão entre tópicos. Seria uma consciência de como os temas que estão sendo vistos se relacionam entre si, com os que já foram ensinados e com os que ainda estão por vir. Mas podemos ir além, essa interconexão, se dá não apenas entre a disciplina de atuação, mas em toda a grade curricular, com as diversas disciplinas vistas pelo estudante. O professor precisa saber se determinado tópico será novamente abordado em diferentes pontos do currículo, em anos distintos, e se será necessário pra outras disciplinas.

Conhecimento Especializado dos Conteúdos (SCK): São os conhecimentos e habilidades necessários exclusivamente para o ensino. Entre elas, conhecer diversos algoritmos para uma mesma situação, pois em uma sala de aula é provável que apareçam diferentes resoluções para uma mesma situação-problema, e o docente deve ser capaz de reconhecê-las e de buscar padrões nos erros cometidos. Assim como dispor de recursos para: explicar um mesmo problema com diferentes abordagens, por exemplo, a possibilidade de dividir por 2 ou multiplicar por $\frac{1}{2}$ na resolução de um mesmo problema; analisar abordagens que fogem do "padrão", mas que são corretas; justificar a validade de determinado algoritmo em vez de simplesmente exigir a memorização de procedimentos mecânicos; e, por fim, ter o conhecimento de uma matemática descompactada, isto é, aquela que mostra a razão de ser dos objetos em estudo e não somente ideias sintéticas visando um resultado final.

Conhecimento do Conteúdo e Estudantes (KCS): É uma junção entre conhecimento matemático e conhecimento sobre os estudantes. O docente precisa ter certa familiaridade com os alunos e uma compreensão matemática específica, sendo capaz de identificar antecipadamente as principais dificuldades dos alunos, de modo a sugerir exemplos e representações, que facilitarão a aprendizagem deles. Assim, o docente, precisa "saber ouvir" para que possa interpretar os raciocínios incompletos e emergentes de cada aluno, em sua própria linguagem, seria, pois [...] um amálgama, envolvendo uma ideia matemática ou um procedimento especifico e a familiaridade com o que os alunos normalmente pensam ou fazem (Ball et al., 2008, p. 401, tradução nossa) ${ }^{7}$. Por exemplo, o professor estaria usando esse tipo de conhecimento ao analisar um erro cometido por um aluno, se sabe o porquê do erro ter ocorrido baseando-se em experiências anteriores.

Conhecimento do Conteúdo e Ensino (KCT): Esse tipo de conhecimento é uma junção entre conhecimento sobre o ensino e conhecimento sobre a Matemática. O docente precisa saber utilizar diferentes representações ao ensinar certo conceito e identificar várias abordagens e procedimentos que são relacionados ao momento. Ele fará com que o professor antecipe as dificuldades dos alunos e consiga preparar a aula a fim de contorná-las. Também envolve questões sobre como iniciar a abordagem de determinado tópico, quais tarefas devem ser deixadas para um futuro e quais podem ser suprimidas para um melhor resultado, ainda que fizessem parte de um planejamento pré-estabelecido.

Conhecimento do Conteúdo e Currículos (KCC): Como citado anteriormente essa

\footnotetext{
${ }^{7}$... an amalgam, involving a particular mathematical idea or procedure and familiarity with what students often think or do.
} 
categoria apenas sofreu mudanças em seu nome.

Nessa etapa, foi percebida a importância que o chamado conhecimento especializado dos conteúdos possui na formação docente. Esse detalhamento, certamente, está entre as maiores contribuições que Ball et al trouxeram às ideias de Shulman, pois ao mesmo tempo que estabelece as bases de uma nova teoria, está fortemente vinculado às situações práticas vivenciadas pelos professores. A fim de esclarecer melhor o que se quer dizer com o conceito introduzido, os autores discutem a situação descrita a seguir.

É comum o aluno cometer erros com o algoritmo da subtração. Notar que a resposta está incorreta não exige nenhum tipo especial de conhecimento, pois basta saber operar a subtração e comparar resultados. Entretanto, perceber qual erro foi cometido, já não é tão trivial. E mais, o professor deve ser capaz de dimensionar a origem do erro por meio de uma análise eficiente, de modo a poder contorná-lo, não apenas com esse grupo de alunos, mas também, em aulas vindouras.

Outro ponto de forte interesse é a necessidade que se reconheça estratégias fora do padrão, levantando questões como: "É legítimo fazer isso?"; "Por quê?"; "Vai funcionar em geral?"; "É mais indicado para algumas situações e menos para outras?".

De modo a compreender melhor essas questões, os autores apresentam um exemplo baseado no simples cálculo da subtração 307-168, por meio da análise de possíveis resoluções distintas da "conta armada". Certamente a maioria das pessoas saberá responder à questão, alguns até o farão sem utilizar o algoritmo tradicional da subtração, mas de fato, apresentarão o resultado correto, isto é, 139. Obviamente é necessário o professor ser capaz de realizar essa subtração para poder ensiná-la, mas não é suficiente, pois o simples ato de saber resolver não habilita alguém a interpretar, por exemplo, os erros cometidos pelos alunos, já que Muitos alunos da terceira série lutam com o algoritmo da subtração cometendo erros (Ball et al., 2008, p. 396, tradução nossa $)^{8}$. Um erro muito comum cometido por esses alunos é o que segue:

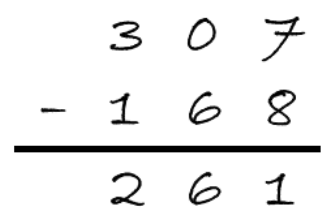

Figura 2.2: Exemplo 1: subtração.

Obviamente é simples perceber que houve um erro, na pior das hipóteses, como dito anteriormente, bastaria resolver o problema (corretamente) e comparar os resultados obtidos. Diante da divergência entre as respostas, certamente poderíamos afirmar que o resultado analisado está errado. É necessário que o professor analise o erro, buscando possíveis causas que tenham levado os alunos a cometê-lo e formas de contorná-lo em futuras aulas. No exemplo dado, é muito provável que ele, respeitando as posições de unidades, dezenas e centenas, tenha subtraído o menor algarismo do maior, mostrando, entretanto, incompreensão do significado da subtração.

Ball et al apontam que outro erro muito comum também cometido pelos alunos é:

\footnotetext{
${ }^{8}$ Many third graders struggle with the subtraction algorithm, often making errors.
} 


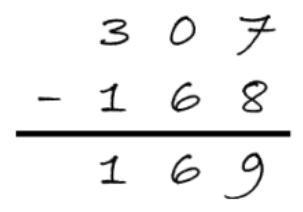

Figura 2.3: Exemplo 2: subtração.

Nesse exemplo, é possível perceber que o algarismo da unidade está correto, certamente foi obtido a partir de " $17-8$ ". Já no algarismo da centena, o aluno respondeu 1 , levando a crer que o 17 no processo anterior, foi obtido, "pegando emprestado" 1 unidade do algarismo 3, resultando portanto no campo das centenas " $2-1$ " o que resultou 1 . Provavelmente esse aluno memorizou o procedimento "pegar emprestado", mas não compreendeu o que está por trás do processo, ou seja, a decomposição dos números e seus valores posicionais. Além disso, deve-se buscar o porquê de ter obtido 6 como resposta, uma vez que nas unidades e centenas ele respeitou a ordem correta da subtração.

Nos dois casos, é nítido que o aluno necessita de intervenção para que consiga se apropriar dos conhecimentos exigidos para efetuar corretamente a subtração, a saber, a compreensão correta sobre os significados de valor posicional e a ideia da subtração, mas de modo algum podemos classificar os erros na mesma categoria. O primeiro efetua a operação sem levar em conta os valores posicionais, ou se o faz, apresenta uma possível incompreensão sobre diferença entre número e numeral e o fato que a subtração é uma operação entre os números envolvidos e não apenas entre os algarismos que compões os numerais que os representam, aparentemente, subtrai os algarismos de cada coluna de modo independente, tomando sempre o maior algarismo como minuendo. Já o segundo mostra incompreensão sobre o significado do zero na posição das dezenas, ignorando-o duplamente, tanto no reagrupamento para efetuar a subtração das unidades, quanto na diferença entre as dezenas. Mostrou, portanto, não ter compreendido o sistema decimal de numeração e o significado da subtração.

Interpretar as duas respostas simplesmente como erradas, certamente é um modo simplista de avaliar. Não somente desatencioso como irresponsável para com o objetivo de assegurar o direito do aluno à aprendizagem. O professor deve atuar como mediador do processo de aprendizagem e os erros são ótimas oportunidades para alavancar o entendimento de toda a classe em um ambiente de discussão e questionamentos que propicie ao aluno formular estratégias de resoluções. A seguir, apresentamos algumas resoluções corretas e não usuais descritas em Ball et al:
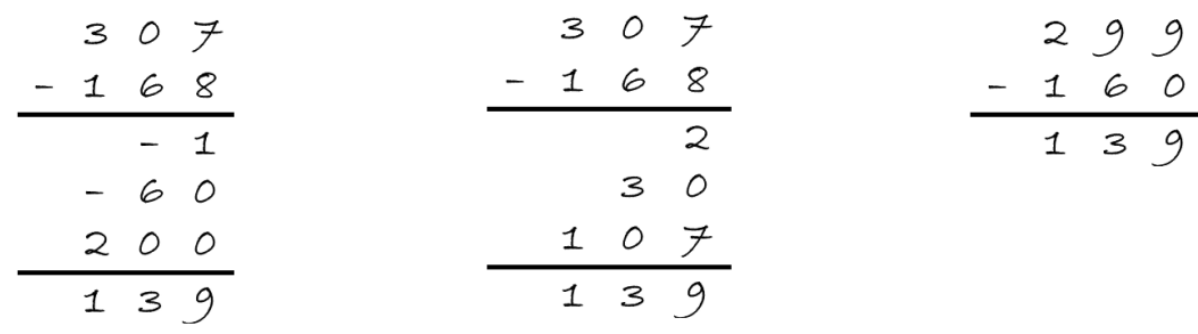

Figura 2.4: Exemplo 3: subtração.

Os exemplos mostram que o professor não deve se limitar a intervir apenas nos erros dos 
alunos, ele deve também possuir um conhecimento especializado para reconhecer possíveis raciocínios que mesmo não sendo o padronizado, ainda assim respeitam os conceitos envolvidos e conduzem a uma resposta correta. Algumas vezes, o próprio modo utilizado por algum aluno pode ser usado a favor do entendimento do conteúdo pela classe. Por exemplo, observando o procedimento acima (último à direita), o aluno transforma a conta "307 - 168" na equivalente "299 - 160" subtraindo 8 de cada um dos termos. Certamente o resultado das duas subtrações será o mesmo, dado que são equivalentes, portanto um professor distraído poderia considerar desnecessário comentar isso em classe. Mas por trás dessa simples equivalência, está um fato interessantíssimo sobre a decomposição dos números. O professor deve ser capaz de rapidamente compreender o raciocínio feito pelo aluno, inferir se é matematicamente correto e se tal abordagem irá funcionar em casos gerais. Nos dois outros exemplos, fica claro que se chegou ao resultado correto, porém os procedimentos utilizados são bem "pouco usuais" e merecem uma atenção por parte do professor, dado que por trás desse meio diferenciado, pode se esconder uma não compreensão real da subtração. De modo que, esse aluno irá buscar uma maneira sui generis para cada problema proposto. A análise, no entanto, mostra que ambos têm uma lógica correta no procedimento. Vale sempre à pena perguntar ao aluno "como pensou", para excluir a possibilidade do "acerto casual". No primeiro caso a lógica baseia-se na soma algébrica de números inteiros. E o segundo parece utilizar a ideia da subtração na resolução de problemas do tipo "quanto falta para".

Podemos concluir essa discussão com a seguinte frase: Análise de erros é uma prática comum entre matemáticos no transcorrer de seu próprio trabalho; a tarefa no ensino difere apenas na medida em que essa análise incide sobre os erros cometidos pelos alunos (Ball et al., 2008, p. 397, tradução nossa) ${ }^{9}$.

A fim de compreender melhor os termos destacados anteriormente, podemos montar o seguinte quadro, enfatizando como e em qual cada um dos seis conhecimentos poderiam ser mobilizados na prática docente:

\begin{tabular}{|c|c|}
\hline O professor é capaz de: & Categoria \\
\hline Reconhecer uma resposta errada & (CCK) \\
\hline Dimensionar a natureza do erro, especialmente os incomuns & (SCK) \\
\hline Buscar referência em sua familiaridade com erros cometidos pelos alunos & (KCS) \\
\hline Selecionar a abordagem que será mais eficiente nesse específico contexto & (KCT) \\
\hline Avaliar defasagens de aprendizado dos alunos relativas ao ano escolar & (KCC) \\
\hline Criar situações didáticas que articulem os conteúdos de modo significativo & (HCK) \\
\hline
\end{tabular}

Obviamente, o quadro anterior, serve apenas como uma ilustração para que se entenda melhor cada uma das categorias na situação específica da discussão de erros, pois na prática, essa separação não é estrita. Uma mesma tarefa que o professor desempenha pode mobilizar mais de uma categoria ao mesmo tempo, por exemplo, ao selecionar uma lista de exercícios para que os alunos resolvam, ele está mobilizando conhecimento básico e especializado dos conteúdos. Ao ordenar uma sequência que seja lógica e ao mesmo tempo didática para esses exercícios, o professor deve levar em consideração as dificuldades que os alunos revelarão e decidir como irá intervir. Nesse ponto, estão sendo mobilizados conhecimentos do conteúdo e estudantes, e conhecimento do conteúdo e ensino. Enfim, é preciso que fique claro que essa subdivisão serve como ponto de referência e compreensão, uma vez que as ações ocorridas ao longo da prática de ensino são orgânicas e contínuas.

\footnotetext{
${ }^{9}$ Error analysis is a commom practice among mathematicians in the course of their own work; the task in teaching differs only in that it focuses on the errors produced by learners.
} 
Parece-nos óbvio que o professor deve conhecer o conteúdo matemático a ser ensinado, mas também, sempre nos pareceu evidente que isso não é suficiente para levar a cabo o trabalho de ensinar. Mais do que acumular conhecimento matemático avançado, o professor deve se perguntar o quão útil é esse conhecimento enciclopédico para sua prática escolar. Os cursos e trabalhos que abordam tais ideias, tendem a ser teóricos e de caráter unicamente acadêmicos, abrindo margem para que se coloque de lado o foco principal das pesquisas, a saber, a sala de aula.

Embora existam exceções, a esmagadora maioria dos cursos de licenciaturas específicos e cursos de formação docentes em geral, são vistos por professores, formuladores de políticas e pela sociedade como tendo pouca influência sobre a realidade do dia-a-dia da prática escolar e pouco efeito sobre a melhoria do ensino e da aprendizagem (Ball et al., 2008, p. 404, tradução nossa) ${ }^{10}$.

Desse modo, foi pensando justamente no professor e em sua prática docente que desenvolvemos este trabalho, buscando contemplar várias das categorias apresentadas anteriormente. Nosso foco prioritário é a formação continuada de professores, entretanto acreditamos que ele também possa ser útil a outros leitores. Tentamos, na medida do possível, trazer o máximo de informações, demonstrações, fatos históricos, aplicações e até curiosidades para que o texto seja auto contido, necessitando de um mínimo de pré-requisitos. Quando julgamos necessária uma extensão maior de conhecimento prévio, optamos por fazer indicações de obras que tratem do assunto de modo agradável e completo, para não alongar demasiadamente o texto.

Contemplamos aqui as categorias conhecimento de horizonte dos conteúdos e conhecimento do conteúdo e currículos uma vez que nosso trabalho estabelece uma conexão entre logaritmos, cálculo de áreas e geometria analítica, bem como traça um apanhado histórico e epistemológico dos mesmos.

Como este trabalho fornece ao professor ferramentas para utilizar diferentes representações ao ensinar os logaritmos, ele traz também elementos pertinentes à categoria conhecimento do conteúdo e ensino.

Entretanto, a categoria principal que abarcamos nesta dissertação é a do conhecimento especializado dos conteúdos. Ao ler este trabalho, o professor conhecerá uma abordagem diferente da que é comum em sala de aula. Não queremos com isso, fazê-lo optar por uma ou outra, que julgue ser melhor, mas sim fornecer subsídios e ferramentas que possibilitem a criação de uma eventual terceira via de acesso ao conhecimento, utilizando aspectos de cada uma das abordagens que julgar mais adequado para seus alunos.

Partindo portanto do ponto de vista que existe um tipo de conhecimento específico para a profissão docente, buscamos, nos autores apresentados, subsídios que mostrem a necessidade e a importância de trabalhos como esse por nós apresentado. Esperamos, dessa forma, que o professor possa fazer uso dele para reforçar seu conhecimento e sentir-se preparado para, enriquecer o que é usualmente apresentado nos livros didáticos, levando informações aqui contidas aos seus alunos.

\footnotetext{
${ }^{10}$ Although there are exceptions, the overwhelming majority of subject matter courses for teachers, and teacher education courses in general, are viewed by teachers, policy makers, and society at large as having little bearing on the day-to-day realities of teaching and little effect on the improvement of teaching and learning.
} 


\section{Capítulo 3}

\section{Contextualização Histórica}

\subsection{Os logaritmos}

Quando pensamos nos primórdios dos logaritmos, dois nomes merecem destaque. De forma independente as principais ideias sobre o assunto foram desenvolvidas pelo matemático, físico e astrônomo escocês John Napier (1550 - 1617) que publicou em 1614 um livro intitulado Mirifici logarithmorum canonis descriptio (Uma descrição da maravilhosa regra dos logaritmos) e pelo matemático suíço Jost Bürgi $(1552$ - 1632) cuja obra de nome Arithmetische und Geometrische Progress Tabulen (Tábuas de progressões aritméticas e geométricas) foi publicada em 1620. De acordo com Boyer (1974, p. 230) é provável que a ideia de logaritmo tenha ocorrido a Bürgi seis anos antes que a Napier, por volta de 1588. Entretanto, como aponta Lima (2009, p. 01), por conta de seu bom relacionamento com professores universitários, a obra de Napier acabou se sobressaindo e seu nome tornou-se referência quando falamos na invenção dessa função. O próprio termo "logaritmo" foi criado por ele (Napier) e quer dizer algo como número idealizado, (Log - prefixo de logos - razão em grego. Aritmo de aritmética, ou número. Literalmente, número concebido pela razão ou pensamento, e portanto, número idealizado), desse modo, daqui em diante vamos sempre nos referir a Napier como criador, obviamente já tendo dado os devidos créditos e méritos a Bürgi.

A data precisa do nascimento de John Napier é desconhecida, mas há um consenso entre estudiosos que o ano foi realmente 1550. Filho de Sir Archibald Napier e Janet Bothwell, aos 13 anos foi mandado para a Universidade de St. Andrews estudar religião. Com pouco mais de 20 anos retorna à sua terra natal, onde passa a tomar partido em controvérsias religiosas da época. Casa-se com Elizabeth Stirling com quem tem dois filhos. Em 1579, após a morte de sua esposa, se casa com Agnes Chisholm com quem tem mais dez filhos, entre eles, Robert Napier que mais tarde exercerá papel importante na ampliação da obra de seu pai.

De início, um dos principais interesses de Napier era o ativismo religioso, tendo inclusive publicado, em 1593, a obra A Plaine Discovery of the whole Revelation of Saint John (Uma descoberta completa de toda a revelação de São João) em que expõe seus pontos de vista e ataca radicalmente a Igreja Católica. Seu livro teve mais de 20 edições e foi traduzido para vários idiomas. Entretanto, não obstante todo o sucesso que teve esse livro, ou ainda as várias disputas envolvendo seu nome, o que lhe colocou nos anais da história e o tornou mundialmente famoso foi seu trabalho com os logaritmos.

De fato tal invenção foi recebida com muita satisfação pelos estudiosos da época. Um dos cientistas que recebeu-a com entusiasmo foi o astrônomo Johannes Kepler que os utilizou em seus cálculos de órbitas planetárias. Aquele era um período de grande expansão do conhecimento científico: as ideias de Copérnico (heliocentrismo); Fernão de Magalhães (cir- 
cunavegação do globo); Galileu Galilei (mecânica) entre várias outras traziam à tona novos problemas. No fim do século XVI, o desenvolvimento da Astronomia e da navegação exigia longos e laboriosos cálculos aritméticos Lima (2009, p. 01). Diante desse panorama, para que a ciência pudesse continuar a progredir, também a Matemática deveria evoluir. A melhor ferramenta para se transformar um produto em uma soma e simplificar um cálculo, até aquele momento, eram as chamadas igualdades de prostaphereses, identidades trigonométricas que determinam produtos a partir de adições e subtrações:

$$
\begin{aligned}
& 2 \operatorname{sen} \alpha \cos \beta=\operatorname{sen}(\alpha+\beta)+\operatorname{sen}(\alpha-\beta) \\
& 2 \cos \alpha \operatorname{sen} \beta=\operatorname{sen}(\alpha+\beta)-\operatorname{sen}(\alpha-\beta) \\
& 2 \cos \alpha \cos \beta=\cos (\alpha+\beta)+\cos (\alpha-\beta) \\
& 2 \operatorname{sen} \alpha \operatorname{sen} \beta=\cos (\alpha-\beta)-\cos (\alpha+\beta)
\end{aligned}
$$

Esse processo era largamente empregado por astrônomos para simplificar cálculos e [...] passaram a ser largamente usadas por matemáticos e astrônomos perto do fim do século XVII como um método de conversão de produtos em somas e diferenças (Eves, 2004, p. 343). Provavelmente disso resultaram muitas das ideias precursoras dos logaritmos, uma vez que Napier inicialmente restringiu seus logaritmos aos senos de ângulos.

\subsection{Progressões e logaritmos}

Uma segunda ideia que possivelmente surgiu como catalisadora da invenção dos logaritmos foram as relações que podem ser estabelecidas entre progressões aritméticas e geométricas como sinalizado no título da obra de Bürgi, mais especificamente, entre os termos de uma PA que podem ser vistos como expoentes dos termos correspondentes de uma PG. Michael Stifel publica em 1544 um livro chamado Arithmetica Integra e nela encontramos lado a lado as sequências:

$\begin{array}{cccccccccccc}0 & 1 & 2 & 3 & 4 & 5 & 6 & 7 & 8 & 9 & 10 & \ldots \\ 0 & 2 & 4 & 8 & 16 & 32 & 64 & 128 & 256 & 512 & 1024 & \ldots\end{array}$

Observe que para obter o produto de dois números da sequência (II), basta somar os correspondentes de (I) e localizar o resultado na sequência (II). Por exemplo, para se multiplicar 4 por 16, basta somar 2 e 4 (correspondentes de 4 e 16 na sequência (I) respectivamente) que resulta 6 e localizar o resultado em (II) que é 64 . Isso decorre claramente da regra simples $4 \cdot 16=2^{2} \cdot 2^{4}=2^{2+4}=2^{6}=64$. Porém lembremos que na época não havia essa notação com potências. Evidentemente não eram esses cálculos, com números tão simples, que necessitavam astrônomos e navegantes. Mas ai estava o germe da ideia (Druck, 1995, p. 3). Foi a partir dessas ideias que o tema evoluiu.

Napier publica sua primeira obra sobre os logaritmos em 1614. Em 1619, postumamente, seu filho Robert publica um segundo volume intitulado Mirifici logarithmorum canonis constructio (Construção da maravilhosa regra dos logaritmos). É importante dizer que as primeiras tabelas apresentadas não se assemelhavam às nossas atuais, onde temos expoentes aos quais elevamos certo valor (base) para assim obter o número dado, tampouco se utilizou a base 10 ou a base $e$ (chamada base Neperiana em homenagem a Napier). 
Henry Briggs (1561-1631), professor de geometria de Oxford ficou tão maravilhado com a nova invenção que resolveu ir até a Escócia conhecer Napier pessoalmente. Tal encontro ocorreu em 1615 e nele Briggs propõe duas mudanças significativas no trabalho para tornar as tabelas mais fáceis de utilizar: que o logaritmo de 1 fosse igual a zero e que o logaritmo de 10 fosse igual a um. Napier recebe bem as sugestões. Entretanto devido à sua idade avançada e delicada saúde, coube ao próprio Briggs computar ${ }^{1}$ e publicar os novos resultados, que saem em 1624 sob o título Arithmetica logarithmica. A obra continha os logaritmos de base 10 dos inteiros de 1 a 20.000 e de 90.000 a 100.000 com 14 casas decimais de precisão. Os valores entre 20.000 e 90.000 foram posteriormente acrescentados pelo editor holandês Adriaan Vlacq (1600 - 1667) em 1628 na segunda edição da Arithmetica logarithmica.

O uso da nova ferramenta se espalhou pela Europa de tal modo que foram feitas traduções da obra de Napier para o inglês, holandês, italiano, alemão indo inclusive muito além do continente [...] o país seguinte a adotar a nova invenção foi a China, onde apareceu, em 1653, um tratado sobre logaritmos escrito por Xue Fengzuo, um discípulo do jesuíta polonês John Nicholas Smoguleçki (1611 - 1656) (Maor, 2006, p. 29). No ano de 1713 as tabelas completas de Vlacq já tinham sido publicadas em Pequim e pouco tempo depois a novidade estava também no Japão.

Nesse meio tempo, período em que era disseminado o novo conhecimento, alguns entusiastas perceberam que era possível construir um engenho mecânico que se encarregaria de calcular os logaritmos. A ideia primitiva apresentada pelo sacerdote inglês Edmund Gunter (1581 1626), surgiu em 1620 e consistiu em uma escala logarítmica na qual as distâncias podiam ser medidas e em seguida somadas e subtraídas com um par de compassos. Posteriormente em torno de 1622 o clérigo e matemático William Oughtred $(1574$ - 1660) teve a ideia de utilizar duas escalas logarítmicas que se moviam uma em relação à outra. Ougthred construiu duas versões para sua régua, uma linear e uma circular, essa última, assim como a primeira, possuía duas escalas marcadas em dois discos distintos que giravam em torno de um mesmo eixo. As réguas de cálculo foram uma importante invenção para os cientistas e engenheiros. Por mais de 300 anos podíamos encontrar essas "máquinas" presas aos cintos de qualquer estudante de exatas, tendo inclusive virado uma tradição um filho ganhar do pai uma régua dessas ao se graduar no ginásio. Mais recentemente, com o avanço da tecnologia e o surgimento de calculadoras cada vez menores e mais baratas, essas réguas perderam seu sentido prático tornando se objetos de decoração para os amantes das exatas ou simplesmente objetos descartáveis.

Uma segunda ferramenta tida como essencial era a tabela de logaritmos que também pouco a pouco foi perdendo seu espaço para a tecnologia, entretanto, com mais vagar, uma vez que ainda podemos encontrar trechos e exemplos de tabelas nos finais de alguns livros. No ensino atual de Matemática vemos um forte desgaste nesse assunto, dado que o ensino dos logaritmos na maior parte das vezes é baseado em regras de manipulação. Permeado de exemplos que pouco ou nada chamam a atenção dos alunos, têm como ponto fulcral o fato de que a maioria das aplicações interessantes em que aparecem os logaritmos, usam por base o irracional $e$, que como visto anteriormente, não é bem explorado nos livros didáticos e não é suficientemente abordado nas aulas. Mas o fato é que os logaritmos e as tabelas [...] representam, para os séculos XVII, XVIII e XIX, o que os computadores representam para o século XX, em matéria de cálculos numéricos (Druck, 1995, p. 12) e ainda, como nos conta o grande matemático Pierre Simon de Laplace: Ao reduzir suas tarefas, a invenção

\footnotetext{
${ }^{1} \mathrm{Na}$ elaboração da sua primeira tabela, em 1617, Briggs usou um método de interpolação linear que será detalhado na seção 3.3 desta dissertação.
} 
dos logaritmos dobrou a vida dos astrônomos (Maor, 2006, p. 39).

Se por um lado a tecnologia tomou dos logaritmos seu papel de destaque na Matemática, por outro a função logarítmica está muito longe de perder sua importância dado seu extenso uso na modelagem de situações em quase todos os ramos da Matemática pura e aplicada. É possível encontrar aplicação para ela na Física, Química, Biologia, Música, Artes e em diversas outras áreas. Napier não dispunha na época do conceito de função e consequentemente, não discutiu a função logarítmica. Porém, como aponta Druck (1995, p. 12), em virtude da necessidade de se atribuir um valor de logaritmo para qualquer número, mesmo intermediários entre os constantes de sua tabela, Napier utilizou uma definição baseada em um movimento contínuo dos pontos ao longo da reta, algo que pode ser pensado como uma definição cinemática. Porém a formalização da função logarítmica (a que aparece com frequência nas áreas citadas) se fez muito tempo após esses acontecimentos. A explanação do modelo cinemático sugerido por Napier foge ao nosso escopo e será omitido aqui, mas a quem interessar, encontrará uma boa explanação em Druck (1995).

\subsection{Interpolação linear}

Não podemos afirmar que a interpolação linear é o único procedimento existente para calcular valores aproximados de um logaritmo, entretanto sabemos que se trata de um método bem antigo. Existem logaritmos que são imediatos, devido à nossa familiaridade com as operações entre números naturais e a potenciação. Por exemplo, não nos traz grandes dificuldades responder quanto vale $\log _{2} 8$ ou ainda resolver a equação $\log _{5} x=3$ bastando conhecer a definição mais comum encontrada nos livros para o logaritmo. Entretanto, uma tarefa que não é tão simples, é calcular $\log _{2} 7$ ou resolver $\log _{5} x=2,5$.

Esse foi um problema que, seguramente, ocupou a mente dos elaboradores das tabelas de logaritmos no século XVII. Ou mesmo aos usuários que, de posse das tabelas, em determinadas ocasiões, tivessem necessidade de um valor de logaritmo com uma precisão maior do que a oferecida ou do logaritmo de um número que delas não constasse. Assim, seria importante haver um método para a obtenção de uma representação decimal aproximada (no grau desejado) do valor do logaritmo de um número intermediário, a partir de dois outros valores conhecidos.

O método, que será apresentado, teve sua ideia extraída do artigo Das Porcentagens aos Logaritmos de Jakubovic (1980). Nele, vemos as propriedades dos logaritmos serem usadas de modo simples, porém extremamente funcional. É notável como as ideias de médias aritmética e geométrica se conectam, lembrando fortemente aquela estabelecida, na seção 3.2, entre uma PA e uma PG. Também é interessante ressaltar, a possibilidade de trabalhar esse procedimento com alunos do Ensino Médio, reforçando a bela conexão existente entre os assuntos e que podemos facilmente caracterizar como um conhecimento especializado defendido por Ball et al (2008). A fim de tornar sua compreensão mais rápida, iniciaremos com um cálculo, do qual já conhecemos o resultado que (supostamente) estamos procurando. Assim, ele servirá para familiarizar o método e ficará como exemplo motivador. Vamos "descobrir" o valor de $\log _{2} 8$.

Obviamente podemos levantar algumas conjecturas utilizando dois logaritmos conhecidos que sejam, um anterior e outro posterior ao valor "desconhecido", nesse caso, temos conhecido que $\log _{2} 4=2$ e também que $\log _{2} 16=4$.

Continuando nossa busca, "não sabemos dizer com certeza" quanto vale $\log _{2} 8$, mas nos 
parece lógico $^{2}$ que ele deve estar em acordo com a desigualdade:

$$
\begin{gathered}
\log _{2} 4<\log _{2} 8<\log _{2} 16 \\
2<\log _{2} 8<4
\end{gathered}
$$

Vamos tirar a média aritmética entre os dois extremos da primeira desigualdade acima:

$$
\frac{\log _{2} 4+\log _{2} 16}{2}=\frac{\log _{2}(4 \cdot 16)}{2}=\frac{1}{2} \cdot \log _{2}(4 \cdot 16)=\log _{2}(64)^{\frac{1}{2}}=\log _{2} 8
$$

Por outro lado, realizando a mesma média aritmética, mas agora usando a segunda desigualdade, obtemos, $\frac{2+4}{2}=\frac{6}{2}=3$ do qual, podemos concluir que $\log _{2} 8=3$.

Partiremos agora para um exemplo mais interessante do que o inicial. Vamos buscar uma aproximação decimal para o valor de $\log _{2} 7$. Podemos, como descrito no exemplo introdutório, partir das desigualdades:

$$
\begin{gathered}
\log _{2} 4<\log _{2} 7<\log _{2} 8 \\
2<\log _{2} 7<3
\end{gathered}
$$

Vamos tirar a média aritmética entre os dois extremos da primeira desigualdade acima:

$$
\frac{\log _{2} 4+\log _{2} 8}{2}=\frac{\log _{2}(4 \cdot 8)}{2}=\frac{1}{2} \cdot \log _{2}(4 \cdot 8)=\log _{2}(4 \cdot 8)^{\frac{1}{2}} \cong \log _{2} 5,7
$$

Por outro lado, $\frac{2+3}{2}=\frac{5}{2}=2,5$ do qual, podemos concluir que $\log _{2} 5,7 \cong 2,5$.

Ora, a partir dessa nova informação, podemos refinar nossa conjectura inicial, isto é,

$$
\log _{2} 4<\log _{2} 7<\log _{2} 8
$$

será substituída pela estimativa melhor

$$
\log _{2} 5,7<\log _{2} 7<\log _{2} 8
$$

$\mathrm{e}$

$$
2<\log _{2} 7<3
$$

será substituída pela estimativa melhor

$$
2,5<\log _{2} 7<3
$$

\footnotetext{
${ }^{2} \mathrm{Na}$ verdade, tal fato está longe de ser óbvio e suas provas envolverão o comportamento desses números, crescimento e injetividade no caso de funções, etc, mas vamos deixar esses pormenores de lado em beneficio de um maior enfoque sobre o que esta em foco, isto é, a interpolação de logaritmos.
} 
Obtemos desse modo uma desigualdade semelhante à anterior, porém essa, com uma informação mais fina, isto é:

$$
\begin{gathered}
\log _{2} 5,7<\log _{2} 7<\log _{2} 8 \\
2,5<\log _{2} 7<3
\end{gathered}
$$

Ora, note que a partir dessa ultima desigualdade obtida, podemos repetir o processo e refinar ainda mais nossa conjectura, ou seja:

$$
\frac{\log _{2} 5,7+\log _{2} 8}{2}=\frac{\log _{2}(5,7 \cdot 8)}{2}=\frac{1}{2} \cdot \log _{2}(5,7 \cdot 8)=\log _{2}(5,7 \cdot 8)^{\frac{1}{2}} \cong \log _{2} 6,8
$$

Por outro lado, $\frac{2,5+3}{2}=\frac{5,5}{2}=2,75$ e podemos concluir que $\log _{2} 6,8 \cong 2,75$. Assim,

$$
\log _{2} 5,7<\log _{2} 7<\log _{2} 8
$$

substituímos por

$$
\log _{2} 6,8<\log _{2} 7<\log _{2} 8
$$

consequentemente,

$$
2,5<\log _{2} 7<3
$$

substituímos por

$$
2,75<\log _{2} 7<3
$$

E por conseguinte:

$$
\begin{gathered}
\log _{2} 6,8<\log _{2} 7<\log _{2} 8 \\
2,75<\log _{2} 7<3
\end{gathered}
$$

Aplicando o processo pela terceira vez, obtemos o resultado $\log _{2} 7,4 \cong 2,88$, consequentemente, nossa desigualdade será:

$$
\begin{gathered}
\log _{2} 6,8<\log _{2} 7<\log _{2} 7,4 \\
2,75<\log _{2} 7<2,88
\end{gathered}
$$

Aplicando o processo pela quarta vez, obtemos o resultado $\log _{2} 7,1 \cong 2,82$ e por conseguinte, nossa desigualdade será:

$$
\begin{gathered}
\log _{2} 6,8<\log _{2} 7<\log _{2} 7,1 \\
2,75<\log _{2} 7<2,82
\end{gathered}
$$

Aplicando o processo pela quinta vez, obtemos o resultado $\log _{2} 6,9 \cong 2,79$ e por conseguinte, 
nossa desigualdade será:

$$
\begin{gathered}
\log _{2} 6,9<\log _{2} 7<\log _{2} 7,1 \\
2,79<\log _{2} 7<2,82
\end{gathered}
$$

Note que, após apenas cinco iterações, obtivemos uma boa aproximação para o valor esperado ao usar uma calculadora, que é, $\log _{2} 7 \cong 2,807355$, com aproximação para seis casas decimais. Essa aproximação pode ser tão boa quanto desejarmos, bastando para isso calcularmos tantas iterações quanto necessárias.

De fato, o método não é muito prático e dependendo da aproximação desejada, a busca pode se tornar muito cansativa. Mas nos tempos em que não haviam máquinas calculadoras ou tabelas logarítmicas, certamente esse método teve papel de destaque na elaboração das tabelas de logaritmos de base 10 de Briggs, em 1617 (Jakubovic, 1980).

Apenas a título de fixação, vamos calcular mais um valor, usando para isso, três iterações.

Nesse exemplo, iremos calcular o valor de $\log _{3} 31$ que não sabemos dizer exatamente quanto vale, procedendo como anteriormente, obtemos:

$$
\begin{gathered}
\log _{3} 27<\log _{3} 31<\log _{3} 81 \\
3<\log _{3} 31<4
\end{gathered}
$$

Vamos tirar a média aritmética entre os dois extremos da desigualdade acima:

$$
\frac{\log _{3} 27+\log _{3} 81}{2}=\frac{\log _{3}(27 \cdot 81)}{2}=\frac{1}{2} \cdot \log _{3}(27 \cdot 81)=\log _{3}(27 \cdot 81)^{\frac{1}{2}} \cong \log _{3} 46,8
$$

Por outro lado, $\frac{3+4}{2}=\frac{7}{2}=3,5$ do qual, podemos concluir que $\log _{3} 46,8 \cong 3,5$.

Ora, a partir dessa nova informação, podemos refinar nossa conjectura inicial, isto é,

$$
\log _{3} 27<\log _{3} 31<\log _{3} 81
$$

substituímos por

$$
\log _{3} 27<\log _{3} 31<\log _{3} 46,8
$$

consequentemente,

$$
3<\log _{3} 31<4
$$

substituímos por

$$
3<\log _{3} 31<3,5
$$

Obtemos desse modo uma desigualdade semelhante à anterior, porém essa, com uma infor- 
mação mais precisa, isto é:

$$
\begin{gathered}
\log _{3} 27<\log _{3} 31<\log _{3} 46,8 \\
3<\log _{3} 31<3,5
\end{gathered}
$$

Ora, note que a partir da ultima desigualdade obtida, podemos repetir o processo e refinar ainda mais nossa conjectura, ou seja:

$$
\frac{\log _{3} 27+\log _{3} 46,8}{2}=\frac{\log _{3}(27 \cdot 46,8)}{2}=\frac{1}{2} \cdot \log _{3}(27 \cdot 46,8)=\log _{3}(27 \cdot 46,7)^{\frac{1}{2}} \cong \log _{3} 35,6
$$

Por outro lado, $\frac{3+3,5}{2}=\frac{6,5}{2}=3,25$ e podemos concluir que $\log _{3} 35,6 \cong 3,25$.

Desta forma,

$$
\log _{3} 27<\log _{3} 31<\log _{3} 46,8
$$

substituímos por

$$
\log _{3} 27<\log _{3} 31<\log _{3} 35,6
$$

consequentemente,

$$
3<\log _{3} 31<3,5
$$

substituímos por

$$
3<\log _{3} 31<3,25
$$

E por conseguinte:

$$
\begin{gathered}
\log _{3} 27<\log _{3} 31<\log _{3} 35,6 \\
3<\log _{3} 31<3,25
\end{gathered}
$$

Aplicando o processo pela terceira vez, obtemos o resultado $\log _{3} 31,003 \cong 3,125$ e por conseguinte, nossa desigualdade será:

$$
\begin{gathered}
\log _{3} 27<\log _{3} 31<\log _{3} 31,003 \\
3<\log _{3} 31<3,125
\end{gathered}
$$

Nesse caso, após três iterações, obtivemos uma aproximação tão boa, para o valor esperado, $\log _{3} 31 \cong 3,1257$, que ela apenas se difere após a quarta casa decimal. Novamente lembramos que essa aproximação pode ser tão boa quanto desejada, bastando aumentar o número de iterações. 


\subsection{Juros Compostos e um limite curioso}

Sem dúvidas o ato de emprestar algum dinheiro e cobrar uma taxa pelo "favor" é uma prática muito antiga. Em tábulas de argila da Mesopotâmia que datam de 1700 a.C. podemos encontrar um problema que, interpretado com a linguagem atual, pede para calcular em quanto tempo uma quantia em dinheiro irá levar para se duplicar caso seja investida a uma taxa de vinte por cento ao ano. Note que para resolver um problema como esse hoje, certamente utilizamos os logaritmos, entretanto, como já sabemos, os babilônios ainda não dispunham de tais conhecimentos, eles utilizavam a ideia chamada interpolação linear apresentada anteriormente, que apesar de um tanto rudimentar apresentava um resultado bem satisfatório [...] sua resposta, $x=3,7870$ encontra-se notavelmente próxima do valor correto, que é 3,8018 (isto é, cerca de três anos, nove meses e dezoito dias) (Maor, 2006, p. 42).

Em notação moderna utilizamos a relação $M=C(1+i)^{t}$ para o cálculo de juros compostos, ou popularmente conhecido como "juros sobre juros", que são aqueles nos quais os juros gerados a cada período são incorporados ao capital para o cálculo do rendimento no período seguinte. Muitos bancos utilizam essa relação, mas com uma "taxa por período". Desse modo, se estipularmos uma taxa anual de $5 \%$ que será composta duas vezes ao ano, o banco utilizará metade da taxa por semestre. Por exemplo: se um valor de 100 será composto duas vezes a uma taxa de $2,5 \%$ ao período (semestre), teremos $100 \cdot(1,025)^{2}$ o que resulta 105,06 (um acréscimo maior que os $5 \%$ iniciais). Nas transações econômicas achamos todo tipo de composição de juros: anual, semestral, bimestral, mensal, semanal, diário entre outros períodos. Vamos generalizar supondo que a composição seja efetuada $n$ vezes ao ano. Para cada período a taxa utilizada pelo banco será dividida por $n$. Como em $t$ anos existem $(n t)$ períodos, após os $t$ anos o capital renderá:

$$
M=C\left(1+\frac{i}{n}\right)^{n t}
$$

Dessa forma podemos encarar a primeira equação como um caso particular da segunda para $n=1$.

Vamos agora observar uma situação bastante interessante a partir da última relação. Mas antes de vê-la, é preciso dizer que, do ponto de vista prático, a situação pode parecer um tanto absurda, pois vamos supor um banco que ofereça uma taxa de juros de $100 \%$ por período. Entretanto do ponto de vista didático a situação é bem esclarecedora. Então vamos admitir, como dito, uma taxa de juros de $100 \%, t$ será igual a um ano e para simplificar nossa discussão vamos começar nossa aplicação com $\$ 1,00$. Desse modo a equação ficará:

$$
M=\left(1+\frac{1}{n}\right)^{n} .
$$

Vamos analisar o comportamento de $M$ a medida que o valor de $n$ cresce: 


\begin{tabular}{|c|c|}
\hline$n$ & $M$ \\
\hline 1 & 2 \\
\hline 2 & 2,25 \\
\hline 3 & $2,37037 \ldots$ \\
\hline 4 & $2,44141 \ldots$ \\
\hline 5 & $2,48832 \ldots$ \\
\hline 10 & $2,59374 \ldots$ \\
\hline 50 & $2,69159 \ldots$ \\
\hline 100 & $2,70481 \ldots$ \\
\hline 1.000 & $2,71692 \ldots$ \\
\hline 1.000 .000 & $2,71828 \ldots$ \\
\hline 10.000 .000 & $2,71828 \ldots$ \\
\hline
\end{tabular}

Note que pelos dados da tabela, aparentemente se tomarmos qualquer valor acima de 1.000.000 para $n$ o valor de $M$ não será afetado, mas para sermos realmente corretos, devemos entender que ele é sim afetado, mas em valores cada vez menos significativos, ou seja, muitas casas após a vírgula. $\mathrm{O}$ resultado de $M$ irá cada vez mais se aproximar de um valor chamado limite, cuja representação decimal tem infinitas casas e não é periódica. Isso é algo muito curioso e nada intuitivo. Apenas os fatos apresentados pela tabela não são suficientes para se demonstrar que esse limite existe e que é o número $e$. Afinal nada nos garante que para algum valor de $n$ maior do que o nosso último "teste" encontremos, por exemplo, $M=3$. Para provarmos tais afirmações, é necessária uma minuciosa análise lógica que será omitida por enquanto.

Não podemos precisar quando e em que contexto esse número foi percebido pela primeira vez, sabemos porém que já a [...] segunda edição da tradução de Edward Wright do Descriptio de Napier (1618) continha uma referência indireta ao e (Maor, 2006, p. 45). De fato, dado as viagens intercontinentais, culminando com o grande crescimento do comércio internacional e das transações financeiras, é de se esperar que tenha sido dada uma atenção maior às questões envolvendo juros compostos e consequentemente aos fatos envolvendo os valores da sequência apresentada. Mas tudo isso não passa de especulação. Com o passar do tempo e a evolução de alguns conceitos matemáticos, entre eles o famoso Cálculo Diferencial e Integral, o número $e$ juntamente com $\pi$ passaram a figurar entre as constantes mais importantes, não apenas da Matemática, mas de inúmeras ciências exatas ou não. Como aponta Simmons, a constante $e$ se tornou [...] o número mais importante encontrado na matemática depois do famoso $\pi$ (Simmons, 1987, p. 351). Dentre as inúmeras aplicações dessa constante nas funções exponenciais e logarítmicas, vamos apresentar agora uma função em que, não obstante sua importância, tanto para a Matemática pura quanto aplicada (como dezenas de outras semelhantes a ela), carrega consigo uma grande curiosidade para os entusiastas desta ciência, pois a partir dela obtemos a famosa Equação de Euler, considerada por muitos como a mais bela equação existente. Porém, antes de abordar tal equação, é interessante conhecermos um pouco mais sobre o matemático que lhe empresta nome.

Um dos maiores matemáticos de todos os tempos foi Leonhard Euler (1707 - 1783). Filho de um pastor protestante, nascido na Basileia - Suíça, ingressou na Universidade da Basileia aos 14 anos para estudar teologia, línguas, medicina entre outros assuntos. Porém o que lhe despertava interesse mesmo era a Matemática. Inclusive, Nas tardes de sábado, tinha aulas particulares com o famoso matemático Johann Bernoulli, e se tornou amigo de seus dois filhos, Nicolaus e Daniel (Crease, 2011, p. 82). Obteve seu diploma em 1723, ocasião em que tentou seguir pelo caminho da teologia a pedido de seu pai, mas logo desistiu voltando 
sua atenção à Matemática, sua verdadeira paixão. Em 1727 recebeu um convite para fazer parte da recém-fundada Academia de Ciências da Rússia, em São Petersburgo e logo se torna matemático-chefe. Sua produção era tão vasta que a revista da instituição não dava contar de publicar todos os seus trabalhos, formando, desse modo, pilhas de materiais que eram usados conforme obtinham espaço para publicar.

A Matemática nessa época já estava bastante desenvolvida, mas era concentrada em ramos de estudo isolados. Os principais eram a Geometria (estudo de pontos, retas, planos e das propriedades de figuras obtidas por meio deles), a Trigonometria (subdivisão da primeira, que estuda as relações entre ângulos e lados de um triângulo) e a Álgebra (estudo das equações, prioritariamente a coeficientes racionais - suas bases remontam à Idade Média e ao famoso matemático árabe Mohammed ibn Musa al-Khwarizmi $(780-850))$. No inicio do século XVIII, nascia um novo ramo da Matemática que ficou conhecido como Análise, e tratava principalmente do estudo de temas como os infinitos, infinitésimos, números reais, medidas, números complexos entre outros. Ela surge a partir do Cálculo Diferencial e Integral, assunto com forte destaque no século anterior e responsável por revolucionar todas as ciências exatas. Coube ao grande matemático Euler organizar as ideias existentes, bem como suas próprias descobertas [...] num corpo de conhecimento coerente e a transformou numa área organizada e robusta da matemática (Crease, 2011, p. 84). Também foi responsável por desenvolver um estudo sistemático das funções - assunto indispensável nos dias atuais - e fez grandes descobertas no estudo das séries (somas com infinitos termos). Introduziu e padronizou diversos símbolos e notações que ainda hoje utilizamos, tais como: $\pi, e, i, f(x)$, sen, cos, $\sum$, entre tantos outros.

Mas nem tudo foram flores no caminho desse importante matemático, Euler sofreu dois grandes golpes da vida. Ainda na Academia de Ciência da Rússia sofreu uma congestão cerebral por conta da fadiga do trabalho que o deixou cego do olho direito. Aos 56 anos descobriu que tinha catarata no olho esquerdo e pouco tempo depois fica cego desse olho também. Mas isso, de modo algum interferiu em sua produção científica. Metade de sua obra foi produzida depois de cego com a ajuda de empregados que anotavam o que Euler ditava e depois liam para que fosse revisado. Faleceu em setembro de 1783 enquanto conversava com o astrônomo, físico e matemático Anders Johan Lexell, seu grande amigo e também membro da Academia de Ciência da Rússia.

O legado deixado por Euler ainda hoje exerce influência nas produções científicas. Ele ajudou a desenvolver principalmente a álgebra, a análise e a topologia (área que nem existia em sua época). Seu livro Instruções completas em álgebra foi, por muito tempo, considerado exemplo de livro didático para o assunto, existindo inclusive traduções para o português. Para a topologia, sua principal contribuição veio com a resolução do famoso Problema das pontes de Königsberg, que questiona a possibilidade de atravessar as sete pontes que ligam as margens e as ilhas da cidade cruzando cada ponte uma única vez. Contudo, suas maiores contribuições foram para o recém criado campo da análise, cujo trabalho mais famoso, intitulado Introdução à análise do infinito, de 1748, e dividido em dois volumes, traz grandes descobertas acerca de funções que são descritas por séries.

Introdução fez para a análise o que os Elementos, de Euclides, fez para a geometria e o Hisab al-jabr wa'l muquabalah, de al-Khwarizmi, fez para a álgebra. Foi um texto clássico, que inspirou gerações a aprender análise, especialmente as séries infinitas (Crease, 2011, p. 84 apud Burton, 1985, p. 503).

Ainda nessa obra, Euler anuncia a descoberta de uma conexão brilhante entre funções expo- 
nenciais, trigonométricas e números imaginários. No capítulo VII, mostra os benefícios de se trabalhar com uma função exponencial cuja base fosse um número que resultasse da soma dos termos da série infinita $1+\frac{1}{1 !}+\frac{1}{2 !}+\frac{1}{3 !}+\frac{1}{4 !}+\ldots$ No capítulo VIII, passa a trabalhar com funções trigonométricas, representando-as pelo que hoje conhecemos por ciclo trigonométrico. Aqui também aparece a prova de fatos já conhecidos, incluindo a possibilidade de demonstrar que $\operatorname{sen}^{2} x+\cos ^{2} x=1$ pela simples aplicação do teorema de Pitágoras. Mais além, começa a relacionar funções trigonométricas com séries infinitas ${ }^{3}$.

Um dos primeiros passos foi representar a função $e^{x}$ por meio da série:

$$
e^{x}=1+\frac{x}{1 !}+\frac{x^{2}}{2 !}+\frac{x^{3}}{3 !}+\frac{x^{4}}{4 !}+\frac{x^{5}}{5 !}+\frac{x^{6}}{6 !}+\frac{x^{7}}{7 !}+\frac{x^{8}}{8 !}+\frac{x^{9}}{9 !}+\frac{x^{10}}{10 !}+\frac{x^{11}}{11 !}+\frac{x^{12}}{12 !} \ldots
$$

E as funções trigonométricas seno e cosseno, por meio de:

$$
\begin{gathered}
\operatorname{sen} x=\frac{x}{1 !}-\frac{x^{3}}{3 !}+\frac{x^{5}}{5 !}-\frac{x^{7}}{7 !}+\frac{x^{9}}{9 !}-\frac{x^{11}}{11 !}+\frac{x^{13}}{13 !}-\frac{x^{15}}{15 !}+\ldots \\
\cos x=1-\frac{x^{2}}{2 !}+\frac{x^{4}}{4 !}-\frac{x^{6}}{6 !} \frac{x^{8}}{8 !}-\frac{x^{10}}{10 !}+\frac{x^{12}}{12 !}-\frac{x^{14}}{14 !}+\ldots
\end{gathered}
$$

Em um grande lampejo de genialidade, Euler toma a série de $e^{x}$ e substitui a variável $x$ por $i y$, em que $i=\sqrt{-1}$, obtendo, portanto:

$$
e^{i y}=1+\frac{i y}{1 !}+\frac{(i y)^{2}}{2 !}+\frac{(i y)^{3}}{3 !}+\frac{(i y)^{4}}{4 !}+\frac{(i y)^{5}}{5 !}+\frac{(i y)^{6}}{6 !}+\frac{(i y)^{7}}{7 !}+\frac{(i y)^{8}}{8 !}+\frac{(i y)^{9}}{9 !}+\frac{(i y)^{10}}{10 !}+\ldots
$$

Lembrando que $i^{2}=-1, i^{3}=-i, i^{4}=1, i^{5}=i$ e assim sucessivamente, resulta:

$$
e^{i y}=1+\frac{i y}{1 !}-\frac{y^{2}}{2 !}-\frac{i y^{3}}{3 !}+\frac{y^{4}}{4 !}+\frac{i y^{5}}{5 !}-\frac{i y^{6}}{6 !}-\frac{i y^{7}}{7 !}+\frac{y^{8}}{8 !}+\frac{i y^{9}}{9 !}-\frac{y^{10}}{10 !}-\frac{i y^{11}}{11 !}+\frac{y^{12}}{12 !}+\ldots
$$

E ao reagrupar os termos múltiplos de $i$, ele obteve:

$$
e^{i y}=\left(1-\frac{y^{2}}{2 !}+\frac{y^{4}}{4 !}-\frac{i y^{6}}{6 !}+\ldots\right)+i\left(y-\frac{i y^{3}}{3 !}+\frac{i y^{5}}{5 !}-\frac{i y^{7}}{7 !}\right)
$$

Analisando agora os termos dentro dos parênteses, podemos notar que são justamente as séries de potência das funções trigonométricas cosseno e seno, do qual substituindo na igualdade ficamos com $e^{i y}=\cos y+i \operatorname{sen} y$ que de maneira espantosa relaciona uma função exponencial com funções trigonométricas. A maneira como o famoso matemático Euler procedeu para chegar a tal resultado certamente envolveu uma grande criatividade, inteligência e, principalmente, audácia em não temer as experimentações com o desconhecido. Mas o passo decisivo talvez tenha sido o mais simples, pois uma vez de posse da última igualdade, podemos tomar $y=\pi$ obtendo então:

$$
e^{i \pi}=\cos \pi+i \operatorname{sen} \pi
$$

\footnotetext{
${ }^{3}$ Neste ponto, utilizaremos algumas propriedades e teoremas que serão omitidos no presente trabalho por fugir ao seu objetivo e alguns outros resultados que serão demonstrados no capítulo 5. Entretanto aos leitores que desejarem conhecer tais demonstrações, poderão encontrá-las em livros de Cálculo e Análise Real. Entre eles, podemos destacar Ávila e Stewart que estão em nossas referências.
} 
O qual resulta em uma das equações ${ }^{4}$ mais belas de todas as ciências exatas, a famosa:

$$
e^{i \pi}+1=0
$$

\footnotetext{
${ }^{4}$ Segundo algumas definições, da maneira como está não é uma equação, mas sim uma identidade, pois não apresenta nenhuma variável. Entretanto, resolvemos manter o termo.
} 


\section{Capítulo 4}

\section{Logaritmos, hipérboles e a área de uma faixa de hipérbole}

\subsection{Logaritmos e a hipérbole}

Existe uma relação entre a área de uma determinada região abaixo da hipérbole e o valor de um logaritmo. Na verdade, podemos ir muito além nessa afirmação, existe uma relação biunívoca entre as áreas da região abaixo de um ramo da hipérbole e os logaritmos, como veremos à frente. Muito provavelmente os dois primeiros a notar tal relação foram, [...] o padre jesuita belga Gregory Saint Vincent, em 1647, e depois Isaac Newton, em 1660 [...] (Lima, 2009, p. 25). Embora eles não tenham estabelecidos fortes ligações ou erigidos grandes teorias entre os dois conceitos, suas observações foram pioneiras e suficientes para incitar interesses em matemáticos posteriores.

Vale lembrar da definição geométrica de Hipérbole como o lugar geométrico que, dados dois pontos distintos $F_{1}$ e $F_{2}$ fixos em um plano $\alpha$, será chamado de Hipérbole o lugar geométrico dos pontos $P$ de $\alpha$ cujo módulo da diferença de suas distâncias aos dois pontos fixos é igual a uma constante $k<F_{1} F_{2}$. Nesse caso, $F_{1}$ e $F_{2}$ são chamados de focos, e temos por definição que

$$
\text { Hipérbole }=\left\{P \in \alpha|| P F_{1}-P F_{2} \mid=k\right\} .
$$

Assim, na reta de $\alpha$ que passa pelos focos existem dois únicos pontos $A_{1}$ e $A_{2}$, entre $F_{1}$ e $F_{2}$, pertencentes à Hipérbole para os quais vale que

$$
F_{1} A_{1}=\frac{F_{1} F_{2}-k}{2} \text { e } F_{2} A_{2}=\frac{F_{1} F_{2}-k}{2} .
$$

Disso decorre que $A_{1} A_{2}=k$. Esse lugar geométrico determina uma curva no plano $\alpha$ que apresenta certas simetrias de reflexão relativamente à reta que passa pelos pontos F1 e F2 e à mediatriz do segmento $\overline{F_{1} F_{2}}$. Esses eixos de simetria poderão ser úteis para a determinação de uma equação que represente a curva, como usualmente é feito na Geometria Analítica e veremos mais adiante.

Antes disso estabeleçamos nomenclaturas úteis. 


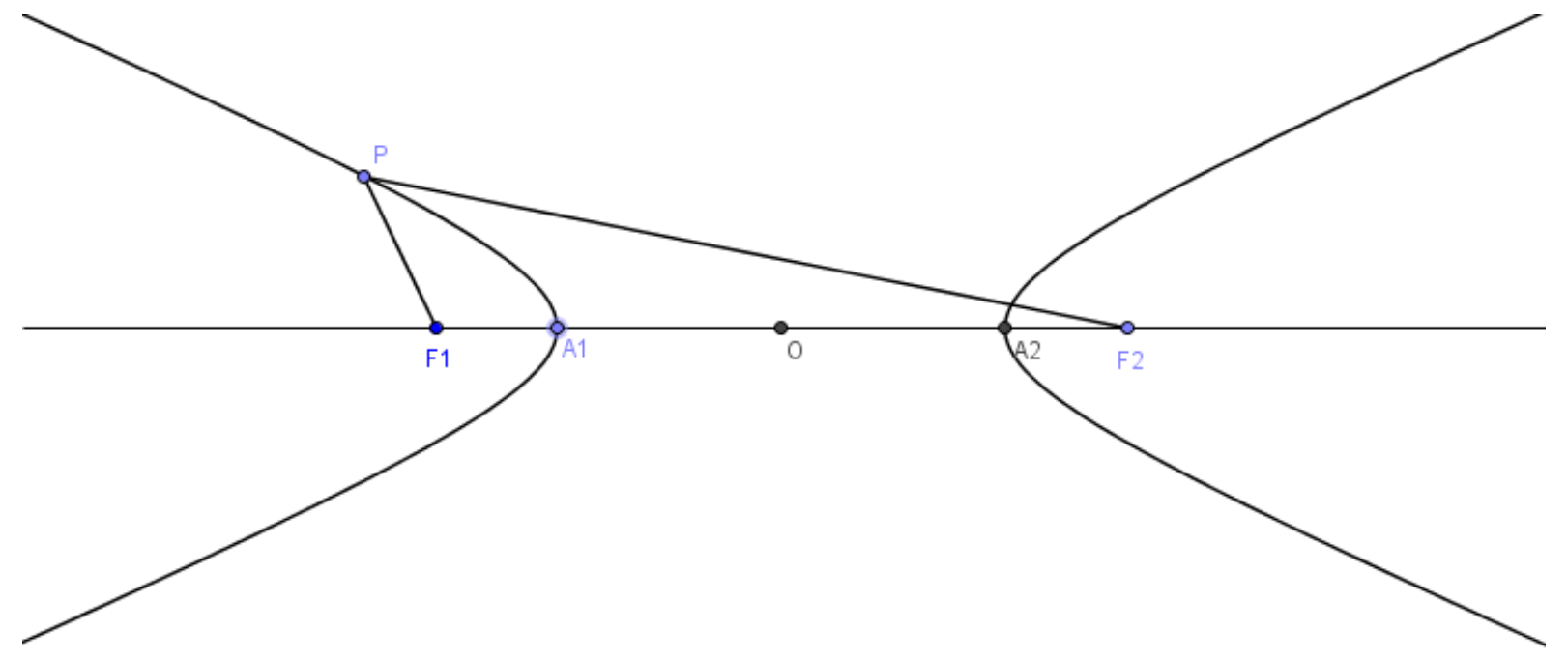

Figura 4.1: Gráfico de Hipérbole.

- Eixo focal que passa pelos focos;

- Eixo central que passa pelo ponto médio entre os focos e é ortogonal ao eixo focal;

Seus principais elementos são:

- Centro $O$ (ponto médio entre os focos);

- Focos $F_{1}$ e $F_{2}$;

- Vértices $A_{1}$ e $A_{2}$ (pontos de intersecção da hipérbole com o eixo focal);

- Distância focal é definida como a medida do segmento $\overline{F_{1} F_{2}}$. Os livros didáticos utilizam usualmente $d\left(F_{1}, F_{2}\right)=2 c$;

- Distância entre vértices é definida como a medida do segmento $\overline{A_{1} A_{2}}$ sendo usual $\operatorname{adotar} d\left(A_{1}, A_{2}\right)=2 a$;

A partir dessas duas medidas encontramos uma terceira por meio da relação $c^{2}=a^{2}+b^{2}$. Chamamos distância auxiliar à medida $\mathrm{b}$, que nos permite determinar o segmento $\overline{B_{1} B_{2}}$ perpendicular a $\overline{F_{1} F_{2}}$ e tendo $O$ como ponto médio, de maneira que $d\left(B_{1}, B_{2}\right)=2 b$. 


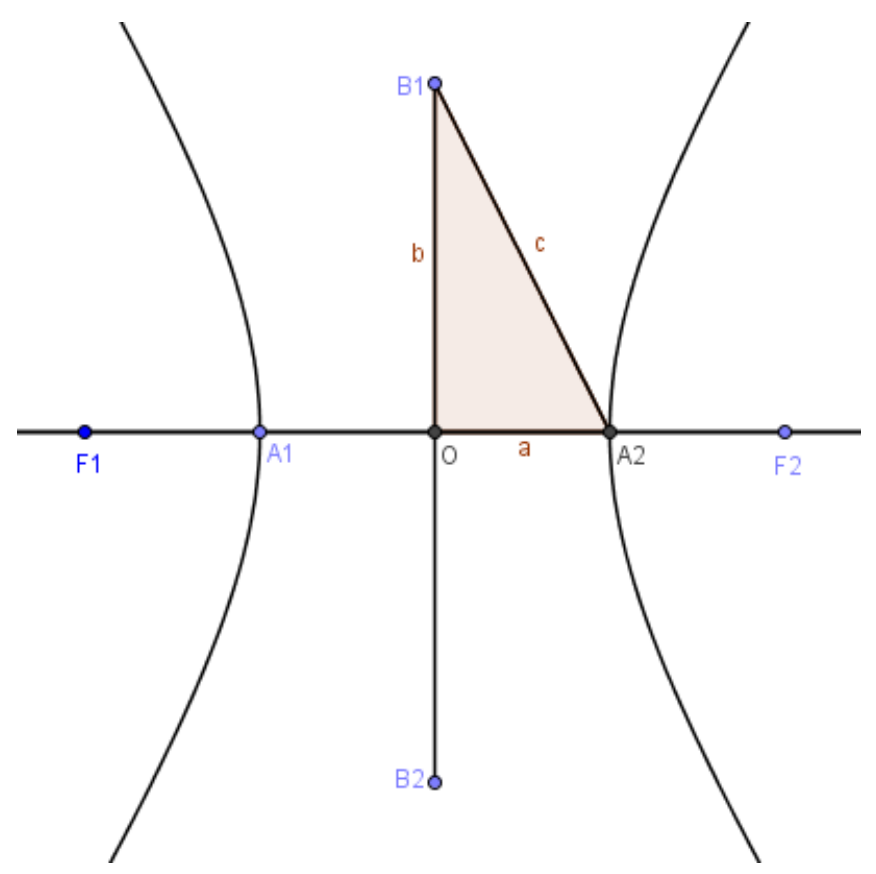

Figura 4.2: Características da Hipérbole.

\subsection{Equação reduzida da Hipérbole na Geometria Ana- lítica}

Na geometria analítica, para simplificar a obtenção de uma equação que represente uma hipérbole, é usual tomar um sistema cartesiano ortogonal de modo que $\overline{A_{1} A_{2}}$ esteja contido no eixo das abscissas e $\overline{B_{1} B_{2}}$ esteja contido no eixo das ordenadas. Nesse sistema, os focos serão os pontos $F_{1}(-c, 0)$ e $F_{2}(c, 0)$ e a chamada equação reduzida da hipérbole pode ser obtida tomando-se qualquer ponto $P(x, y) \in \alpha$ a partir da seguinte relação: $P \in$ hipérbole $\Leftrightarrow$ $\left|P F_{1}-P F_{2}\right|=2 a$.

Vamos provar que $\left|P F_{1}-P F_{2}\right|=2 a \Leftrightarrow P \in$ hipérbole:

$$
\begin{gathered}
\sqrt{(x+c)^{2}+(y-0)^{2}}-\sqrt{(x-c)^{2}+(y-0)^{2}}= \pm 2 a \Leftrightarrow \\
\sqrt{(x+c)^{2}+y^{2}}-\sqrt{(x-c)^{2}+y^{2}}= \pm 2 a \Leftrightarrow \\
(x+c)^{2}+y^{2}=(x-c)^{2}+y^{2} \pm 4 a \sqrt{(x-c)^{2}+y^{2}}+4 a^{2} \Leftrightarrow 1 \\
4 c x-4 a^{2}= \pm 4 a \sqrt{(x-c)^{2}+y^{2}} \Leftrightarrow \\
c x-a^{2}= \pm a \sqrt{(x-c)^{2}+y^{2}} \Leftrightarrow \\
c^{2} x^{2}-2 a^{2} c x+a^{4}=a^{2} x^{2}-2 a^{2} c x+a^{2} c^{2}+a^{2} y^{2} \Leftrightarrow
\end{gathered}
$$

\footnotetext{
${ }^{1}$ Note que a volta nessa etapa, só é possível porque $x \leq-a<0,-c<-a<0$, que resulta $x-c<-2 a<0$ e portanto $(x-c)^{2}>4 a^{2}$ e por maior razão $(x-c)^{2}+y^{2}>4 a^{2}$ por fim resultando $\sqrt{(x-c)^{2}+y^{2}}-2 a>0$
} 


$$
\begin{gathered}
c^{2} x^{2}+a^{4}=a^{2} x^{2}+a^{2} c^{2}+a^{2} y^{2} \Leftrightarrow \\
\left(c^{2}-a^{2}\right) x^{2}-a^{2} y^{2}=a^{2}\left(c^{2}-a^{2}\right)
\end{gathered}
$$

Como $c$ é o valor do centro ao foco e $a$ é a menor distância do centro a um dos ramos, podemos afirmar, que sempre teremos $c \neq a$. Assim, $b^{2} x^{2}-a^{2} y^{2}=a^{2} b^{2}$ de onde por fim obtemos

$$
\frac{x^{2}}{a^{2}}-\frac{y^{2}}{b^{2}}=1
$$

\subsection{Hipérbole $x y=1$}

Veremos nessa dissertação que podemos definir o valor dos logaritmos utilizando áreas abaixo do gráfico da hipérbole de equação $x y=1$, sendo frequente inclusive encontrar essa definição em livros de cálculo integral:

[...] a importância dos logaritmos no desenvolvimento histórico do cálculo resulta de uma descoberta publicada em 1647 pelo Jesuita Belga Gregory St. Vincent, que acarreta uma conexão surpreendente entre a função de logaritmo natural e da hipérbole retangular $x y=1$ (Edwards, 1979, p. 154, tradução nossa) $)^{2}$.

Essa abordagem possibilita um tratamento rigoroso para o logaritmo baseado no conceito de área que é mais elementar ou intuitivo, do que o de função exponencial (Druck, 1995, p. 18).

Porém, longe de ser intuitivo, é o fato da curva de equação $x y=1$ ser realmente uma hipérbole uma vez que tal equação não lembra em nada a equação reduzida da hipérbole, deduzida anteriormente. Nesse ponto é interessante observar que, no Ensino Médio, é frequente serem apresentadas as equações das cônicas em Geometria Analítica. Porém nem sempre é garantida a identificação como tais curvas, dos gráficos de funções trabalhadas em anos anteriores, como $y=x^{2}$ (parábola) e $y=\frac{1}{x}$ (hipérbole). Ou seja, não é usual que os alunos sejam levados a comprovar que tais gráficos satisfazem as definições das respectivas cônicas como lugares geométricos. O que faremos a seguir pode ser transposto para uma situação de sala de aula do $3^{\circ}$ ano do Ensino Médio, com as adaptações necessárias a cada turma específica. Acreditamos que esse tipo de atividade pode ajudar muito os estudantes na atribuição de significados às noções que o estudo das hipérboles abrange. Vamos então provar que o gráfico da equação é realmente de uma hipérbole. Para tanto, utilizemos o seguinte argumento baseado na definição da hipérbole como lugar geométrico de pontos em um plano, já retomada.

Vamos primeiro encontrar os pontos $F_{1}$ e $F_{2}$ (focos) e algum $a>0$ de tal forma que um ponto $P(x, y)$ pertencerá ao gráfico de $y=\frac{1}{x}$ se, e somente se, $\left|P F_{1}-P F_{2}\right|=2 a$

Note que a constante $2 a$ é a distância entre os vértices da hipérbole. Devido ao fato do gráfico $y=\frac{1}{x}$ ter intersecção não vazia com a reta de equação $y=x$ e desta ser um eixo

\footnotetext{
${ }^{2}[. .$.$] the importance of logarithms in the historical development of the calculus stems from a discovery$ published in 1647 by the Belgian Jesuit Gregory St. Vincent, that implies a surprising connection between the natural logarithm function and the rectangular hyperbola $x y=1$.

Observação: Hipérboles são ditas retangulares se suas assíntotas são retas perpendiculares.
} 


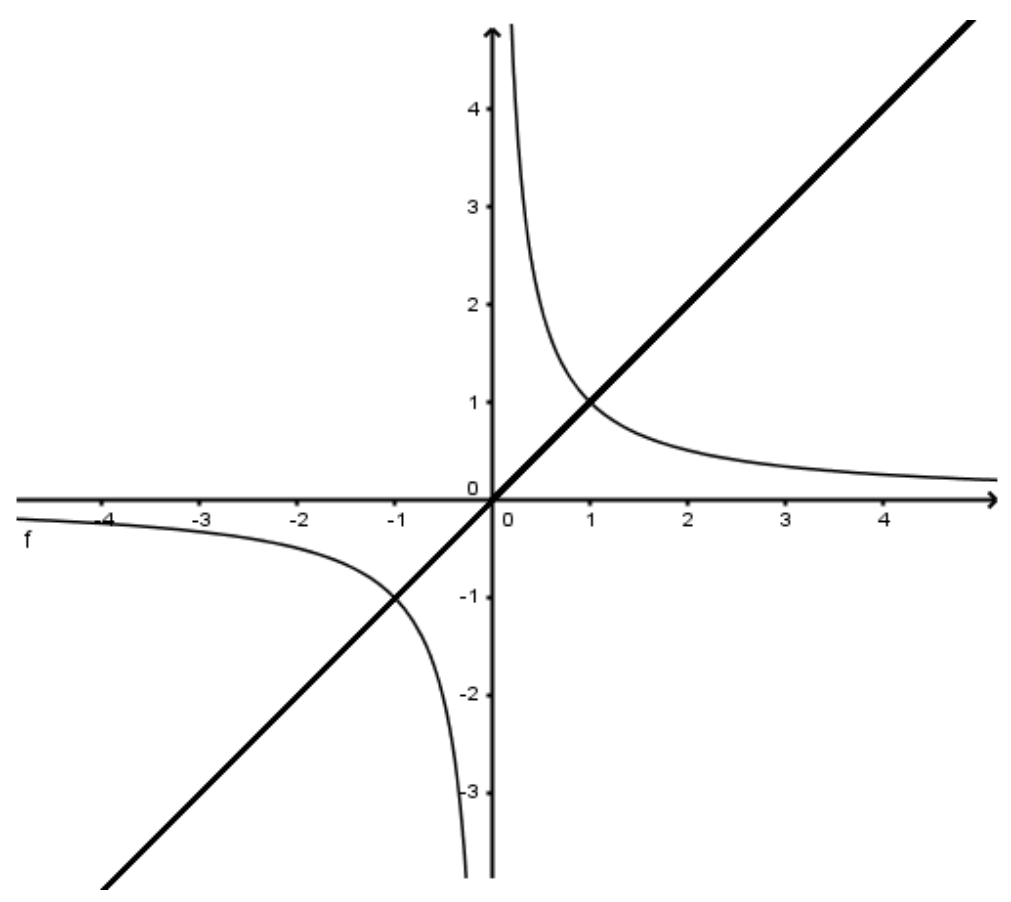

Figura 4.3: Gráfico da curva $x y=1$.

de simetria do mesmo, os candidatos a vértice do gráfico da função que estamos analisando, são os pontos da reta de equação $y=x$, que coincidam com o gráfico de $y=\frac{1}{x}$.

Igualando as duas equações obtemos que $x=\frac{1}{x}$ de onde podemos concluir facilmente ser $x= \pm 1$. Desse modo, os possíveis candidatos a vértice, são os pontos $A_{1}=(-1,-1)$ e $A_{2}=(1,1)$. Podemos então concluir sem dificuldades que tal fato acarreta:

$$
a=\sqrt{2} \quad \text { ou } \quad 2 a=2 \sqrt{2} .
$$

Sabemos que os focos pertencem à reta que contém os vértices. E também que são igualmente espaçados deles, ou seja, são simétricos em relação ao ponto médio da reta à qual pertencem. Logo, partindo das hipóteses assumidas sobre os possíveis vértices, necessariamente os focos serão $F_{1}=(-f,-f)$ e $F_{1}=(f, f)$ para algum $f$ real positivo.

Para descobrir o valor de $f$, tomemos um ponto $P(x, y)$ em $y=\frac{1}{x}$, distinto de $A_{1}$ e $A_{2}$, com $x>0$. Substituindo em $\left|P F_{1}-P F_{2}\right|=2 \sqrt{2}$ obtemos (note que sendo $x>0, P F_{1}>P F_{2}$ ):

$$
\begin{gathered}
\sqrt{(x+f)^{2}+(y+f)^{2}}-\sqrt{(x-f)^{2}+(y-f)^{2}}=2 \sqrt{2} \\
\sqrt{(x+f)^{2}+(y+f)^{2}}=2 \sqrt{2}+\sqrt{(x-f)^{2}+(y-f)^{2}} \\
(x+f)^{2}+(y+f)^{2}=8+(x-f)^{2}+(y-f)^{2}+4 \sqrt{2} \sqrt{(x-f)^{2}+(y-f)^{2}} \\
4(x f+y f)+x^{2}+f^{2}+y^{2}+f^{2}=8+x^{2}+f^{2}+y^{2}+f^{2}+4 \sqrt{2} \sqrt{(x-f)^{2}+(y-f)^{2}} \\
4(x f+y f)=8+4 \sqrt{2} \sqrt{(x-f)^{2}+(y-f)^{2}}
\end{gathered}
$$




$$
\begin{gathered}
(x+y) f-2=\sqrt{2} \sqrt{(x-f)^{2}+(y-f)^{2}} \\
x^{2} f^{2}+2 x y f^{2}+y^{2} f^{2}-4 x f-4 y f+4=2\left[(x-f)^{2}+(y-f)^{2}\right] \\
x^{2} f^{2}+2 x y f^{2}+y^{2} f^{2}-4 x f-4 y f+4=2\left[x^{2}-2 x f+f^{2}+y^{2}-2 y f+f^{2}\right] \\
x^{2} f^{2}+2 x y f^{2}+y^{2} f^{2}+4=2 x^{2}+4 f^{2}+2 y^{2} \\
x^{2} f^{2}+2 x y f^{2}+y^{2} f^{2}-4 f^{2}=2 x^{2}+2 y^{2}-4 \\
f^{2}\left(x^{2}+2 x y+y^{2}-4\right)=2\left(x^{2}+y^{2}-2\right)
\end{gathered}
$$

E como $y=\frac{1}{x}$ substituindo na equação obtida temos:

$$
f^{2}\left(x^{2}+\frac{2 x}{x}+\frac{1}{x^{2}}-4\right)=2\left(x^{2}+\frac{1}{x^{2}}-2\right)
$$

Perceba que $x \neq \pm 1$, logo temos: $f=\sqrt{2}$.

Chegamos, portanto, à coordenada do foco $F_{2}=(\sqrt{2}, \sqrt{2})$. Como os focos são simétricos em relação ao eixo central, concluímos que $F_{1}=(-\sqrt{2},-\sqrt{2})$.

Podemos ainda determinar a distância $2 c$ entre os focos desta hipérbole. Observando que $(0,0)$ é o ponto médio entre $F_{1}$ e $F_{2}$, obtemos que:

$$
\begin{gathered}
c=\sqrt{(\sqrt{2})^{2}+(\sqrt{2})^{2}} \\
c=\sqrt{2+2}=\sqrt{4}
\end{gathered}
$$

ou seja, $c=2$.

Mostremos agora que todos os pontos do gráfico da função $y=\frac{1}{x}$ são também pontos da hipérbole de focos $F_{1}=(-\sqrt{2},-\sqrt{2})$ e $F_{2}=(\sqrt{2}, \sqrt{2})$ com vértices $A_{1}=(-1,-1)$ e $A_{2}=(1,1)$. Mostremos finalmente que, de modo recíproco, todos os pontos desta hipérbole são também pontos do gráfico $y=\frac{1}{x}$.

Seja $P(x, y)$ tal que $\left|P F_{1}-P F_{2}\right|=2 \sqrt{2}$, temos então:

$$
\begin{gathered}
\left|P F_{1}-P F_{2}\right|^{2}=8 \\
\left|\sqrt{(x+\sqrt{2})^{2}+(y+\sqrt{2})^{2}}-\sqrt{(x-\sqrt{2})^{2}+(y-\sqrt{2})^{2}}\right|^{2}=8 \\
(x+\sqrt{2})^{2}+(y+\sqrt{2})^{2}+(x-\sqrt{2})^{2}+(y-\sqrt{2})^{2}-2 \sqrt{(x+\sqrt{2})^{2}+(y+\sqrt{2})^{2}} \sqrt{(x-\sqrt{2})^{2}+(y-\sqrt{2})^{2}}=8
\end{gathered}
$$




$$
\begin{gathered}
2 x^{2}+2 y^{2}+8-2 \sqrt{x^{4}+y^{4}+2 x^{2} y^{2}-16 x y+16}=8 \\
2 x^{2}+2 y^{2}=2 \sqrt{x^{4}+y^{4}+2 x^{2} y^{2}-16 x y+16} \\
4 x^{4}+8 x^{2} y^{2}+4 y^{4}=4\left(x^{4}+y^{4}+2 x^{2} y^{2}-16 x y+16\right) \\
4 x^{4}+8 x^{2} y^{2}+4 y^{4}=4 x^{4}+4 y^{4}+8 x^{2} y^{2}-64 x y+64
\end{gathered}
$$

$64 x y=64 \Rightarrow x y=1$, ou seja, $(x, y)$ pertence ao gráfico $y=\frac{1}{x}$.

Sendo assim, comprovamos o que foi afirmado inicialmente, a saber, a existência de pontos $F_{1}$ e $F_{2}$ (focos) e de um $a>0$ de tal forma que um ponto $P(x, y)$ pertencerá ao gráfico de $y=\frac{1}{x}$ se, e somente se, $\left|P F_{1}-P F_{2}\right|=2 a$.

A partir de agora, vamos trabalhar com determinados valores de áreas relacionadas a essa curva. Encontrar a área de uma figura plana e fechada é conhecido como problema de quadratura. Como o próprio nome sugere, ele busca expressar a área por meio de unidades de área (que são quadrados). Os gregos buscavam maneiras de transformar a figura em questão em uma que fosse equivalente, mas cuja área pudesse ser calculada a partir de princípios fundamentais. Como exemplo, podemos pensar em um retângulo cuja medida da base é $b$ e sua altura $a$. Facilmente concluímos que sua área será $a b$. Por outro lado, utilizando régua e compasso, podemos construir um quadrado cuja medida do lado seja $\sqrt{a b}$. Sendo sempre possível encontrar a quadratura de um retângulo, podemos encontrar também a de qualquer paralelogramo ou triângulo, já que são facilmente obtidos de retângulos por simples construções. Conseguimos ainda obter a quadratura (ou área) de qualquer polígono, já que todo polígono pode ser subdividido em triângulos. Com o passar do tempo, esse problema abandonou seu caráter geométrico e passou a ter uma abordagem mais computacional, inclusive:

A construção real de uma forma equivalente não era mais considerada necessária, desde que pudéssemos demonstrar que tal construção poderia ser feita em princípio (Crease, 2011, p. 85).

Entre todas as formas que foram estudadas com o passar dos anos, uma que se mantinha inflexível quanto a sua quadratura era a hipérbole. Apesar de todos os esforços gastos desde a época dos gregos, os avanços significativos apareceram apenas no século XVII, com o aparecimento do método dos indivisíveis. Muitas "dessas" crises deram-se pelo fato dessa curva, [...] ao contrário do círculo e da elipse, é uma curva que vai ao infinito, assim é preciso esclarecer o que queremos dizer por quadratura neste caso (Crease, 2011, p. 86), como veremos a seguir.

\subsection{Faixa da Hipérbole $x y=1$}

Seja $H$ a curva do primeiro quadrante do plano cartesiano constituído pelo gráfico de equação $x y=1$, ou seja, todos os pontos do plano cujas coordenadas sejam do tipo $\left(x, \frac{1}{x}\right)$ para $x$ tal que $x>0$. Em notação de conjuntos temos:

$$
H=\left\{(x, y) \mid x>0 \quad \text { e } \quad y=\frac{1}{x}\right\}
$$




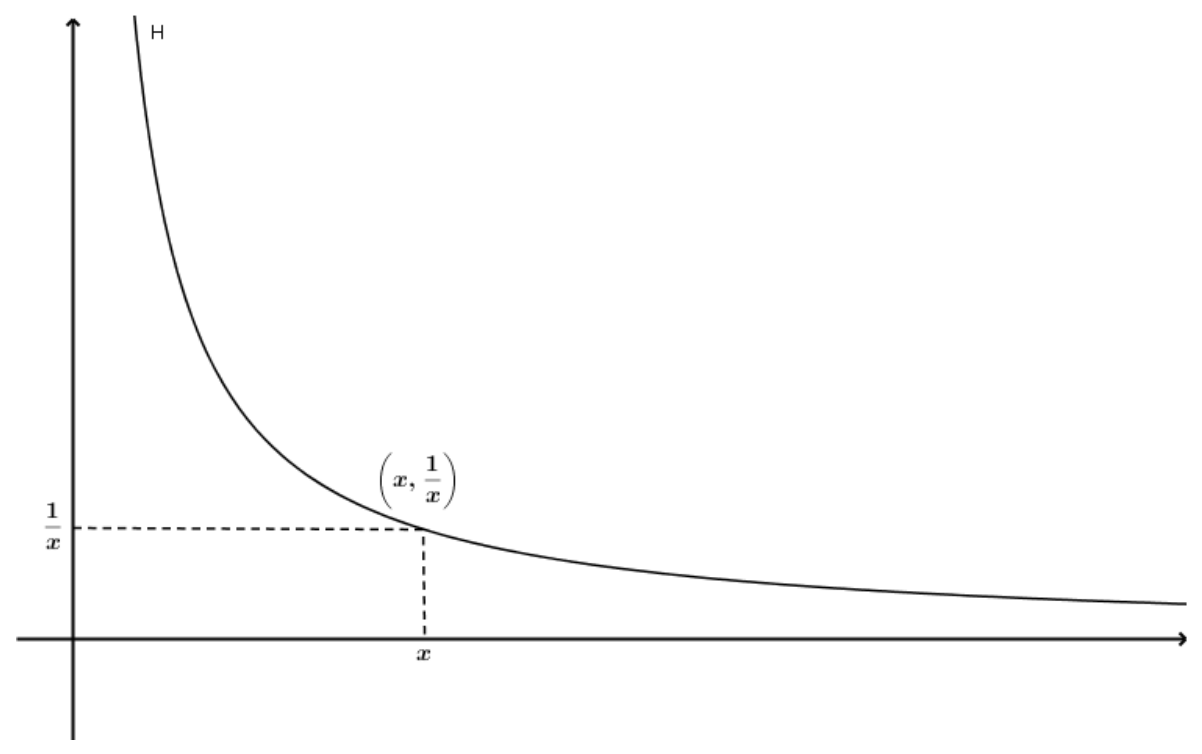

Figura 4.4: Ramo positivo da curva $x y=1$.

Sejam $a, b$ números reais positivos com $a>b$, teremos por faixa de hipérbole a região delimitada pelas retas $x=a, x=b, y=0$ e $H$. Ela será chamada faixa de hipérbole no intervalo $[a, b]$ e indicaremos essa região pelo símbolo $H_{a}^{b}$.

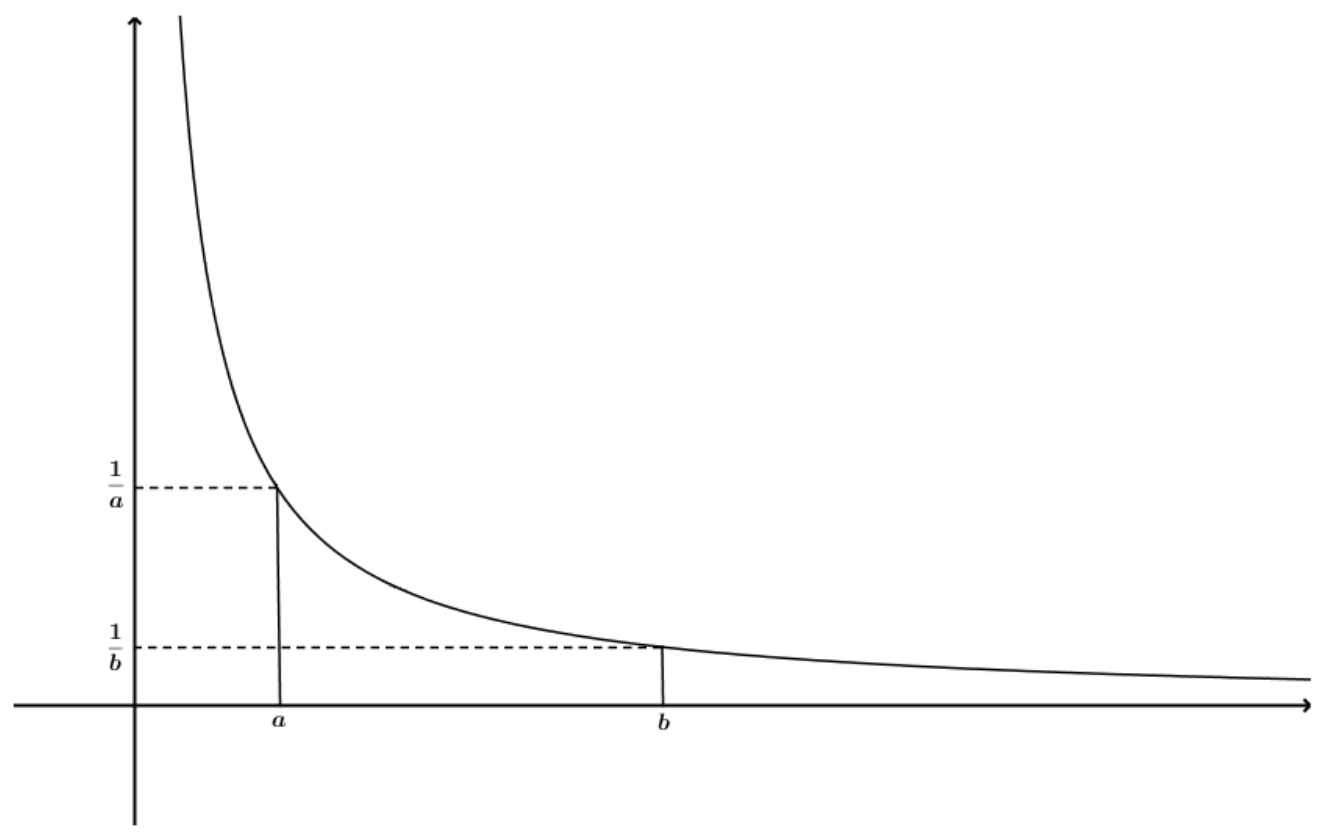

Figura 4.5: Faixa de Hipérbole.

Essa região, formada pelos pontos $(x, y)$ de modo a cumprir as condições $a \leq x \leq b$ e $0 \leq y \leq \frac{1}{x}$ em notação de conjuntos pode ser definida por:

$$
H_{a}^{b}=\left\{(x, y) \mid a \leq x \leq b, 0 \leq y \leq \frac{1}{x}\right\}
$$


Vamos agora conhecer uma forma de calcular a área de uma determinada faixa $H_{a}^{b}$. Na verdade, nosso primeiro passo será conseguir estimar um valor que seja próximo ao real valor. Para tal, usaremos um método que consiste em dividir o intervalo $[a, b]$ utilizando para isso um conjunto finito de $n+1$ pontos $P \subset[a, b]$, da forma:

$$
P=\left\{a=t_{0}, t_{1}, t_{2}, \ldots, t_{n}=b\right\}
$$

e de tal modo que

$$
a=t_{0}<t_{1}<t_{2}<\ldots<t_{n-1}<t_{n}=b .
$$

A partir desses pontos, decompomos o intervalo inicial em um número finito de subintervalos adjacentes $\left[t_{i-1}, t_{i}\right]$, que por sua vez nos permitem considerar $n$ retângulos $R_{i}$ de base $\left[t_{i-1}, t_{i}\right]$ e altura de valor $\frac{1}{t_{i}}$ ou $\left(\frac{1}{t_{i-1}}\right)$. É importante notar, nesse momento, que cada um dos retângulos citados encontrará o gráfico de nossa hipérbole no ponto $\left(t_{i}, \frac{1}{t_{i}}\right)$ ou $\left(t_{i-1}, \frac{1}{t_{i-1}}\right)$. Eles serão chamados de retângulos inscritos da região $H_{a}^{b}$ ou sobrescritos no segundo caso. Ao calcular a soma das áreas de todos os retângulos $R_{i}$ em $H_{a}^{b}$ obteremos aproximações do valor exato da área da faixa $H_{a}^{b}$, por falta, no caso da soma de retângulos inscritos e por excesso no caso da soma de retângulos sobrescritos.

De modo a fixar melhor as ideias apresentadas acima, vamos ver dois exemplos utilizando para isso a região $H_{1}^{4}$.

Primeiro vamos calcular a área de $H_{1}^{4}$ utilizando para tal o intervalo $[1,4]$ decomposto em 3 subintervalos disjuntos consecutivos (por questão de praticidade, utilizaremos pontos igualmente espaçados).

Como o intervalo foi decomposto desse modo, obtivemos 3 segmentos de medida 1, do qual é possível formar três retângulos cuja soma de suas áreas será:

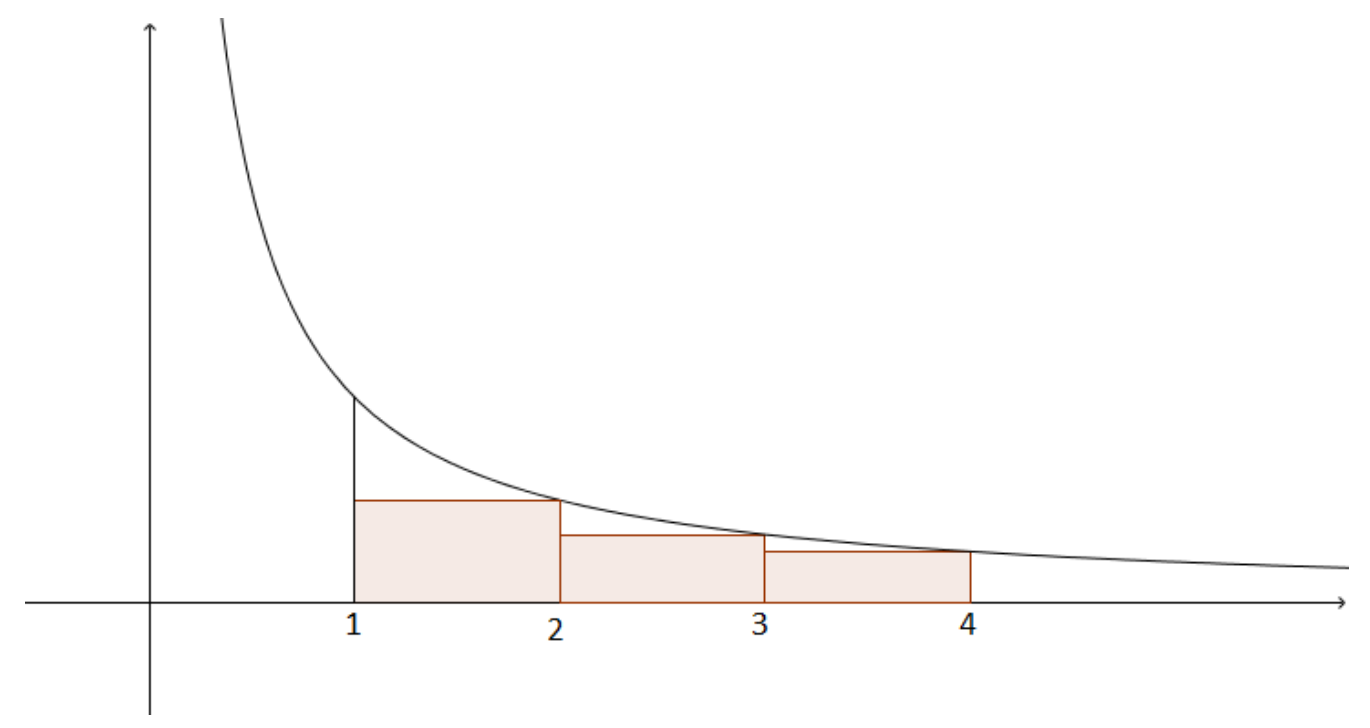

Figura 4.6: Aproximação por falta com três retângulos de $H_{1}^{4}$.

Nesse caso, estamos estimando uma área por falta, desse modo, os retângulos ficam todos abaixo da curva, do qual: $\left(1 \cdot \frac{1}{2}\right)+\left(1 \cdot \frac{1}{3}\right)+\left(1 \cdot \frac{1}{4}\right)=\frac{1}{2}+\frac{1}{3}+\frac{1}{4}=\frac{13}{12} \cong 1,083$. 


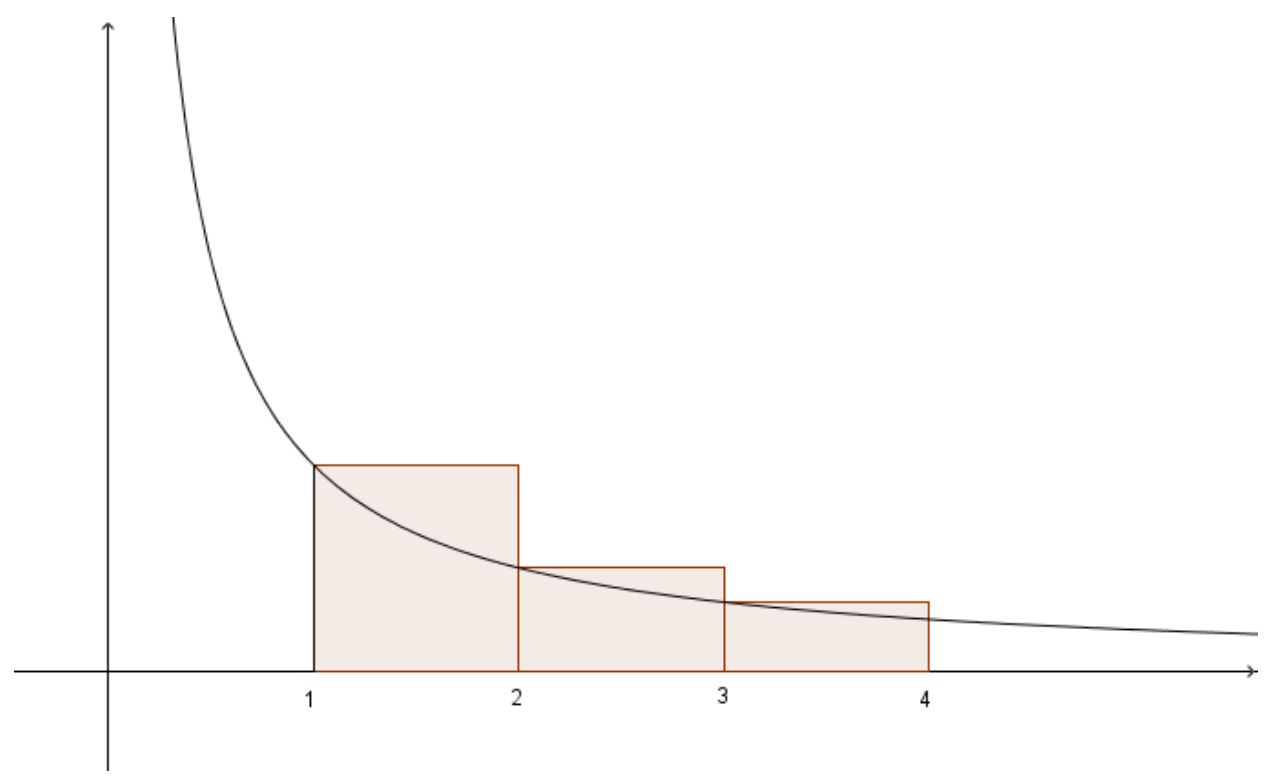

Figura 4.7: Aproximação por excesso com três retângulos de $H_{1}^{4}$.

Aqui, a área estimada será por excesso, portanto, os retângulos ultrapassam a curva, do qual resulta: $(1 \cdot 1)+\left(1 \cdot \frac{1}{2}\right)+\left(1 \cdot \frac{1}{3}\right)=1+\frac{1}{2}+\frac{1}{3}=\frac{11}{6} \cong 1,833$.

Podemos repetir o mesmo processo acima na área de $H_{1}^{4}$, utilizando uma subdivisão mais fina, tomando o mesmo intervalo [1,4], porém agora, decompondo em 6 subintervalos disjuntos consecutivos e igualmente espaçados. Portanto o intervalo fica dividido em 6 segmentos de medida $\frac{1}{2}$, do qual é possível formar seis retângulos cuja soma de suas áreas se da por:

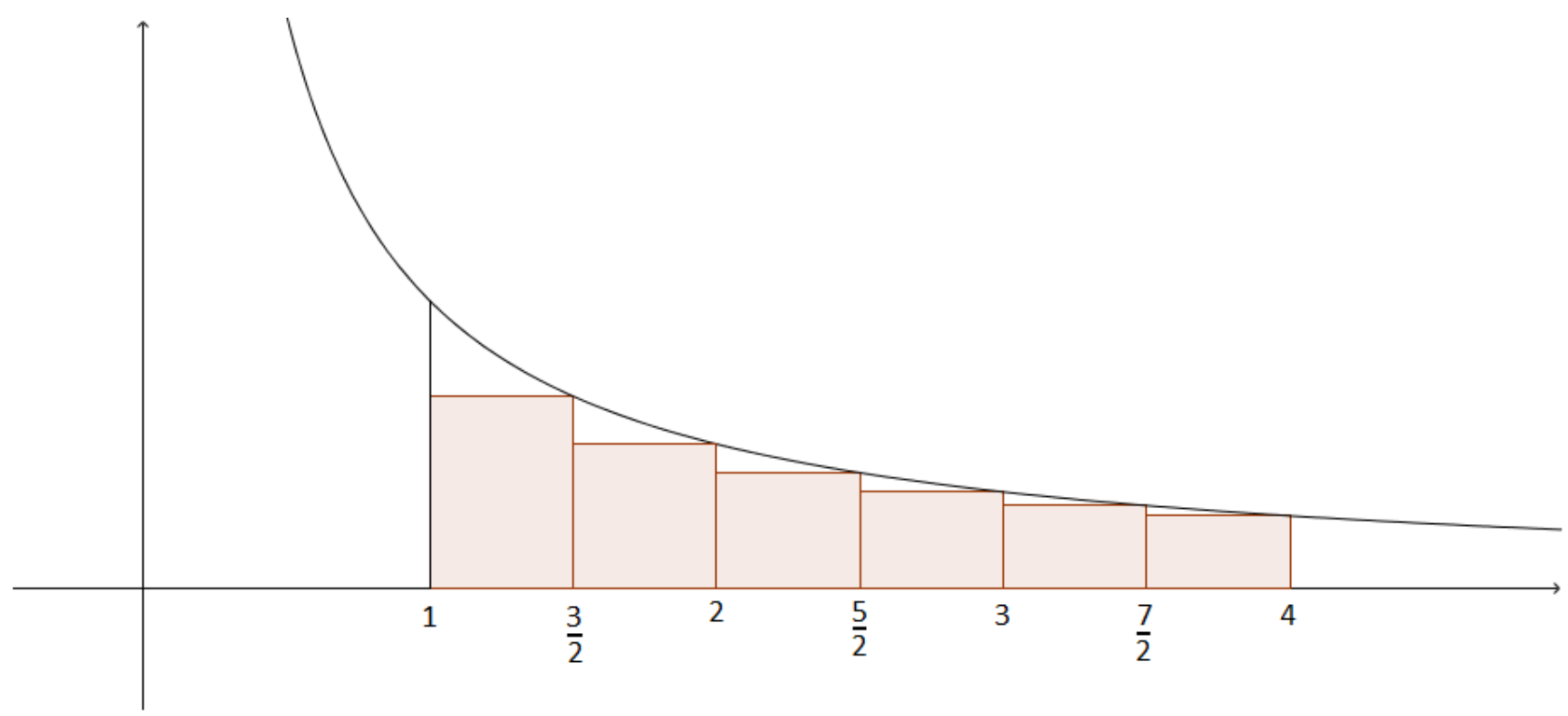

Figura 4.8: Aproximação por falta com seis retângulos de $H_{1}^{4}$.

$$
\left(\frac{1}{2} \cdot \frac{2}{3}\right)+\left(\frac{1}{2} \cdot \frac{1}{2}\right)+\left(\frac{1}{2} \cdot \frac{2}{5}\right)+\left(\frac{1}{2} \cdot \frac{1}{3}\right)+\left(\frac{1}{2} \cdot \frac{2}{7}\right)+\left(\frac{1}{2} \cdot \frac{1}{4}\right)=\frac{1}{3}+\frac{1}{4}+\frac{1}{5}+\frac{1}{6}+\frac{1}{7}+\frac{1}{8}=\frac{341}{280} \cong 1,2179 .
$$




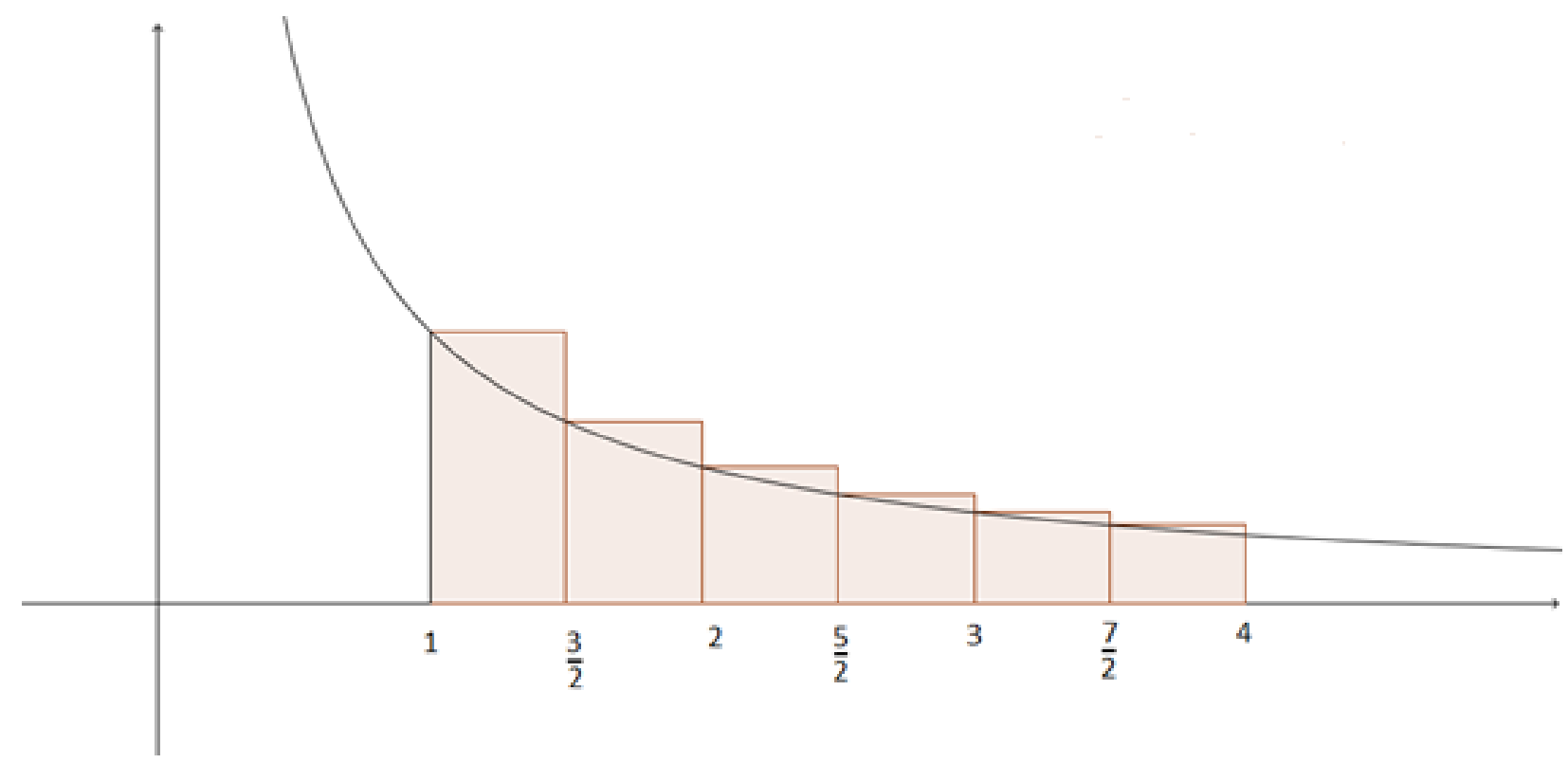

Figura 4.9: Aproximação por excesso com seis retângulos de $H_{1}^{4}$.

$\left(\frac{1}{2} \cdot 1\right)+\left(\frac{1}{2} \cdot \frac{2}{3}\right)+\left(\frac{1}{2} \cdot \frac{1}{2}\right)+\left(\frac{1}{2} \cdot \frac{2}{5}\right)+\left(\frac{1}{2} \cdot \frac{1}{3}\right)+\left(\frac{1}{2} \cdot \frac{2}{7}\right)=\frac{1}{2}+\frac{1}{3}+\frac{1}{4}+\frac{1}{5}+\frac{1}{6}+\frac{1}{7}=\frac{446}{280} \cong 1,593$

Procedendo dessa forma é possível notar que as escadas formadas pela união dos retângulos obtidos nos exemplos anteriores são polígonos escalonados inscritos e sobrescritos em $H_{a}^{b}$ que fornecerão aproximações (por falta ou excesso) da real área da faixa. Esse valor será mais próximo do valor exato quanto mais fina for a subdivisão, ou seja, quantos mais pontos utilizarmos na decomposição de $[a, b]$, isto é, quanto mais a distância entre quaisquer dois pontos consecutivos se aproximem de zero. Sendo assim, podemos obter polígonos escalonados (formados por retângulos adjacentes) cujas áreas sejam tão próximas quanto se queira da área de $H_{a}^{b}$, bastando para tal, refinarmos suficientemente a subdivisão de $[a, b]$.

É razoável nesse ponto aceitar, para casos práticos (que não necessitam do valor exato), que o processo acima é suficiente para calcular a área de uma faixa, com o grau de aproximação desejado. Ou seja, para qualquer $\alpha \in \mathbb{R}$ onde $\alpha<$ Área $\left(H_{a}^{b}\right)$ podemos encontrar um polígono escalonado inscrito em $H_{a}^{b}$, de área $E=\sum_{i=1}^{n}$ Área $\left(R_{i}\right)$ de tal modo que podemos aceitar que se tenha $\alpha<E<$ Área $\left(H_{a}^{b}\right)$. Entretanto devemos ter em mente que para fins teóricos, ao utilizarmos um número finito de subdivisões em $[a, b]$ teremos sempre Área $\left(H_{a}^{b}\right)>E$.

Observando nossos dois exemplos para $H_{1}^{4}$ obtivemos primeiro $\frac{13}{12}$ como aproximação por falta para a área e posteriormente ao refinar a subdivisão do intervalo $\frac{341}{280}$. Do mesmo modo, observando as aproximações por excesso, $\frac{11}{6}$ e posteriormente $\frac{446}{280}$. Como já era esperado, obtivemos aproximações melhores nas subdivisões mais finas. A pergunta que surge é: como encontrar o valor exato da área de uma determinada faixa de hipérbole? Uma vez que todos os polígonos escalonados calculáveis de área E serão formados por um número finito de retângulos a partir da subdivisão de $[a, b]$, podemos definir a área de $H_{a}^{b}$ como sendo o extremo superior (supremo) do conjunto de todas as áreas dos polígonos escalonados inscritíveis em $H_{a}^{b}$ e o extremo inferior (ínfimo) do conjunto de todas as áreas dos polígonos 
escalonados circunscritíveis em $H_{a}^{b}$. Em outras palavras a área de $H_{a}^{b}$ será o valor real tal que $E_{c} \geq$ Área $\left(H_{a}^{b}\right) \geq E_{i}$ para todo polígono $E_{i}$ escalonado inscritível em $H_{a}^{b}$ e para todo polígono $E_{c}$ escalonado circunscritíveis em $H_{a}^{b}$. 


\section{Capítulo 5}

\section{Principais propriedades dos logaritmos, bases e definições}

\subsection{Faixas da hipérbole $x y=1$ : propriedade fundamental}

Vamos agora conhecer e provar um fato que será de extrema importância para o desenvolvimento dos nossos estudos, a chamada propriedade fundamental que relaciona diferentes faixas de hipérbole e o valor de suas áreas, através do seguinte teorema:

Teorema 5.1.1. Dado qualquer número $k \in \mathbb{R}$ tal que $k>0$, as áreas das faixas $H_{a}^{b}$ e $H_{k a}^{k b}$ são iguais.

Demonstração. Primeiro vamos observar e provar um fato nada óbvio: Se tomarmos um retângulo $R_{1}$ inscrito em $H$ com base igual a $[c, d]$ e um segundo retângulo $R_{2}$ também inscrito em $H$ de base $[k c, k d]$, as áreas de $R_{1}$ e $R_{2}$ serão iguais:

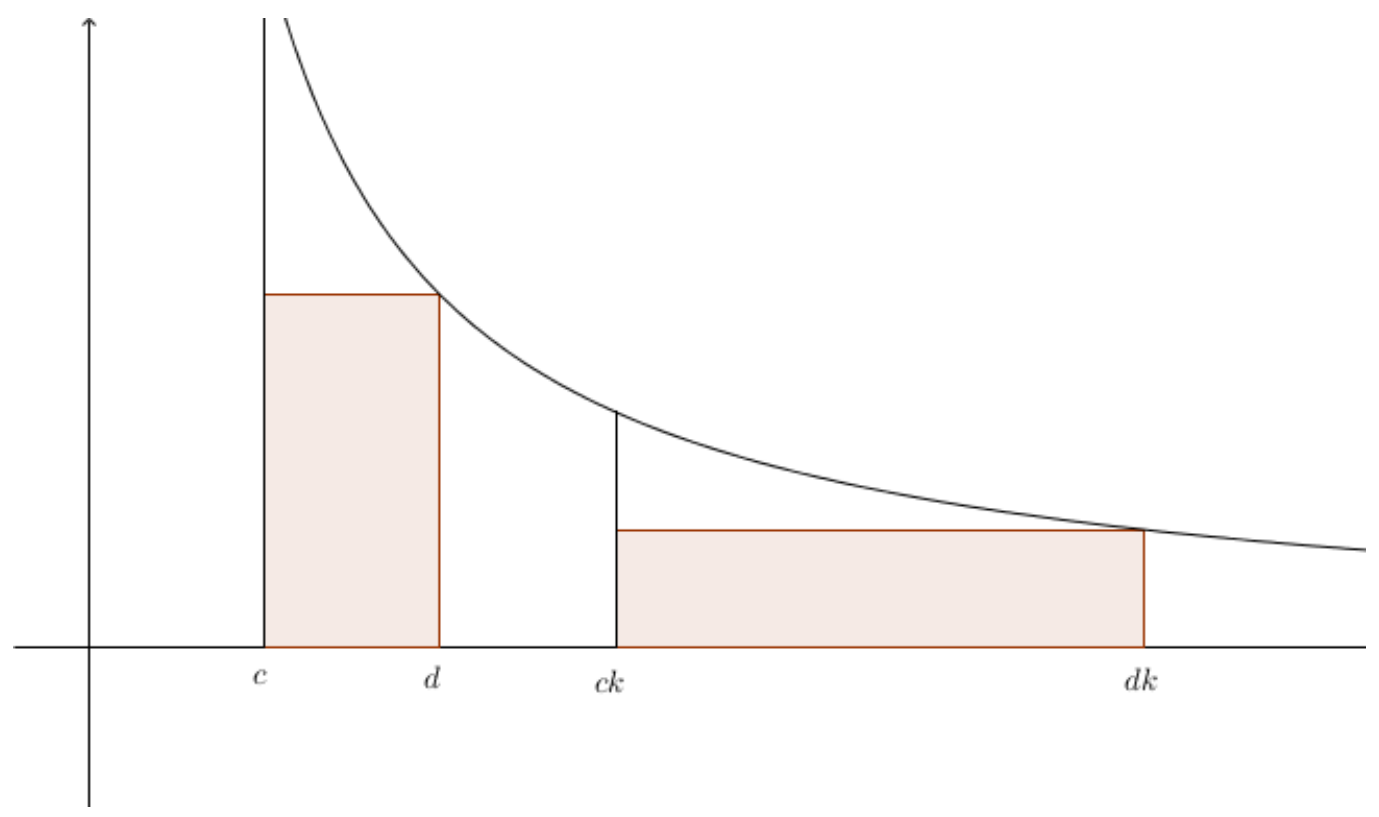

Figura 5.1: Propriedade Fundamental. 
Na figura, temos que a área do primeiro retângulo será dada por

$$
(d-c) \cdot \frac{1}{d}=1-\frac{c}{d}
$$

enquanto a área do segundo será:

$$
(k d-k c) \cdot \frac{1}{k d}=k \cdot(d-c) \cdot \frac{1}{k d}=(d-c) \cdot \frac{k}{k d}=(d-c) \cdot \frac{1}{d}=1-\frac{c}{d}
$$

ou seja, elas são iguais.

Tomemos então um polígono escalonado $E=\bigcup_{i=1}^{n} R_{i}$ de área $\sum_{i=1}^{n}$ Área $\left(R_{i}\right)$ inscrito em $H_{a}^{b}$, vamos multiplicar cada um dos pontos da subdivisão de $[a, b]$ pela constante $k$, obteremos uma nova sequência de pontos, mas que agora farão parte do intervalo $[k a, k b]$ e por consequência do novo polígono $E^{\prime}=\sum_{i=1}^{n}$ Área $\left(R_{i}^{\prime}\right)$ inscrito em $H_{k a}^{k b}$. Nesse caso, cada um dos retângulos $R_{i}$ terá a mesma área que os correspondentes retângulos $R_{i}^{\prime}$ para $i=1,2, \ldots, n$, dessa forma, podemos afirmar que as áreas de $E$ e $E^{\prime}$ serão iguais.

A título de exemplo, vamos tomar o polígono $E=\sum_{i=1}^{3}$ Área $\left(R_{i}\right)$ inscrito em $H_{a}^{b}$ e o polígono $E^{\prime}=\sum_{i=1}^{3}$ Área $\left(R_{i}^{\prime}\right)$ inscrito em $H_{k a}^{k b}$

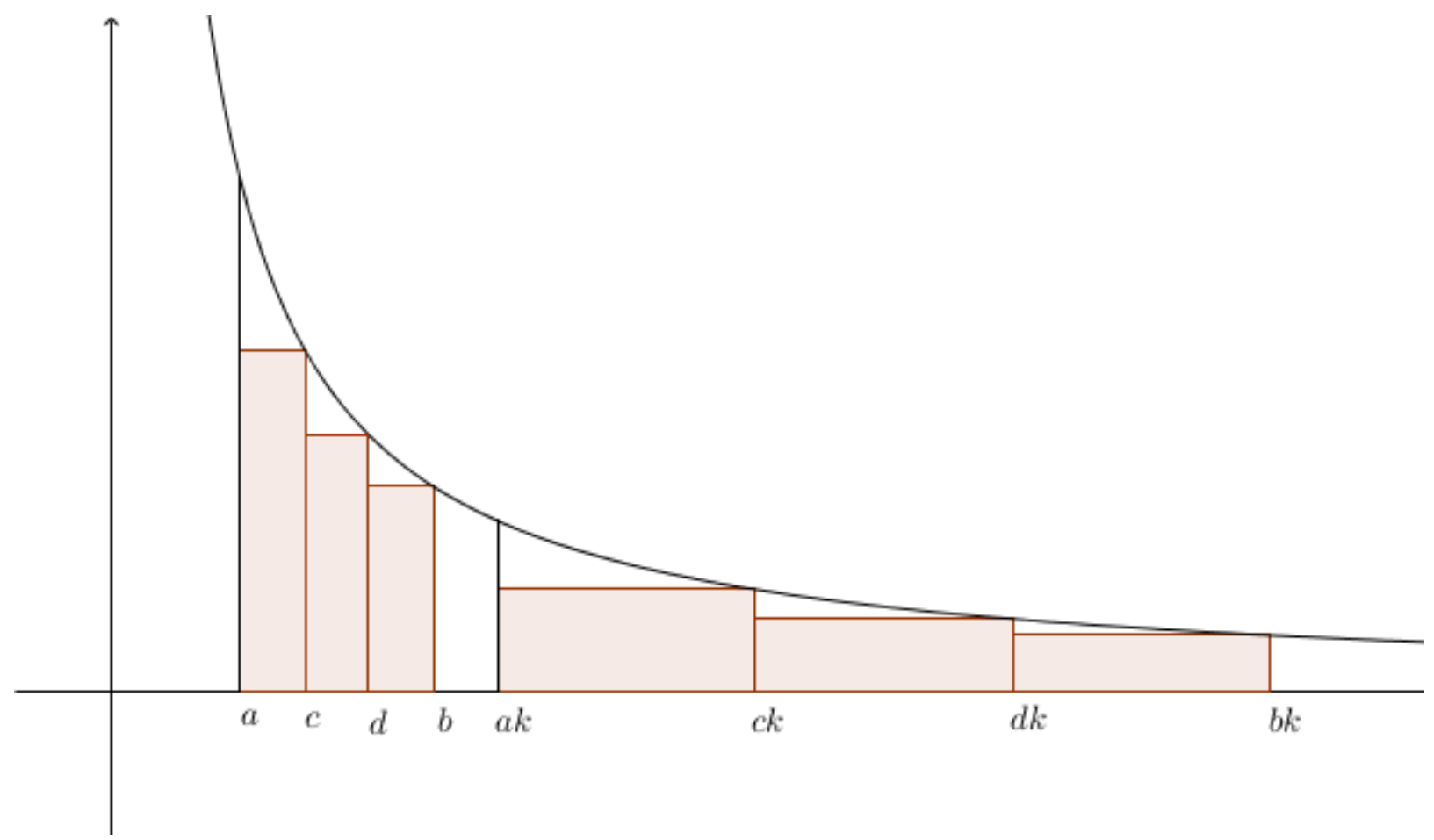

Figura 5.2: Propriedade Fundamental três retângulos. 
Observe que em relação às áreas dos retângulos temos:

$$
\begin{aligned}
& R_{1}=(c-a) \cdot \frac{1}{c}=\left(\frac{c-a}{c}\right) \cdot \frac{k}{k}=(k c-k a) \cdot \frac{1}{k c}=R_{1}^{\prime} \\
& R_{2}=(d-c) \cdot \frac{1}{d}=\left(\frac{d-c}{d}\right) \cdot \frac{k}{k}=(k d-k c) \cdot \frac{1}{k d}=R_{2}^{\prime} \\
& R_{3}=(b-d) \cdot \frac{1}{b}=\left(\frac{b-d}{b}\right) \cdot \frac{k}{k}=(k b-k d) \cdot \frac{1}{k b}=R_{3}^{\prime}
\end{aligned}
$$

Logo

$$
E=\sum_{i=1}^{3} R_{i}=R_{1}+R_{2}+R_{3}=R_{1}^{\prime}+R_{2}^{\prime}+R_{3}^{\prime}=\sum_{i=1}^{3} R_{i}^{\prime}=E^{\prime}
$$

Cabe aqui retomar o que se combinou sobre os cálculos aproximados e observar que para cada polígono escalonado inscrito em $H_{a}^{b}$ corresponde naturalmente um polígono escalonado inscrito em $H_{k a}^{k b}$ com mesma área. Portanto, os supremos de ambos os conjuntos das áreas dos polígonos inscritos em $H_{a}^{b}$ e em $H_{k a}^{k b}$ também serão iguais. Logo se conclui que Área $H_{a}^{b}=$ Área $H_{k a}^{k b}, \forall k>0$.

Uma consequência muito importante desse fato, é que podemos restringir as faixas tomadas para as da forma $H_{1}^{c}$, pois

$$
\text { Área } H_{a}^{b}=\text { Área } H_{1}^{b / a}=\text { Área } H_{1}^{c} \text { para } c=\frac{b}{a} .
$$

Vamos lembrar uma propriedade importante das áreas que diz: se uma figura $E$ se decompõe na união de figuras $P_{i}, \operatorname{com} i=1,2, \ldots, n(n \in \mathbb{N})$ de tal maneira que entre as figuras $E_{i}$ não exista sobreposição de áreas, então a área de $E$ é a soma das áreas $E_{i}(i=1,2, \ldots, n)$. Do qual, inferimos sem dificuldades que para $a, b, c$ reais positivos com $a<b<c$, temos

$$
\text { Área }\left(H_{a}^{c}\right)=\text { Área }\left(H_{a}^{b}\right)+\text { Área }\left(H_{b}^{c}\right) \text {. }
$$

Outro fato elementar a respeito das áreas diz que

$$
\operatorname{Area}\left(H_{a}^{a}\right)=0 \text {. }
$$

Uma vez que é a área do segmento formado por

$$
\left\{(a, y) \mid 0 \leq y \leq \frac{1}{a}\right\}
$$

Na obra Opus geometricum quadratura e circuli et sectionum coni, St. Vincent prova que se ao marcarmos pontos $\left(a_{0}, a_{1}, a_{2}, \ldots, a_{n}, \ldots\right)$ no eixo das abscissas formando uma P.G. então as áreas consecutivas abaixo da hipérbole delimitadas pelas retas $x=a_{i}$ para $i=$ $0,1,2, \ldots, n, \ldots$, possuirão todas a mesma área, ou seja, $A_{0}=A_{1}=A_{2}=\ldots=A_{n}=\ldots$ onde $A_{i}=$ Área $\left(H_{a_{i}}^{a_{i+1}}\right)$. Esse fato tem grande importância por apresentar certa correlação na busca de uma função logarítmica, ou seja, com a propriedade de transformar produtos em somas, uma vez que como decorrência da propriedade fundamental provada, as PGs nas abscissas, correspondem naturalmente a uma sequência de áreas que crescem em PAs 
(Área $\left(H_{a_{0}}^{a_{n}}\right) \operatorname{com} n$ natural).

Aqui temos uma das propriedades mais elementares dos logaritmos que diz que dados $b, c$ e $\beta$ reais positivos sendo $\beta \neq 1$, temos $\log _{\beta} b c=\log _{\beta} b+\log _{\beta} c$. Obviamente queremos que essa propriedade valha também na teoria de St. Vincent de logaritmo como área sob a hipérbole, ou seja, que seja válida para todo $b$ e $c$ reais positivos:

$$
\text { Área }\left(H_{a}^{b c}\right)=\text { Área }\left(H_{a}^{b}\right)+\text { Área }\left(H_{a}^{c}\right) \text {. }
$$

Por outro lado, uma pergunta que pode surgir naturalmente, é se essa igualdade (5.1) vale para todo $a$ ? Analisemos essa questão:

Observe o exemplo da figura 5.3, em que $a>0, b>a$ e $c>1$, obtemos faixas de uma hipérbole, em que é possível concluir facilmente:

$$
\text { Área }\left(H_{a}^{b c}\right)=\text { Área }\left(H_{a}^{b}\right)+\text { Área }\left(H_{b}^{b c}\right) \text {. }
$$

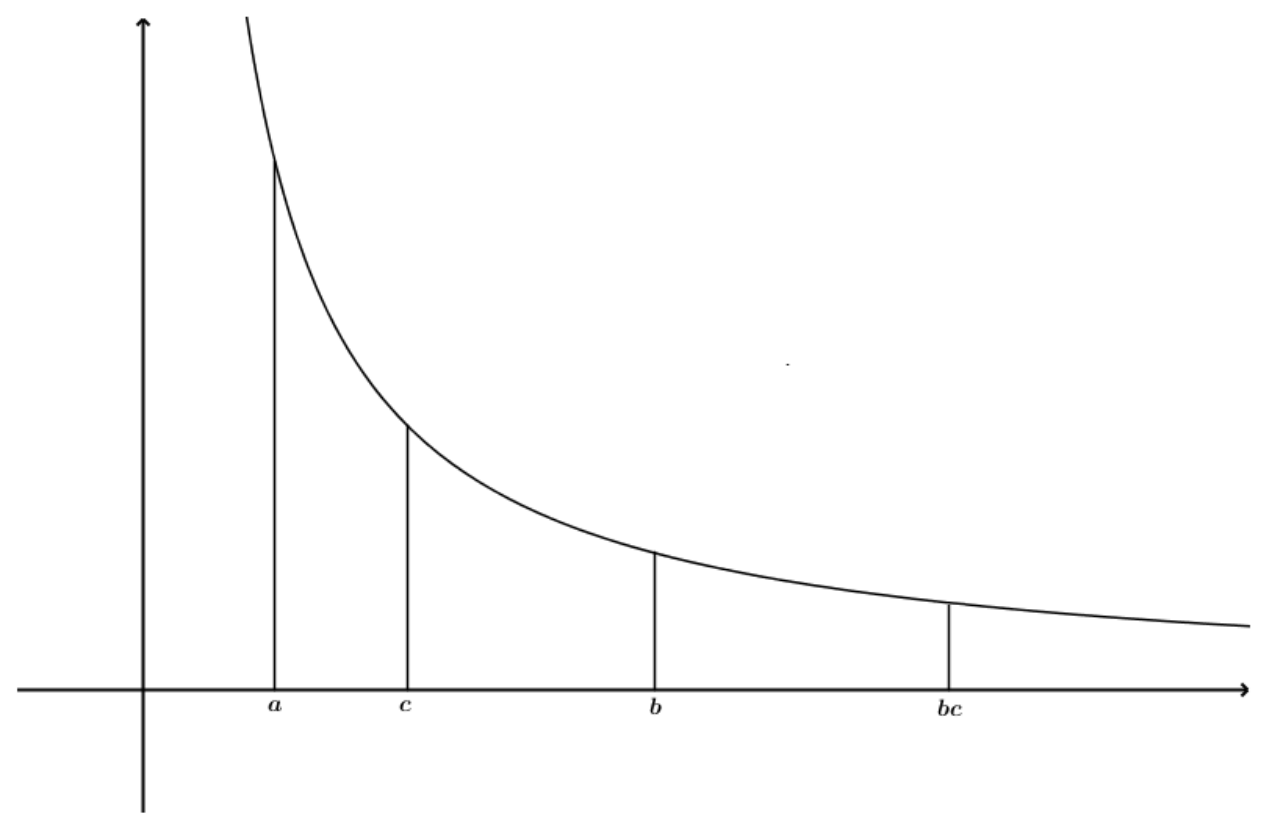

Figura 5.3: Propriedade soma de logaritmos.

Da validade de (5.1) e (5.2) obtemos:

$$
\text { Área }\left(H_{a}^{b}\right)+\text { Área }\left(H_{a}^{c}\right)=\text { Área }\left(H_{a}^{b}\right)+\text { Área }\left(H_{b}^{b c}\right) .
$$

de onde:

$$
\text { Área }\left(H_{a}^{c}\right)=\text { Área }\left(H_{b}^{b c}\right) \text {. }
$$

Utilizando a propriedade fundamental no lado direito dessa última igualdade, obtemos:

$$
\text { Área }\left(H_{a}^{c}\right)=\text { Área }\left(H_{b \cdot \frac{1}{b}}^{(b c) \cdot \frac{1}{b}}\right)
$$


ou seja,

$$
\text { Área }\left(H_{a}^{c}\right)=\text { Área }\left(H_{1}^{c}\right)
$$

igualdade essa que só vale se $a=1$.

A partir da análise desse exemplo, concluímos ser necessário que $a=1$ para que o modelo das áreas sob a hipérbole possa funcionar como logaritmo. Sendo assim, no exemplo da figura 5.3, vale:

$$
\text { Área }\left(H_{1}^{b c}\right)=\text { Área }\left(H_{1}^{b}\right)+\text { Área }\left(H_{b}^{b c}\right)=\text { Área }\left(H_{1}^{b}\right)+\text { Área }\left(H_{1}^{c}\right) .
$$

como queríamos.

Essa conclusão ainda nos fornece um fato importantíssimo que será essencial mais à frente, ao trabalharmos com abscissas cujos valores formam uma sequência em P.G.. Concluímos agora que tal P.G. deve iniciar com 1, ou seja, será $\left(1, a_{1}, a_{2}, \ldots, a_{n}, \ldots\right)$.

Por fim, vamos lembrar que, ao construir seus logaritmos, Napier os fez como uma tabela de valores. Caso alguém quisesse um valor intermediário (que não existia na tabela), deveria usar métodos de interpolação como, por exemplo, o que foi mostrado na seção 3.3 (interpolação linear). Mas, via de regra, ainda eram valores tabelados. Porém, quando o matemático jesuíta belga Gregory de St. Vincent começou a relacionar os logaritmos com áreas de faixas de hipérbole, ele estava lidando com duas teorias já existentes. Além disso, já era conhecido na sua época, que o logaritmo de números entre 0 e 1 possuem valores negativos, o que não acontece com áreas. Desse modo, para que sua teoria ficasse consistente, mantendo a origem das faixas de hipérboles na abscissa 1, ele utilizou a ideia de convencionar uma "orientação" às áreas, de tal modo que se a extremidade final da faixa fosse um ponto de abscissa menor do que 1 , o sinal negativo seria atribuído à área da respectiva faixa na sua teoria. O que St. Vincent buscava, era uma forma de tornar os valores dos logaritmos contínuos, e não mais discretos como os da tabela, e ao idealizar tal ideia, conseguiu justificar geometricamente as propriedades já existentes dos logaritmos.

Vamos, portanto ver o que devemos entender por "área orientada". Partimos da seguinte premissa:

Se nossas faixas de hipérboles sempre deverão ser iniciadas em $a_{0}=1$, como devemos interpretar, por exemplo, o caso da faixa $H_{1}^{1 / x}$ quando $x>1$ ?

Primeiro, sabemos pela propriedade fundamental que:

$$
\text { Área }\left(H_{1}^{1 / x}\right)=\text { Área }\left(H_{x}^{1}\right) \text {. }
$$

Também temos, que do ponto de vista geométrico não importa a ordem no qual aparecem as abscissas dos pontos extremos da faixa de hipérbole, ou seja, vale:

$$
\text { Área }\left(H_{x}^{1}\right)=\operatorname{Area}\left(H_{1}^{x}\right) \text {. }
$$

Desse modo, podemos concluir que Área $\left(H_{1}^{1 / x}\right)=$ Área $\left(H_{1}^{x}\right)$.

Por outro lado queremos que a teoria das faixas de hipérbole represente uma função logarítmica, e sabemos que $\log _{\beta} \frac{1}{x}=-\log _{\beta} x$. Sendo assim, será muito conveniente atribuir um valor negativo para Área $\left(H_{1}^{1 / x}\right)$ a fim de compatibilizar as duas teorias. Generalizando, adotamos a convenção de atribuir, na teoria dos logaritmos como área, o oposto do valor de 
todas as áreas das faixas cujo extremo inferior seja maior que o extremo superior. Assim, nesta teoria, o sinal do valor da função obtida será positivo ou negativo segundo a orientação crescente ou decrescente dos extremos das faixas de hipérbole, respectivamente.

Sabemos que uma área é sempre positiva, entretanto, o que estamos buscando aqui é uma definição de logaritmos que se apoie no conceito de área, desse modo só temos a ganhar do ponto de vista matemático ao aceitar tal convenção. Podemos ainda nos recordar das aulas de cálculo em que muitas vezes ao calcular a integral definida de certa função a valores positivos, obtínhamos um valor negativo como resposta, e tudo se justificava ao perceber que isso ocorria por conta da orientação dos extremos que se tomou ao calcular a integral. Esse "acordo", de aceitar valores negativos para a definição de logaritmos por áreas está na origem da teoria das integrais, que acabou por assumir a mesma convenção para todas as funções, e não apenas $f(x)=\frac{1}{x}$. No que segue, enquanto não introduzimos uma notação final para o logaritmo que estamos definindo, colocaremos aspas na palavras Área ("Área") sempre que quisermos referir que o número considerado é negativo.

Por fim, vamos à definição:

Definição 5.1.1. Seja $x>1$ real tal que Área $\left(H_{1}^{x}\right)=A$, definimos "Área" $\left(H_{x}^{1}\right)=-$ Área $\left(H_{1}^{x}\right)=$ $-A$, ou seja, "Área" $\left(H_{1}^{1 / x}\right)=-$ Área $\left(H_{1}^{x}\right)$.

O que nos possibilita afirmar para $x>1$ e $y>1$, que:

$$
0=\text { Área }\left(H_{1}^{1}\right)=\text { Área }\left(H_{1}^{x}\right)+\text { "Área" }\left(H_{x}^{1}\right)=\text { Área }\left(H_{1}^{x}\right)-\text { Área }\left(H_{1}^{x}\right) .
$$

ou ainda a relação na qual, fazemos uso da propriedade discutida sobre a possibilidade de transformar produtos em soma, isto é;

$$
\text { Área }\left(H_{1}^{x / y}\right)=\text { Área }\left(H_{1}^{x \cdot 1 / y}\right)=\text { Área }\left(H_{1}^{x}\right)+\text { "Área" }\left(H_{1}^{1 / y}\right)=\text { Área }\left(H_{1}^{x}\right)-\text { Área }\left(H_{1}^{y}\right) \text {. }
$$

\subsection{Definição de Logaritmo via área da hipérbole $x y=1$}

Observando o ramo positivo da hipérbole como mostra a figura 5.4, vamos fixar no eixo das abscissas a reta $x=1$ como ponto de partida para as faixas de hipérbole e uma reta arbitrária $x>0$ indicando seu término: $H_{1}^{x}$ ou $H_{1}^{1 / x}$.

Definiremos como logaritmo de um número $x$ real positivo, a área da faixa $H_{1}^{x}$, isto é: $L O G(x)=$ Área $\left(H_{1}^{x}\right)$ para qualquer número $x>0$, onde adotamos obviamente a convenção para a orientação de áreas definidas anteriormente (relembrando, $L O G(x)$ é a própria área da faixa, se $x \geq 1$ e $L O G(x)$ é negativo e com valor absoluto igual à área da faixa, se $0<x<1$ ). Observe que esta definição, mesmo sem fazer referência a qualquer "base", nos fornece uma função com propriedades típicas dos logaritmos, de $\mathbb{R}_{+}^{*}$ em $\mathbb{R}$. Uma vez que convencionamos a orientação para as áreas, vamos firmar um novo "acordo" para dinamizar sobremaneira nossa notação. Daqui por diante, utilizaremos apenas $H_{1}^{x}$ para designar a área (orientada) da faixa de extremo inferior 1 e extremo superior $x$ no lugar de Área $\left(H_{1}^{x}\right)$.

Temos então, para qualquer número real $x>0, L O G(x)=H_{1}^{x}$.

Sempre que precisarmos nos referir unicamente à faixa da hipérbole, explicitaremos tal fato (por exemplo, Observe a faixa de hipérbole $H_{1}^{a} \ldots$ ). 


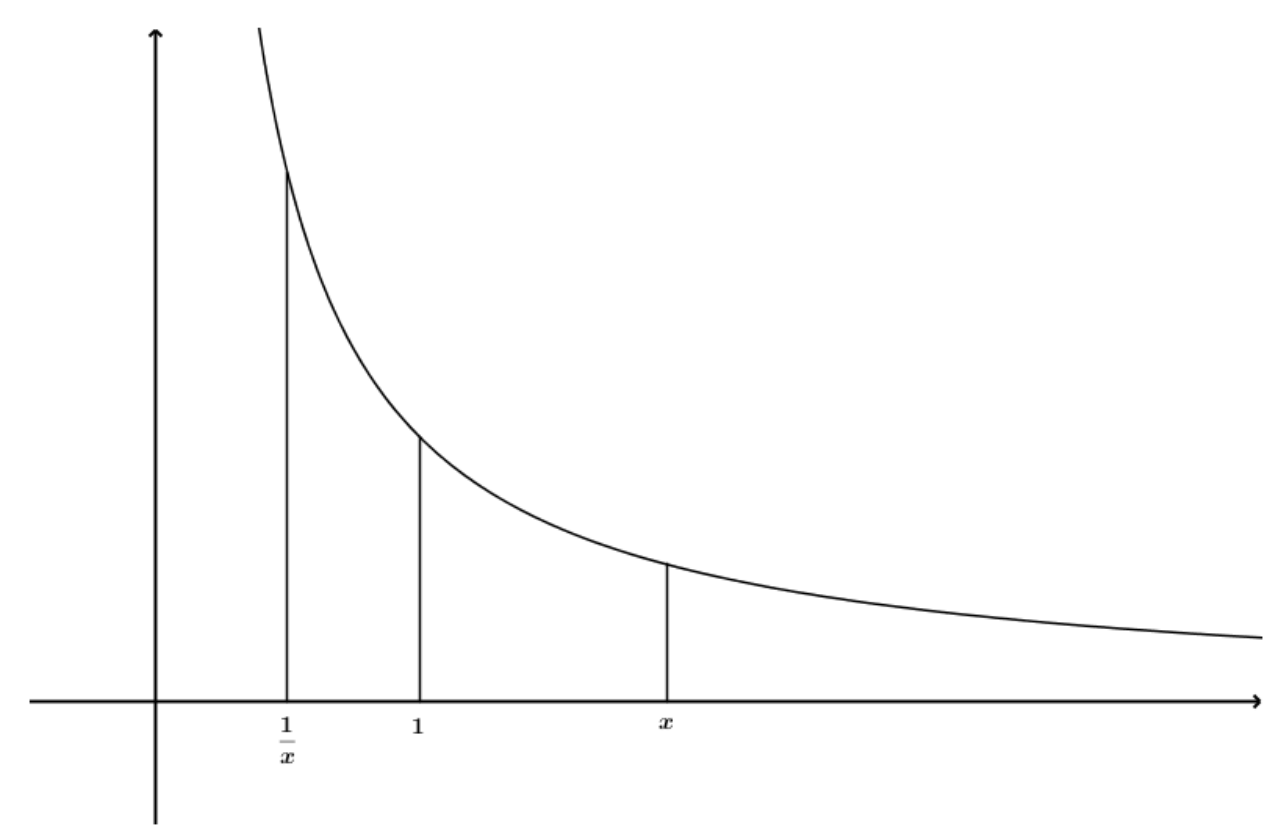

Figura 5.4: Definição Logaritmo.

Seja uma função $L: \mathbb{R}_{+}^{*} \rightarrow \mathbb{R}$, a chamamos de função logarítmica quando satisfizer as seguintes condições, para quaisquer $x, y \in \mathbb{R}_{+}^{*}$ temos:

(i) $L(x y)=L(x)+L(y)$.

(ii) L é uma função crescente ${ }^{1}$, ou seja, $x<y \Rightarrow L(x)<L(y)$.

Vamos então provar que a função $L O G: \mathbb{R}_{+}^{*} \rightarrow \mathbb{R}$ é uma função logarítmica. Para tanto, devemos mostrar a validade de (i) e (ii) para a função $L O G$ :

Demonstração. (i) Vamos agora mostrar que $L O G(x y)=L O G(x)+L O G(y)$. Já vimos anteriormente que: $H_{1}^{x y}=H_{1}^{x}+H_{x}^{x y}=H_{1}^{x}+H_{x / x}^{(x y) / x}=H_{1}^{x}+H_{1}^{y}$. Portanto, $\operatorname{LOG}(x y)=$ $H_{1}^{x y}=H_{1}^{x}+H_{1}^{y}=L O G(x)+L O G(y)$.

(ii) Mostremos agora que $L O G$ é uma função crescente, isto é, $x<y \Rightarrow L O G(x)<L O G(y)$. Observe antes que vale o resultado preliminar $L O G(1)=0$. De fato, $L O G(1)=H_{1}^{1}$ se reduz à área de um segmento de reta, portanto igual a zero. Sejam $x, y \in \mathbb{R}_{+}^{*}$ dados, com $x<y$, tal desigualdade implica que existe algum número real $a>1$ tal que $y=a x$.

Disso segue que: $\operatorname{LOG}(y)=\operatorname{LOG}(a x)=L O G(a)+L O G(x)$. Como $a>1$, temos que $L O G(a)>0$ e, portanto, $L O G(y)>L O G(x)$. Concluindo assim nossa demonstração.

\footnotetext{
${ }^{1}$ Sabemos que uma função logarítmica pode ser crescente ou decrescente, dependendo de sua base. Entretanto, a fim de não sobrecarregar o leitor fazendo demonstrações duplicadas para cada proposição, optamos por manter apenas o caso crescente (base maior que 1), uma vez que estamos preparando caminho para estudar uma função logarítmica de base $e$. Para o leitor que desejar, as proposições para o caso decrescente, são análogas as feitas aqui, bastando substituir a desigualdade e adaptar alguns detalhes.
} 


\subsection{Propriedade das Funções Logarítmicas}

Demonstraremos uma série de consequências, bem como dois teoremas muito importantes, a partir das duas propriedades característica das funções logarítmicas provadas anteriormente. É interessante notar que as demonstrações a seguir são válidas para qualquer função logarítmica, independentemente da concepção escolhida para a sua definição. Assim elas podem ser utilizadas em qualquer viés de abordagem adotado, inclusive no nosso caso, da função definida por área.

Seja $L: \mathbb{R}_{+}^{*} \rightarrow \mathbb{R}$ uma função logarítmica, então, para quaisquer $x, y \in \mathbb{R}_{+}^{*}$, por definição ela satisfaz as seguintes condições:

(i) $L(x y)=L(x)+L(y)$;

(ii) $L(x)$ é uma função crescente.

Vamos convencionar que, dado $x \in \mathbb{R}_{+}^{*}$, o valor $L(x)$ será chamado logaritmo de $x$ ou, quando necessário, poderemos chamar de logaritmo de $x$ segundo o sistema L.

Provemos agora uma lista de propriedades para essa função, utilizando (i) e (ii).

P1) Uma função $L: \mathbb{R}_{+}^{*} \rightarrow \mathbb{R}$ é sempre injetora.

Para isso basta lembrar que, para mostrar ser uma função injetora, é suficiente verificar que, ao tomarmos $x \neq y$ teremos que $L(x) \neq L(y)$. Dados dois números $x, y$ quaisquer, sendo $x \neq y$ obrigatoriamente uma e apenas uma das duas condições serão satisfeitas: $x<y$ ou $y<x$. A partir de (ii) concluímos que valem: $x<y \Rightarrow L(x)<L(y)$ ou $y<x \Rightarrow L(y)<L(x)$. Logo, $L(x) \neq L(y)$.

Note aqui que nossa função $L$ não pode ser definida para $x=0$, pois caso assim fosse, teríamos para todo $x \geq 0, L(0)=L(0 \cdot x)=L(0)+L(x)$, isto é, $L(x)=0$ o que contraria o exposto acima. Justificando a restrição do domínio de $L$ a $\mathbb{R}_{+}^{*}$.

P2) O logaritmo de 1 resulta zero.

Por (i) e propriedades algébricas, obtemos que:

$$
L(1)=L(1 \cdot 1)=L(1)+L(1)
$$

Logo, $L(1)=0$.

P3) Sempre que tomarmos números maiores que 1, obtemos logaritmos positivos; e números entre 0 e 1 resultam em logaritmos negativos. Ou seja, $x>1 \Rightarrow L(x)>0$ e $0<x<$ $1 \Rightarrow L(x)<0$.

Tomando, portanto, $0<x<1<y$ obtemos que $L(x)<L(1)<L(y)$. Logo, $L(x)<0<$ $L(y)$.

P4) Para todo $x>0$, temos $L\left(\frac{1}{x}\right)=-L(x)$. 
De $x \cdot\left(\frac{1}{x}\right)=1$, obtemos que $L\left(x \cdot\left(\frac{1}{x}\right)\right)=L(1)$. Assim, por (i) e (P2), $L(x)+L\left(\frac{1}{x}\right)=0$. Logo, $L\left(\frac{1}{x}\right)=-L(x)$.

P5) Para todo $x, y \in \mathbb{R}_{+}^{*}$, vale a igualdade $L\left(\frac{x}{y}\right)=L(x)-L(y)$.

$$
L\left(\frac{x}{y}\right)=L\left(x \cdot\left(\frac{1}{y}\right)\right)=L(x)+L\left(\frac{1}{y}\right) .
$$

Mas, por (P4), temos

$$
L(x)+L\left(\frac{1}{y}\right)=L(x)-L(y) .
$$

P6) Para todo $x \in \mathbb{R}_{+}^{*}$ e todo $r$ racional, temos $L\left(x^{r}\right)=r \cdot L(x)$.

Primeiro devemos observar que a propriedade $L(x y)=L(x)+L(y)$ pode ser estendida, por indução finita, para qualquer número de fatores, uma vez que $L: \mathbb{R}_{+}^{*} \rightarrow \mathbb{R}$.

Agora vamos dividir nossa demonstração nos seguintes casos:

- Para $n=0$ temos: $L\left(x^{0}\right)=L(1)=0=0 \cdot L(x)$.

- Para $n \in \mathbb{N}^{*}: L\left(x^{n}\right)=L(x \cdot x \cdot x \cdot \ldots \cdot x)=L(x)+L(x)+L(x)+\cdot+L(x)=n \cdot L(x)$.

- Considerando então o caso em que $r=-n$, com $n \in \mathbb{N}^{*}$, para todo $x>0$ temos que $x^{n} \cdot x^{-n}=1 \Rightarrow L\left(x^{n}\right)+L\left(x^{-n}\right)=0$. Logo, $L\left(x^{-n}\right)=-n \cdot L(x)$.

- Finalmente, quando $r=\frac{p}{q}$ em que $p \in \mathbb{Z}$ e $q \in \mathbb{N}^{*}$, para todo $x \in \mathbb{R}_{+}^{*}$ temos: $\left(x^{r}\right)^{q}=\left(x^{\frac{p}{q}}\right)^{q}=x^{p}$. De onde segue $L\left[\left(x^{r}\right)^{q}\right]=L\left(x^{p}\right)$. Em virtude do que foi provado anteriormente, vale $q \cdot L\left(x^{r}\right)=p \cdot L(x)$. Logo, $L\left(x^{r}\right)=\left(\frac{p}{q}\right) \cdot L(x)=r \cdot L(x)$.

Aqui cabe um comentário conveniente: o fato de termos adotado r como sendo racional, decorre da dificuldade pela qual passamos para definir o valor de potência cujo expoente é irracional.

P7) Uma função logarítmica $L: \mathbb{R}_{+}^{*} \rightarrow \mathbb{R}$ é ilimitada superior e inferiormente.

Essa afirmação nos diz que, tomando quaisquer números reais $\alpha>0$ e $\beta<0$, sempre encontraremos $x, y$ positivos tais que $L(x)>\alpha$ e $L(y)<\beta$. Entretanto antes de provar essa propriedade, vamos ver alguns exemplos que nos ajudarão a entender com mais facilidade a demonstração.

Considere as funções $f, g$ e $h$ com domínio $\mathbb{R}$ e cada qual com sua imagem, dadas por $f(x)=\operatorname{sen} x, g(x)=x^{2}$ e $h(x)=x^{3}$.

Sabemos que $-1 \leq \operatorname{sen} x \leq 1$ para todo $x \in \mathbb{R}$, logo essa função é limitada inferior e superiormente. 


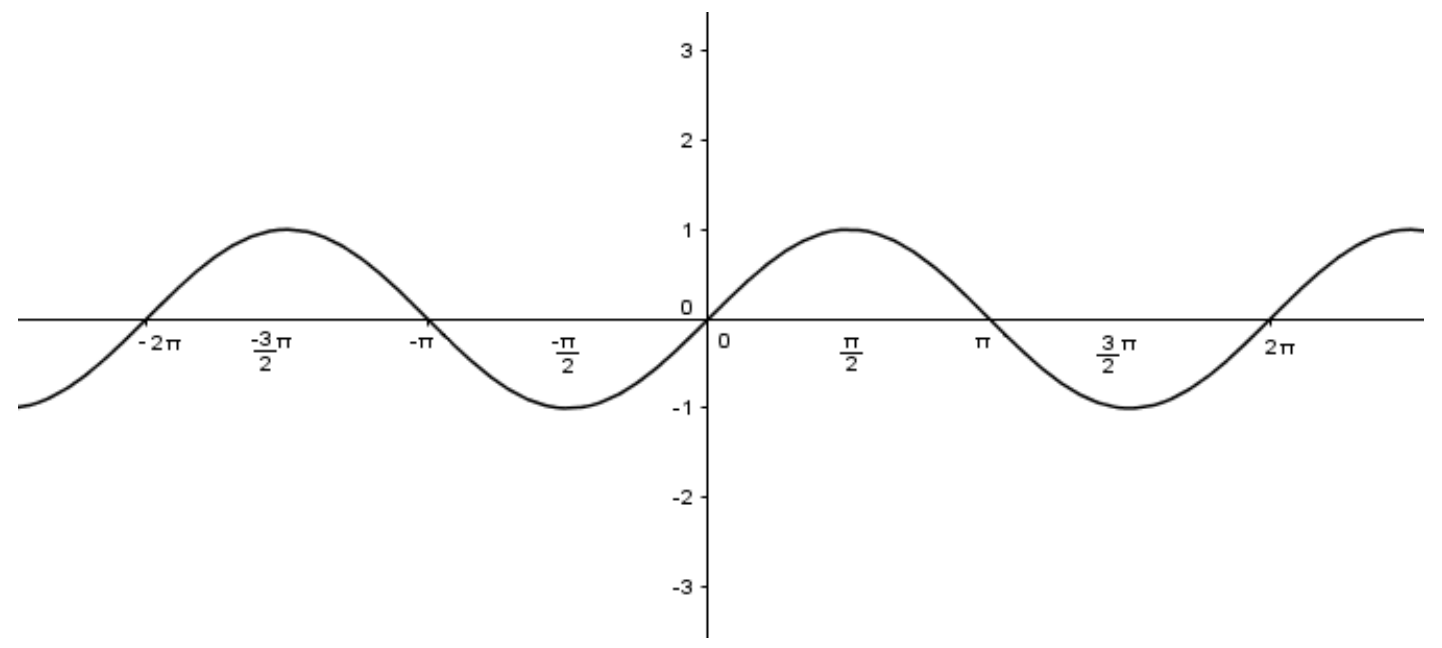

Figura 5.5: Gráfico $f(x)=\operatorname{sen} x$.

Por outro lado, sabemos que $x^{2} \geq 0$ para todo $x \in \mathbb{R}$. Logo $g(x)$ é uma função limitada inferiormente, entretanto ela é ilimitada superiormente, pois dado qualquer $\alpha$ sempre conseguimos exibir um $x \in \mathbb{R}$ tal que $x^{2} \geq \alpha$. Basta para tal, tomar $x>\sqrt{\alpha}$, se $\alpha$ for zero ou positivo, ou qualquer $x$ se $\alpha$ for um número negativo.

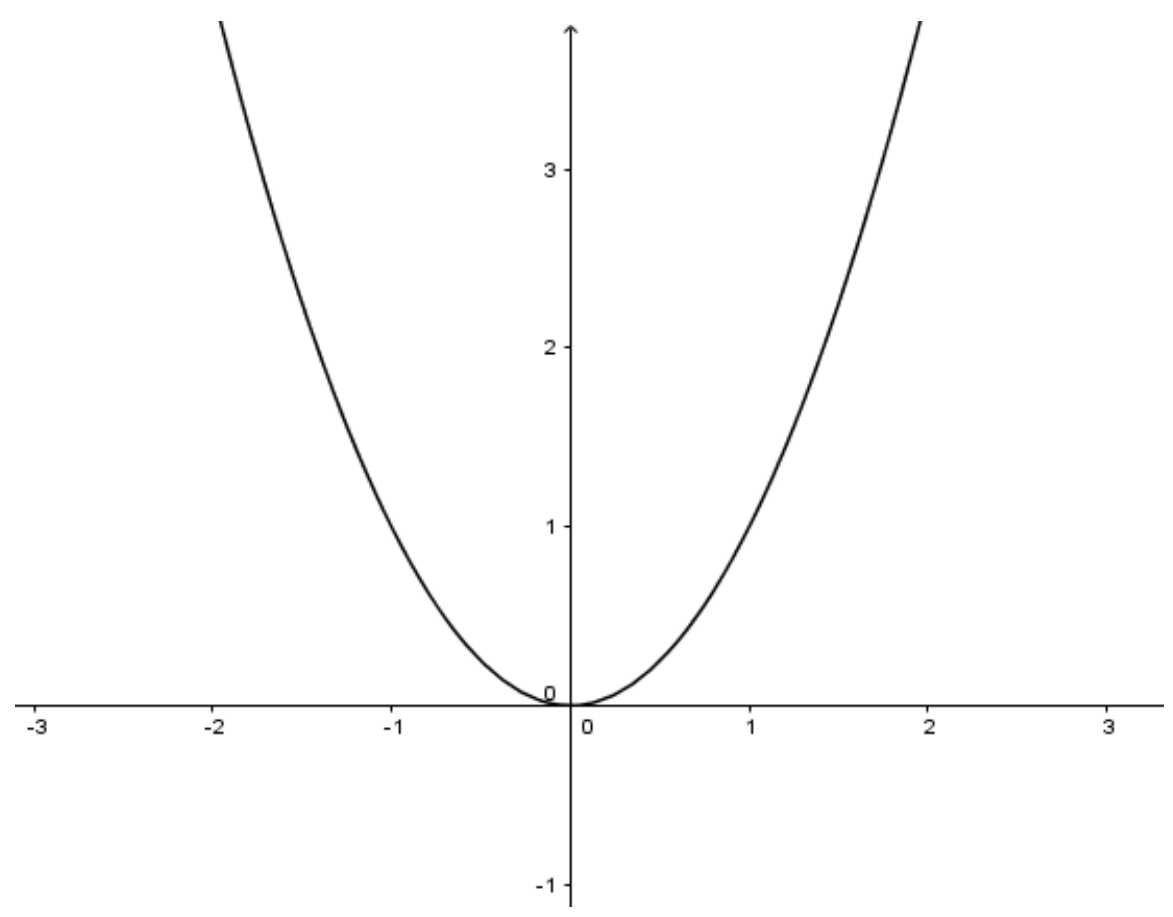

Figura 5.6: Gráfico $g(x)=x^{2}$.

Finalmente a função $h(x)$ é ilimitada inferior e superiormente em todo o seu domínio, como se pode concluir usando um argumento semelhante ao anterior. Dado qualquer $\alpha \geq 0$ sempre conseguimos exibir um $x \in \mathbb{R}$ tal que $x^{3}>\alpha$. Basta para tal, tomar $x>\sqrt[3]{\alpha}$, se $\alpha$ for zero ou positivo, e valerá que $x^{3}>\alpha \operatorname{logo}, h(x)$ é ilimitada superiormente. Por outro lado, se $\alpha<0$, basta tomar $(-\alpha)>0$, e pelo exposto anteriormente, existe $x>\sqrt[3]{(-\alpha)}$, de onde concluímos que basta tomar $x>-\sqrt[3]{\alpha}$, e portanto, é ilimitada inferiormente. Observe 
que esse último raciocínio poderia ser "simplificado" bastando tomar $x<\sqrt[3]{\alpha}$ obtendo então $x^{3}<\alpha$. Mas optamos pela abordagem utilizando o oposto $(-\alpha)>0$ e repetindo o argumento para o caso positivo, a fim de familiarizar o leitor com o tipo de argumento a ser empregado, posteriormente no caso de nossa função.

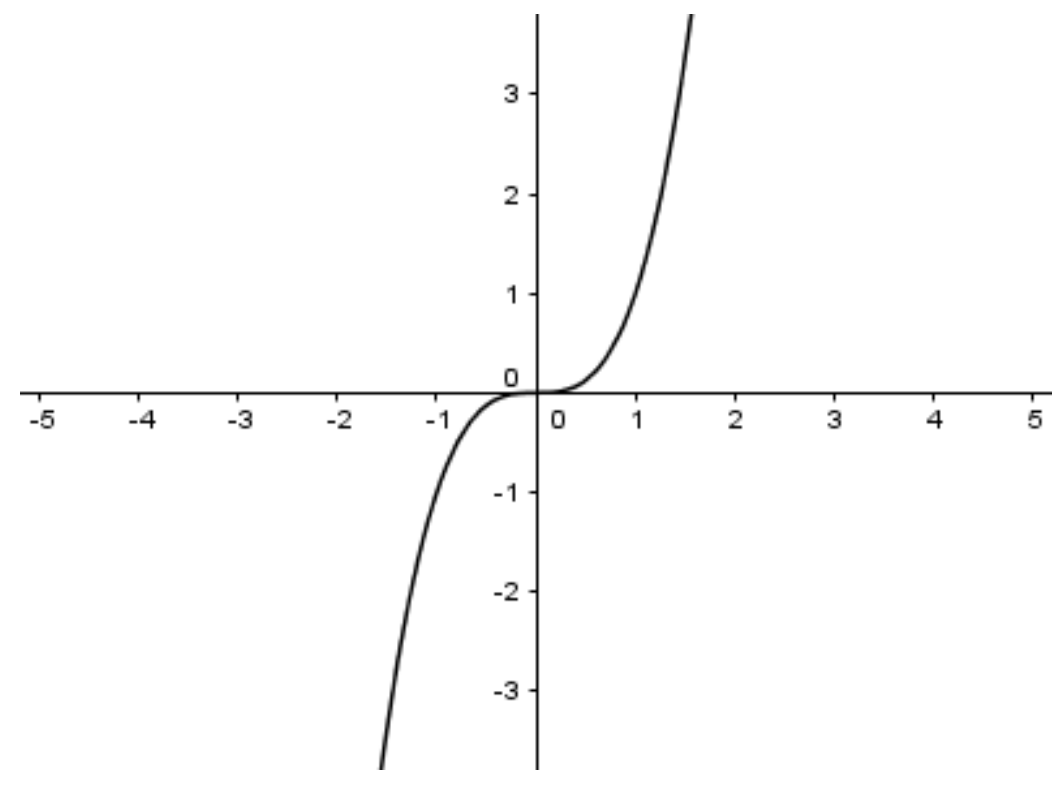

Figura 5.7: Gráfico $h(x)=x^{3}$.

Voltando agora para as funções logarítmicas, procedemos da seguinte forma para a prova de (P7):

- Primeiro vamos provar que $L$ é ilimitada superiormente. Para tanto, basta mostrar que dado um número real $\alpha>0$, sempre é possível achar um $x \in \mathbb{R}_{+}^{*}$ tal que $L(x)>\alpha$. Tome $n$ natural de modo que $n>\frac{\alpha}{L(2)}$. Por $L(2)$ ser positivo, obtemos $n \cdot L(2)>\alpha \Rightarrow L\left(2^{n}\right)>\alpha$, desse modo, basta tomar $x=2^{n}$, obtendo portanto $L(x)>\alpha$. Observe que utilizar $L(2)$ é mera conveniência. De fato, bastaria que o valor escolhido fosse um logaritmo positivo, em particular poderia ser $L(3), L(\pi), L(5)$, $L(99)$, etc. A escolha desse valor específico foi por ser ele o primeiro natural cujo logaritmo atende à condição exposta e também por ser um número com potências relativamente conhecidas. Pensando desse modo, um valor igualmente conveniente, seria $L(10)$, pois suas potências também são "imediatas", entretanto, fiquemos com nossa escolha inicial.

- Para provar agora ser $L$ ilimitada inferiormente, devemos mostrar que dado um número real $\beta<0$, sempre é possível encontrar $y \in \mathbb{R}_{+}^{*}$ tal que $L(y)<\beta$. Tomemos o número real $(-\beta)$. Pelo exposto anteriormente, é possível achar $x \in \mathbb{R}_{+}^{*}$ tal que $L(x)>(-\beta)$. Logo $-L(x)<\beta$ e portanto $L\left(\frac{1}{x}\right)<\beta$. Escolhendo então $y=\frac{1}{x}$, obtemos o que desejamos, ou seja, $L(y)<\beta$.

Para terminar este tópico, vamos enunciar e provar dois teoremas que são de extrema importância nessa teoria. Por fim provaremos um corolário que trará fortes implicações: o fato das funções logarítmicas serem bijeções entre $\mathbb{R}_{+}^{*}$ e $\mathbb{R}$. 
O Teorema 5.3.1 vai nos garantir que, em particular, a função por nós definida é sobrejetora, e o Teorema 5.3.2 nos dirá que, dada uma função logarítmica $L(x)$ qualquer e dada uma constante $c$, a função $c \cdot L(x)$ também será logarítmica. Sendo assim, basta que se estude uma função $L: \mathbb{R}_{+}^{*} \rightarrow \mathbb{R}$ crescente tal que $L(x y)=L(x)+L(y)$ que todas as demais funções logarítmicas resultarão da multiplicação de $L$ por uma constante conveniente. Vamos agora aos teoremas e ao corolário:

Teorema 5.3.1. Toda função logarítmica $L$ é sobrejetora, ou seja, dado qualquer real c, existe sempre um real positivo $x$ tal que $L(x)=c$.

Para fazer a prova desse teorema, faremos uso do seguinte resultado:

Lema 5.3.1. Seja $L: \mathbb{R}_{+}^{*} \rightarrow \mathbb{R}$ uma função logarítmica. Dados dois reais quaisquer $u<v$, existe $x>0$ tal que $u<L(x)<v$.

Em outras palavras, o lema nos assegura que todo intervalo $I=(u, v)$ do contradomínio de $L$, contém pelo menos um valor $L(x) \operatorname{com} x \in \mathbb{R}_{+}^{*}$. Vamos à demonstração do Lema:

Demonstração. Tome um $n$ natural de modo que $n>\frac{L(2)}{(v-u)}$. Assim temos que $(v-u)>\frac{L(2)}{n}$, além disso, $\frac{L(2)}{n}>0$ uma vez que é o quociente entre dois positivos. A fim de facilitar nossa notação, vamos escrever $\delta=\frac{L(2)}{n}=L\left(2^{\frac{1}{n}}\right)>0$.

Os vários múltiplos $\ldots<-4 \delta<-3 \delta<-2 \delta<-\delta<0 \delta<\delta<2 \delta<3 \delta<4 \delta<\ldots$, isto é, os pontos de coordenadas $m \cdot \delta=\frac{m}{n} \cdot L(2)=L\left(2^{\frac{m}{n}}\right)$ com $m \in \mathbb{Z}$, irão decompor a reta real em intervalos congruentes de tamanho $\delta$.

Note que, como $\delta<v-u$, teremos ao menos um número $m \cdot \delta$ no intervalo $(u, v)$, isto é, satisfazendo a desigualdade $u<m \cdot \delta<v$. Portanto $u<L\left(2^{\frac{m}{n}}\right)<v$. Se tomarmos então $x=2^{\frac{m}{n}}$, teremos por fim, $u<L(x)<v$.

Vamos agora ao teorema, ou seja, provar que $L$ é sobrejetora:

Teorema 5.3.1. Seja $b$ um real qualquer, devemos obter um número real positivo $\alpha$ tal que $L(\alpha)=b$. O processo consiste em determinar o $\alpha$ conveniente, encontrando primeiro a parte inteira $a$ do seu valor e, posteriormente, buscar um a um, os dígitos que compõe sua parte decimal: $\alpha=a, a_{1} a_{2} a_{3} \ldots a_{n} \ldots$ para $a_{i} \in\{0,1,2,3, \ldots, 9\}$ com $i \geq 1$. Em seguida, mostremos que, de fato, $L(\alpha)=b$.

Para determinar a parte inteira $a$, lembremos que $L$ é ilimitada e crescente, (note que isso não acarreta ser ela sobrejetora), logo existem inteiros $k$ tais que $L(k)>b$. Seja $(a+1)$ o menor inteiro tal que $L(a+1)>b$. Desse modo vale $L(a) \leq b<L(a+1)$.

Considere os números $a ; a+\frac{1}{10} ; a+\frac{2}{10} ; a+\frac{3}{10} ; \ldots ; a+\frac{9}{10} ; a+1$ (observe que usamos o ";" na enumeração dos 10 valores, a fim de guardar o uso da "," para o registro de números em notação decimal, como feito usualmente).

Note que existem dois e apenas dois algarismos consecutivos em $\{0,1,2,3, \ldots, 9\}$ tais que: $L\left(a+\frac{m}{10}\right) \leq b<L\left(a+\frac{m+1}{10}\right)$. Fazendo $a_{1}=m$, obtemos, em notação decimal, que $a+\frac{m}{10}$ $=a, a_{1}$. Logo, $L\left(a, a_{1}\right) \leq b<L\left(a, a_{1}+\frac{1}{10}\right)$.

Para determinar o dígito do centésimo procederemos de forma análoga. Mas antes, a fim de "limpar" nossa notação e não cometermos equívocos pelo grande número de vírgulas e 
índices seguidos utilizaremos a notação $\mu_{1}$ no lugar de $a, a_{1}$. Como antes, podemos obter a sequência de números:

$$
\mu_{1} ; \mu_{1}+\frac{1}{10^{2}} ; \mu_{1}+\frac{2}{10^{2}} ; \mu_{1}+\frac{3}{10^{2}} ; \ldots ; \mu_{1}+\frac{9}{10^{2}} ; \mu_{1}+\frac{1}{10}
$$

Novamente devemos tomar os dois únicos valores consecutivos tais que:

$$
L\left(\mu_{1}+\frac{m^{\prime}}{10^{2}}\right) \leq b<L\left(\mu_{1}+\frac{m^{\prime}+1}{10^{2}}\right)
$$

Fazendo $a_{2}=m^{\prime}$ obtemos:

$$
L\left(a, a_{1} a_{2}\right) \leq b<L\left(a, a_{1} a_{2}+\frac{1}{10^{2}}\right) .
$$

Prosseguindo analogamente, o processo termina se encontrarmos um valor $a_{n}$ tal que valha $L\left(\mu_{n}\right)=b$. Se isso não ocorrer, de qualquer forma, é intuitivo admitir que o processo convirja para a representação decimal de um número real $\mu=a, a_{1} a_{2} a_{3} \ldots a_{n} \ldots=a+\frac{a_{1}}{10}+\frac{a_{2}}{10^{2}}+\frac{a_{3}}{10^{3}}+$ $\ldots+\frac{a_{n}}{10^{n}}+\ldots$ de maneira que para todo número natural $n$ tenhamos $\mu_{n}=a, a_{1} a_{2} a_{3} \ldots a_{n}$ satisfazendo as desigualdades: $L\left(\mu_{n}\right) \leq b<L\left(\mu_{n}+\frac{1}{10^{n}}\right)$, (mesmo que a demonstração formal desse fato extrapole os objetivos desta dissertação).

Afirmo que $L(\mu)=b$. Com efeito, se fosse $L(\mu)<b$, pelo lema provado anteriormente, obteríamos um $x>0$ tal que $L(\mu)<L(x)<b$. Como $L$ é uma função crescente, temos que $\mu<x$, podemos tomar $n$ natural, tão grande que $x-\mu>\frac{1}{10^{n}}$, de onde, $\mu+\frac{1}{10^{n}}<x$.

Portanto, $\mu_{n}+\frac{1}{10^{n}} \leq \mu+\frac{1}{10^{n}}<x \Rightarrow L\left(\mu_{n}+\frac{1}{10^{n}}\right)<L(x)$ ou ainda, $b<L\left(\mu_{n}+\frac{1}{10^{n}}\right)<L(x)$.

Obtemos então que $b<L(x)$, o que seria um absurdo, pois $x$ foi obtido de modo que $L(x)<b$. Desse modo não podemos ter a validade de $L(\mu)<b$.

De modo similar, se supusermos que $L(\mu)>b$, novamente utilizando o lema, podemos obter $x>0$ de modo que $b<L(x)<L(\mu)$, de onde, por $L$ ser crescente, $x<\mu$. Mas isso implicaria que $x<\mu_{n}$ para algum $n$ natural. Então, $L(x)<L\left(\mu_{n}\right) \leq b$, ou seja, $L(x)<b$ o que seria novamente um absurdo, pois $x$ foi obtido de modo a $b<L(x)$. Portanto também não pode valer $b<L(\mu)$. Assim só resta valer $L(\mu)=b$, como afirmamos antes. Isto conclui a demonstração do teorema.

Antes de ir ao Teorema 5.3.2, vamos mostrar o seguinte resultado preliminar:

Lema 5.3.2. Seja L uma função logarítmica e uma constante $k \in \mathbb{R}_{+}^{*}$ então $k L$ também será uma função logarítmica.

Demonstração. Seja $N=k L$, então $N(x y)=k L(x y)=k(L(x)+L(y))=k L(x)+k L(y)=$ $N(x)+N(y)$, para $x, y>0$. E assim vale a primeira propriedade das funções logarítmicas para $N$.

Tome $x<y$. Como $L$ é logarítmica, vale $L(x)<L(y)$. Sendo $k>0$, obtemos $k L(x)<k L(y)$, ou seja, $N(x)<N(y)$. Portanto, $N=k L$ é também uma função crescente, e, portanto, logarítmica. 
Teorema 5.3.2. Dadas as funções logarítmicas $L, M: \mathbb{R}_{+}^{*} \rightarrow \mathbb{R}$, existe uma constante $c>0$ tal que $M(x)=c \cdot L(x)$ para todo $x>0$.

Demonstração. Suponha que exista $a>1$ tal que $L(a)=M(a)$. Nessa condição, se pode provar que vale $L(x)=M(x)$ para todo $x>0$. Com efeito, note primeiro que para qualquer $r$ racional, a condição acarreta que $L\left(a^{r}\right)=M\left(a^{r}\right)$, pois $L\left(a^{r}\right)=r \cdot L(a)=r \cdot M(a)=M\left(a^{r}\right)$.

O caso geral do Teorema 5.3.2, pode ser reduzido ao seguinte caso particular: dadas $L$ e $M$, funções logarítmicas arbitrárias, temos $L(2)>0$ e $M(2)>0$, já que, $2>1$. Seja $c=\frac{M(2)}{L(2)}$. Tome a função logarítmica $N: \mathbb{R}_{+}^{*} \rightarrow \mathbb{R}$, definida por $N(x)=c \cdot L(x)$.

Temos que: $N(2)=c \cdot L(2)=\left[\frac{M(2)}{L(2)}\right] \cdot L(2)=M(2)$.

Do provado anteriormente segue que $N(x)=M(x)$ para todo $x>0$, isto é, $M(x)=c \cdot L(x)$ para todo $x>0$.

Suponha agora por absurdo que exista algum $b>0$ tal que $L(b) \neq M(b)$. Tomemos sem perda de generalidade que $L(b)<M(b)$, dessa forma $M(b)-L(b)>0$ tome então um número natural $n$ tal que:

$$
n \cdot[M(b)-L(b)]>L(a) \Rightarrow[M(b)-L(b)]>\frac{L(a)}{n}
$$

que por sua vez temos

$$
[M(b)-L(b)]>\frac{L(a)}{n} \Rightarrow L\left(a^{\frac{1}{n}}\right)<M(b)-L(b) .
$$

Para facilitar nossa compreensão vamos tomar $\delta=L\left(a^{\frac{1}{n}}\right)$ que certamente é um número real. A partir dos valores $\delta, 2 \delta, 3 \delta, 4 \delta, \ldots$ podemos dividir $\mathbb{R}_{+}$em intervalos congruentes de tamanho $\delta$. Como $\delta<M(b)-L(b)$ teremos ao menos um número $m \cdot \delta$ pertencente ao intervalo $(L(b), M(b))$, isto é, $L(b)<m \cdot \delta<M(b)$. Por outro lado, temos $L\left(a^{r}\right)=M\left(a^{r}\right)$ e $\delta=L\left(a^{\frac{1}{n}}\right)$, então temos: $L(b)<L\left(a^{\frac{m}{n}}\right)$ e $M\left(a^{\frac{m}{n}}\right)<M(b)$. Como vale $L\left(a^{\frac{m}{n}}\right)=M\left(a^{\frac{m}{n}}\right)$ e ambas são funções crescentes, obtemos:

$$
\begin{gathered}
M\left(a^{\frac{m}{n}}\right)<M(b) \Rightarrow a^{\frac{m}{n}}<b \\
L(b)<L\left(a^{\frac{m}{n}}\right) \Rightarrow b>a^{\frac{m}{n}}
\end{gathered}
$$

Esse absurdo mostra não existir b nessas condições. Logo, $L(x)=M(x)$ para todo $x>0$. 


\section{Capítulo 6}

\section{O número $e$}

No capítulo 3, ao tratar a questão dos juros, nos deparamos com uma situação muito intrigante. O senso comum leva-nos a pensar que investindo certa quantia em um sistema de juros compostos por um período determinado, o montante obtido ao final desse período aumentará tanto mais quanto maior for o número de capitalizações ao longo dele. Mas vimos que não é isso o que ocorre. De fato o capital aplicado não chega sequer a triplicar. Entretanto, o mais importante é que, em uma situação hipotética na qual se dispõe de "capitalizações infinitas" o fator de aumento será algo em torno de 2,72. Vamos formalizar alguns conceitos subjacentes a tal valor (número irracional $e$ ).

\subsection{Número $e$ via área de uma faixa da hipérbole $x y=1$}

Uma vez que definimos os logaritmos utilizando as faixas de hipérboles e provamos que nossa função definida anteriormente é bijetora, a questão que devemos responder agora é para qual valor real $\alpha>0$ obtemos $L O G(\alpha)=1$ ? A esse valor damos o nome de base para esse sistema de logaritmos.

De fato, podemos afirmar que esse valor $\alpha$ procurado é o número irracional $e$, isto é, que $L O G(e)=1$. Facilmente conseguimos notar que $\mathrm{x}>1$, pois $L O G(1)=0$ e para valores do intervalo $0<x<1$ os resultados são negativos como afirmamos em 5.2 (Definição de Logaritmo via área da hipérbole $x y=1$ ). Vamos então apresentar argumentos que comprovem estar este número (que já sabemos qual é) entre 2 e 3.

Obviamente que apenas apresentando esse fato, não podemos de modo algum afirmar ser ele realmente o número $e$. Entretanto, os argumentos utilizados para comprovar tal fato, são baseados em cálculos de áreas de figuras elementares e manuseio algébrico acessível, podendo dessa forma, ser facilmente trabalhado com os alunos da Educação Básica. Seria um bom ponto de partida, propor que os alunos obtivessem aproximações de $L O G(2)$ e $L O G(3)$ e que buscassem uma maneira de justificar o fato apresentado. Além de tornar a afirmação mais crível, possivelmente deixará os alunos mais motivados ao trabalhar com o número $e$.

O raciocínio baseia-se em provar que (a) $L O G(2)<1$ e que (b) $L O G(3)>1$. Ora, para comprovar (a), basta encontrar uma aproximação por excesso de $L O G(2)$ que seja menor do que 1. Analogamente, se uma aproximação por falta de $L O G(3)$ for maior do que 1 , evidentemente também valerá (b).

Vamos primeiro calcular uma aproximação por excesso de $L O G(2)$, utilizando para tal uma subdivisão da abscissa em quatro segmentos congruentes e tomando os retângulos acima da curva, isto é: 


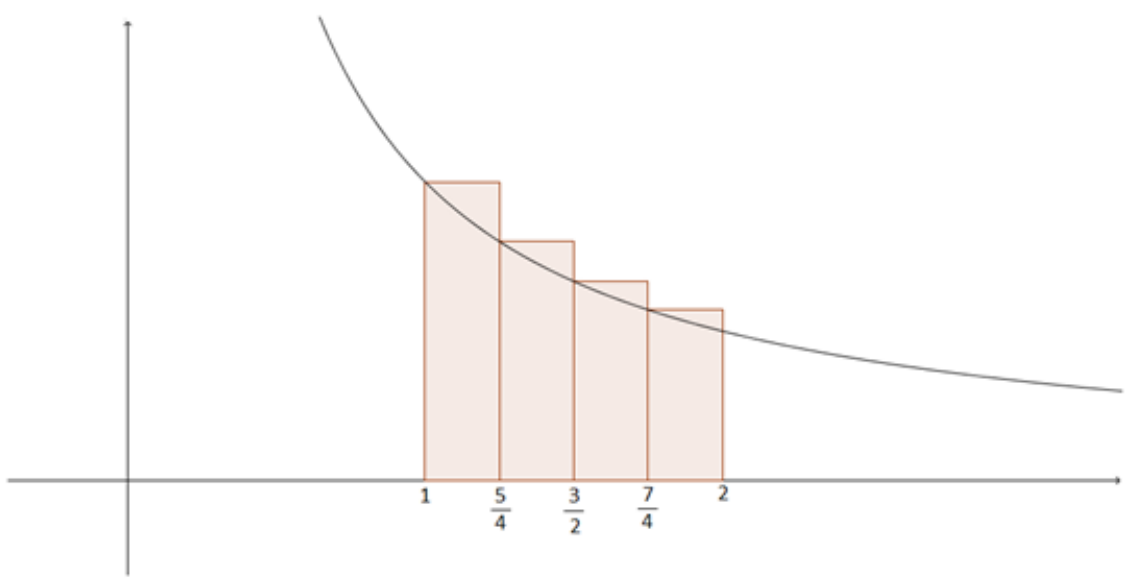

Figura 6.1: Aproximação $L O G(2)$ por sobra com 4 retângulos.

$$
\left(\frac{1}{4} \cdot 1\right)+\left(\frac{1}{4} \cdot \frac{4}{5}\right)+\left(\frac{1}{4} \cdot \frac{2}{3}\right)+\left(\frac{1}{4} \cdot \frac{4}{7}\right)=\frac{1}{4}+\frac{1}{5}+\frac{1}{6}+\frac{1}{7} \cong 0,76
$$

Logo,

$$
\operatorname{LOG}(2)<0,76<1 .
$$

Calculemos agora uma aproximação por falta de $L O G(3)$. Para isso, utilizaremos uma subdivisão da abscissa em oito ${ }^{1}$ segmentos congruentes, mas aqui tomaremos os retângulos abaixo da curva, ou seja:

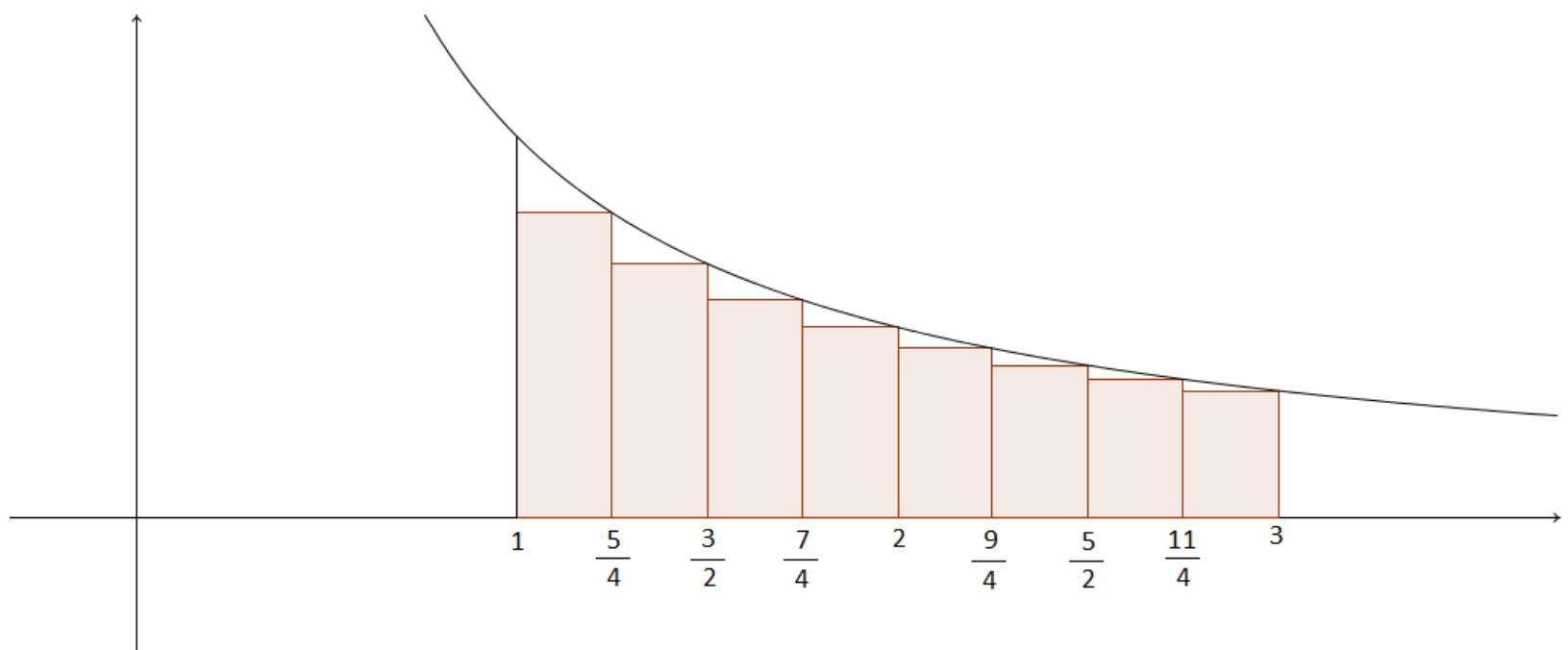

Figura 6.2: Aproximação $L O G(3)$ por falta com 8 retângulos.

\footnotetext{
${ }^{1}$ Perceba que, pelo fato dos retângulos se encontrarem abaixo da curva, uma aproximação com, por exemplo, quatro segmentos, pode ser "grosseira" a tal ponto que resulte um valor menor que 1 , não sendo suficiente portanto para comprovar nossa afirmação.
} 


$$
\begin{aligned}
& \left(\frac{1}{4} \cdot 1\right)+\left(\frac{1}{4} \cdot \frac{4}{5}\right)+\left(\frac{1}{4} \cdot \frac{2}{3}\right)+\left(\frac{1}{4} \cdot \frac{4}{7}\right)+\left(\frac{1}{4} \cdot \frac{4}{9}\right)+\left(\frac{1}{4} \cdot \frac{2}{5}\right)+\left(\frac{1}{4} \cdot \frac{4}{1}\right)+\left(\frac{1}{4} \cdot \frac{1}{3}\right)= \\
& =\frac{1}{4}+\frac{1}{5}+\frac{1}{6}+\frac{1}{7}+\frac{1}{8}+\frac{1}{9}+\frac{1}{10}+\frac{1}{11}+\frac{1}{12} \cong 1,02 .
\end{aligned}
$$

Logo,

$$
\operatorname{LOG}(3)>1,02>1
$$

Ora, por (6.1), (6.2) e da desigualdade $0,76<1<1,02$ podemos concluir que: $L O G(2)<$ $L O G(\alpha)<L O G(3)$ e por ser uma função crescente, afirmamos que: $2<\alpha<3$ para $\alpha$ tal que $\operatorname{LOG}(\alpha)=1$.

Vamos agora mostrar, de fato, que o valor real $\alpha$ tal que $\operatorname{LOG}(\alpha)=1$, é realmente o número irracional $e$.

Para isso, procederemos da seguinte forma para encontrar um número maior do que 1 cujo logaritmo resulte 1 .

Considere no eixo das abscissas a seguinte sequência em que $n$ será um número natural pré-fixado:

$$
a_{0}=1, a_{1}=\left(1+\frac{1}{n}\right), a_{2}=\left(1+\frac{1}{n}\right)^{2}, a_{3}=\left(1+\frac{1}{n}\right)^{3}, \ldots, a_{k}=\left(1+\frac{1}{n}\right)^{k}, \ldots
$$

Note que essa sequência é uma progressão geométrica cujo primeiro termo é $a_{0}=1$ e a razão é $q=\left(1+\frac{1}{n}\right)$. Vamos calcular o valor de $L O G\left(a_{n}\right)$ utilizando, para tal, a soma das áreas $A_{1}, A_{2}, \ldots, A_{n}, \ldots$

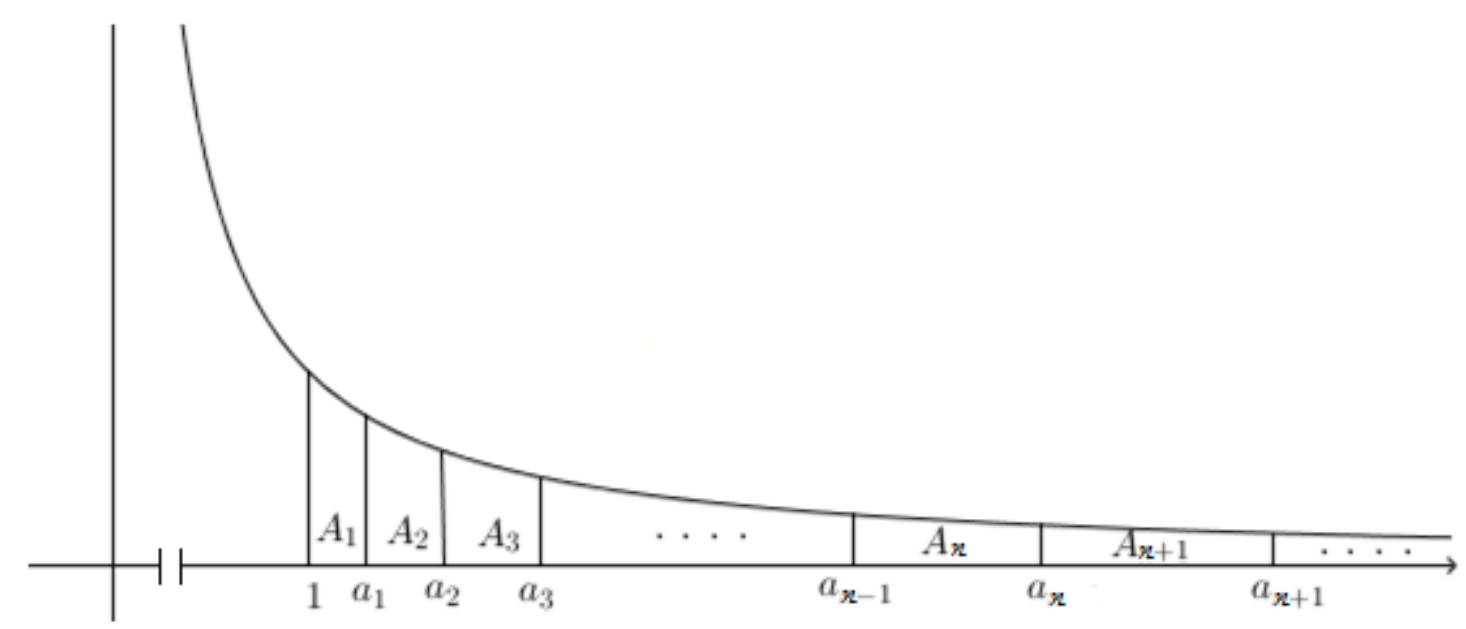

Figura 6.3: Subdivisão com valor das áreas igual a uma constante.

Ora, já vimos que a área de qualquer faixa está compreendida entre a soma de um número finito de retângulos inscritos e a soma de um número finito de retângulos circunscritos à 
faixa. Desse modo, para estimar o valor de $\operatorname{LOG}\left(a_{n}\right)$ utilizaremos a subdivisão do eixo das abscissas fornecido pelos pontos da PG descrita anteriormente. A partir desses pontos, tomemos $n$ retângulos inscritos e circunscritos à curva como mostra a figura $6.4, L O G\left(a_{n}\right)$ será estimado pela soma desses $n$ retângulos definidos.

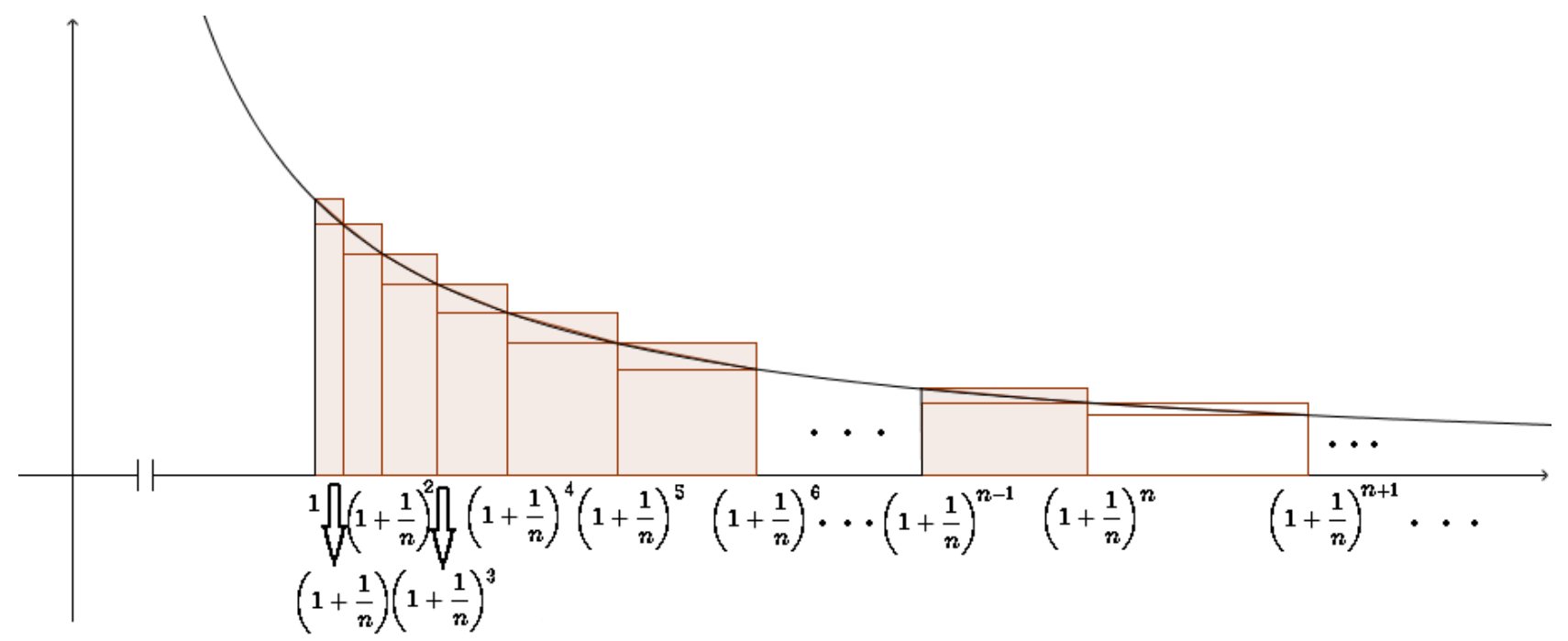

Figura 6.4: Subdivisão com valor das áreas igual a uma constante e abscissas em P.G.

Vamos então chamar as áreas dos retângulos inscritos de $r_{i}$ e as dos retângulos circunscritos de $R_{i}$ para todo $i=1,2,3, \ldots, n$.

O primeiro ponto interessante a notar é que as áreas de quaisquer dois retângulos inscritos serão iguais, assim como quaisquer dois retângulos circunscritos ${ }^{2}$.

Note que a base (que chamaremos de $c_{i}$ ) para qualquer retângulo de área $r_{i}$ será:

$c_{i}=\left(a_{i}-a_{i-1}\right)=\left(1+\frac{1}{n}\right)^{i}-\left(1+\frac{1}{n}\right)^{i-1}=\left(1+\frac{1}{n}\right)^{i-1}\left[\left(1+\frac{1}{n}\right)-1\right]=\left(1+\frac{1}{n}\right)^{i-1}\left(\frac{1}{n}\right)$.

E sua altura $\left(h_{i}\right)$ será $\frac{1}{a_{i}}=\left(1+\frac{1}{n}\right)^{-i}$.

Portanto, a área $r_{i}$ pode ser escrita por:

$$
r_{i}=c_{i} \cdot h_{i}=\left(a_{i}-a_{i-1}\right) \cdot \frac{1}{a_{i}}=\left(1+\frac{1}{n}\right)^{i-1}\left(\frac{1}{n}\right)\left(1+\frac{1}{n}\right)^{-i}=\left(1+\frac{1}{n}\right)^{-1}\left(\frac{1}{n}\right)=\frac{1}{n+1} .
$$

Por outro lado, para qualquer retângulo de área $R_{i}$, teremos a mesma base, ou seja, $\left(a_{i}-a_{i-1}\right)$, porém sua altura $\left(h_{i}\right)$ será $\frac{1}{a_{i-1}}$ e, portanto, sua área:

$$
R_{i}=c_{i} \cdot h_{i}=\left(a_{i}-a_{i-1}\right) \cdot \frac{1}{a_{i-1}}=\left(1+\frac{1}{n}\right)^{i-1}\left(\frac{1}{n}\right)\left(1+\frac{1}{n}\right)^{1-i}=\left(1+\frac{1}{n}\right)^{0}\left(\frac{1}{n}\right)=\frac{1}{n} .
$$

Em resumo, temos que para todo $i=1,2,3, \ldots, n$, as áreas dos retângulos inscritos e cir-

\footnotetext{
${ }^{2}$ Isso pode facilmente ser justificado se lembrarmos a Propriedade Fundamental demonstrada em 5.1, mas optamos por refazer os cálculos a fim de poupar esforço ao leitor.
} 
cunscritos à curva serão respectivamente:

$$
r_{i}=\frac{1}{n+1} \text { e } R_{i}=\frac{1}{n}
$$

Também, enquanto os pontos na abscissas crescem em PG, a soma das áreas dos retângulos inscritos crescem em acordo com a PA $\left(\frac{1}{n+1}, \frac{2}{n+1}, \frac{3}{n+1}, \ldots, \frac{n}{n+1}\right)$ e a soma das áreas dos retângulos circunscritos crescem em acordo com a PA $\left(\frac{1}{n}, \frac{2}{n}, \frac{3}{n}, \ldots, \frac{n}{n}\right)$.

No início da seção, estávamos buscando um valor de abscissa que resultasse valor de área 1 , ou em outros termos, $\operatorname{LOG}\left(a_{n}\right)=1$. Desse modo, qualquer que seja o valor escolhido para $n$, serão necessários $n$ retângulos $R_{i}$ para que se obtenha uma "escada" com área igual a 1 , uma vez que, $n \cdot \frac{1}{n}=1$.

Isso implica que o valor de abscissa procurado é $a_{n}=\left(1+\frac{1}{n}\right)^{n}$ e portanto

$$
\operatorname{LOG}\left(a_{n}\right)=A_{1}+A_{2}+\ldots+A_{n}<R_{1}+R_{2}+\ldots+R_{n}=n \cdot R_{i}=n \cdot \frac{1}{n}=1 .
$$

Já para o caso dos retângulos inscritos $r_{i}$, tomando $n$ retângulos obteremos como soma:

$$
r_{1}+r_{2}+\ldots+r_{n}=n \cdot r_{i}=n \cdot \frac{1}{n+1}=\frac{n}{n+1}<1 .
$$

A partir de todas essas informações, podemos concluir: para $i=1,2,3, \ldots, n, 0<r_{i}<A_{i}<$ $R_{i}$ e, portanto,

$$
0<\sum_{i=1}^{n} r_{i}<\sum_{i=1}^{n} A_{i}<\sum_{i=1}^{n} R_{i}
$$

ou ainda

$$
0<\frac{n}{n+1}<\sum_{i=1}^{n} A_{i}<1
$$

Se tomarmos o limite das desigualdades quando $n$ tende para $\infty$, obtemos:

$$
1=\lim _{n \rightarrow \infty} \frac{n}{n+1}<\lim _{n \rightarrow \infty} \sum_{i=1}^{n} A_{i} \leq \lim _{n \rightarrow \infty} 1=1
$$

Ou seja, pelo teorema do confronto, concluímos que:

$$
\lim _{n \rightarrow \infty} \sum_{i=1}^{n} A_{i}=1 .
$$

Mas como vimos anteriormente, a área $A_{n}$ é delimitada, à direita, pela reta:

$$
x=a_{n}=\left(1+\frac{1}{n}\right)^{n}
$$


Então o valor $x$ que estamos procurando é $\lim _{n \rightarrow \infty}\left(1+\frac{1}{n}\right)^{n}$.

Recapitulando, temos o ramo positivo da curva $x y=1$ em um par de eixos cartesianos $x, y$. Delimitando a área em questão, temos a reta $y=0$, a curva já mencionada $x y=1 \mathrm{e}$ verticalmente pelas retas $x=1$ e $x=a_{n}$.

Tomando a área limite, ou seja, $\lim _{n \rightarrow \infty}=\sum_{i=1}^{n} A_{i}=1$, ela será delimitada à direita por $x=$ $\lim _{n \rightarrow \infty} a_{n}=\lim _{n \rightarrow \infty}\left(1+\frac{1}{n}\right)^{n}$. Note que por esse limite expressar o valor da abscissa tal que $H_{1}^{\alpha}=L O G(\alpha)$, é intuitivamente "natural" que tal limite exista pela continuidade da função $f(x)=H_{1}^{x}$.

\subsection{Limite exponencial fundamental}

Vamos definir a função $f(n)=\left(1+\frac{1}{n}\right)^{n}$ com domínio em $\mathbb{N}^{*}$ e vamos mostrar que:

I. $f$ é uma função crescente no domínio;

II. $2 \leq f(n)<3$;

III. Existe o $\lim _{n \rightarrow \infty}\left(1+\frac{1}{n}\right)^{n}$.

Demonstração de I. Observe que desenvolvendo $\left(1+\frac{1}{n}\right)^{n}$ pelo Binômio de Newton obtemos:

$$
\begin{gathered}
f(n)=\left(1+\frac{1}{n}\right)^{n}=1+\left(\begin{array}{l}
n \\
1
\end{array}\right) \cdot \frac{1}{n}+\left(\begin{array}{l}
n \\
2
\end{array}\right) \cdot \frac{1}{n^{2}}+\left(\begin{array}{l}
n \\
3
\end{array}\right) \cdot \frac{1}{n^{3}}+\ldots+\left(\begin{array}{l}
n \\
n
\end{array}\right) \cdot \frac{1}{n^{n}} \\
\left(1+\frac{1}{n}\right)^{n}=1+\frac{n}{1 !} \cdot \frac{1}{n}+\frac{n(n-1)}{2 !} \cdot \frac{1}{n^{2}}+\frac{n(n-1)(n-2)}{3 !} \cdot \frac{1}{n^{3}}+\ldots+\frac{n(n-1) \ldots 2 \cdot 1}{n !} \cdot \frac{1}{n^{n}}= \\
=2+\frac{1}{2 !}\left(1-\frac{1}{n}\right)+\frac{1}{3 !}\left(1-\frac{1}{n}\right)\left(1-\frac{2}{n}\right)+\ldots+\frac{1}{n !}\left(1-\frac{1}{n}\right)\left(1-\frac{2}{n}\right) \ldots\left(1-\frac{n-1}{n}\right) .
\end{gathered}
$$

Substituindo os produtos por:

$$
\left(1-\frac{1}{n}\right)\left(1-\frac{2}{n}\right)\left(1-\frac{3}{n}\right) \ldots\left(1-\frac{i-1}{n}\right)\left(1-\frac{i}{n}\right)=\prod_{j=1}^{i}\left(1-\frac{j}{n}\right)
$$

obtemos

$$
f(n)=2+\sum_{i=1}^{n-1} \frac{1}{(i+1) !} \prod_{j=1}^{i}\left(1-\frac{j}{n}\right) .
$$

Tomando agora essa mesma expressão, mas para $(n+1)$, temos:

$$
f(n+1)=2+\sum_{i=1}^{n} \frac{1}{(i+1) !} \prod_{j=1}^{i}\left(1-\frac{j}{n+1}\right)
$$


Vamos então mostrar que $f(n+1)>f(n)$, ou seja;

$$
\begin{array}{r}
2+\sum_{i=1}^{n} \frac{1}{(i+1) !} \prod_{j=1}^{i}\left(1-\frac{j}{n+1}\right)>2+\sum_{i=1}^{n-1} \frac{1}{(i+1) !} \prod_{j=1}^{i}\left(1-\frac{j}{n}\right) \\
\sum_{i=1}^{n} \frac{1}{(i+1) !} \prod_{j=1}^{i}\left(1-\frac{j}{n+1}\right)>\sum_{i=1}^{n-1} \frac{1}{(i+1) !} \prod_{j=1}^{i}\left(1-\frac{j}{n}\right) \\
\frac{1}{(n+1) !} \prod_{j=1}^{n}\left(1-\frac{j}{n+1}\right)+\sum_{i=1}^{n-1} \frac{1}{(i+1) !} \prod_{j=1}^{i}\left(1-\frac{j}{n+1}\right)>\sum_{i=1}^{n-1} \frac{1}{(i+1) !} \prod_{j=1}^{i}\left(1-\frac{j}{n}\right)
\end{array}
$$

Para tal, vamos dividir a demonstração em duas etapas:

(i) $\sum_{i=1}^{n-1} \frac{1}{(i+1) !} \prod_{j=1}^{i}\left(1-\frac{j}{n+1}\right)>\sum_{i=1}^{n-1} \frac{1}{(i+1) !} \prod_{j=1}^{i}\left(1-\frac{j}{n}\right)$;

(ii) $\frac{1}{(n+1) !} \prod_{j=1}^{i}\left(1-\frac{j}{n+1}\right)>0$.

Prova de (i). Perceba que para todo $i, j \in \mathbb{N}$ tal que $1 \leq j \leq i \leq n-1$, temos

$$
\frac{j}{n+1}<\frac{j}{n} \Rightarrow-\frac{j}{n+1}>-\frac{j}{n} \Rightarrow 1-\frac{j}{n+1}>1-\frac{j}{n} \Rightarrow \prod_{j=1}^{i}\left(1-\frac{j}{n+1}\right)>\prod_{j=1}^{i}\left(1-\frac{j}{n}\right) .
$$

Note que para todo $i=1,2, \ldots,(n-1)$ vale $\frac{1}{(i+1) !}>0$, portanto

$$
\frac{1}{(i+1) !} \prod_{j=1}^{i}\left(1-\frac{j}{n+1}\right)>\frac{1}{(i+1) !} \prod_{j=1}^{i}\left(1-\frac{j}{n}\right)
$$

e como a desigualdade é válida para todas as $(n-1)$ parcelas, concluímos por fim que:

$$
\sum_{i=1}^{n-1} \frac{1}{(i+1) !} \prod_{j=1}^{i}\left(1-\frac{j}{n+1}\right)>\sum_{i=1}^{n-1} \frac{1}{(i+1) !} \prod_{j=1}^{i}\left(1-\frac{j}{n}\right)
$$

Prova de (ii).

$$
\frac{1}{(n+1) !} \prod_{j=1}^{n}\left(1-\frac{j}{n+1}\right)=\frac{1}{(n+1) !} \prod_{j=1}^{n}\left(\frac{n+1-j}{n+1}\right)
$$

que pode ser escrito como

$$
\frac{1}{(n+1) !} \cdot \frac{1}{(n+1)^{n}} \prod_{j=1}^{n}(n+1-j)=\frac{1}{(n+1) !} \cdot \frac{1}{(n+1)^{n}} \cdot n !
$$


e por sua vez, simplificando

$$
\frac{n !}{(n+1) \cdot n ! \cdot(n+1)^{n}}=\frac{1}{(n+1)^{n+1}}
$$

que é positivos, pois $n \in \mathbb{N}^{*}$. Portanto, $f$ é uma função crescente em $\mathbb{N}^{*}$.

Demonstração de II. Sendo $f$ uma função crescente com domínio em $\mathbb{N}^{*}$, ela assumirá seu menor valor em $n=1$, ou seja, $f(1)=\left(1+\frac{1}{1}\right)^{1}=2^{1}=2$, desse modo, $f(n) \geq 2$ para todo $n \in \mathbb{N}^{*}$.

Vamos então mostrar que $f(n)<3$ para todo $n \in \mathbb{N}^{*}$. Mas antes, observe o seguinte resultado preliminar que provaremos por indução finita sobre i:

Lema 6.2.1. Para todo $i \in \mathbb{N}^{*}$ vale a desigualdade $(1+i) ! \geq 2^{i}$.

Demonstração. Tomando $i=1$, temos que $(1+1) ! \geq 2^{1} \Rightarrow 2 \geq 2$. Suponha então válido o resultado para $i=n$, obtemos $(1+n) ! \geq 2^{n}$. Queremos provar que $[1+(n+1)]$ ! $\geq 2^{n+1}$, note que:

$$
[1+(n+1)] !=[1+(n+1)] \cdot[(1+n) !]
$$

e por hipótese de indução,

$$
[(1+n) !] \cdot[1+(n+1)] \geq 2^{n} \cdot[1+(n+1)]
$$

$\log 0$

$$
[1+(n+1)] ! \geq 2^{n} \cdot(2+n)
$$

de onde

$$
[1+(n+1)] ! \geq\left(2^{n+1}+n 2^{n}\right)>2^{n+1}
$$

e finalmente temos

$$
[1+(n+1)] ! \geq 2^{n+1}
$$

Logo, nosso resultado é válido para todo $i$ natural.

Note agora que, para todo $i, j \in \mathbb{N}$, se $1 \leq j \leq i \leq n-1$ valem:

$$
1-\frac{j}{n}<1 \Rightarrow \prod_{j=1}^{i}\left(1-\frac{j}{n}\right)<1
$$

e também

$$
2^{i} \leq(1+i) ! \quad \Rightarrow \quad \frac{1}{(1+i) !} \leq \frac{1}{2^{i}} .
$$

De sorte que $\frac{1}{(1+i) !} \prod_{j=1}^{i}\left(1-\frac{j}{n}\right)<\frac{1}{2^{i}}$ irá valer para todas as $(n-1)$ parcelas, então:

$$
\sum_{i=1}^{n-1} \frac{1}{(i+1) !} \prod_{j=1}^{i}\left(1-\frac{j}{n}\right)<\sum_{i=1}^{n-1} \frac{1}{2^{i}}
$$


Por outro lado, $\sum_{i=1}^{n-1} \frac{1}{2^{i}}$ é a soma finita dos termos de uma Progressão Geométrica de primeiro termo $a_{1}$ e razão $q$ iguais a $\frac{1}{2}$ com soma dada por $S_{n}=\frac{a_{1}\left(1-q^{n}\right)}{1-q}$, portanto

$$
\sum_{i=1}^{n-1} \frac{1}{2^{i}}=\frac{1}{2}+\frac{1}{2^{2}}+\frac{1}{2^{3}}+\ldots+\frac{1}{2^{n-2}}+\frac{1}{2^{n-1}}=\frac{\frac{1}{2}\left(1-\frac{1}{2^{n-1}}\right)}{1-\frac{1}{2}}=1-\frac{1}{2^{n-1}}<1 .
$$

$\operatorname{logo}$ de

$$
\sum_{i=1}^{n-1} \frac{1}{(i+1) !} \prod_{j=1}^{i}\left(1-\frac{j}{n}\right)<\sum_{i=1}^{n-1} \frac{1}{2^{i}}<1 \Rightarrow \sum_{i=1}^{n-1} \frac{1}{(i+1) !} \prod_{j=1}^{i}\left(1-\frac{j}{n}\right)<1 .
$$

E portanto

$$
2+\sum_{i=1}^{n-1} \frac{1}{(i+1) !} \prod_{j=1}^{i}\left(1-\frac{j}{n}\right)<3 \Rightarrow f(n)<3
$$

Demonstração de III. Já mostramos ser $f$ crescente e limitada em $\mathbb{N}^{*}$.

Tome agora $\mathscr{L}=\sup \left\{f(n) \mid n \in \mathbb{N}^{*}\right\}$ com $2 \leq \mathscr{L}<3$ de modo que:

(i) $f(n)<\mathscr{L}$ para todo $n \in \mathbb{N}^{*}$;

(ii) Se $f(n)<\mathscr{K}$ para todo $n \in \mathbb{N}^{*}$, então obrigatoriamente $\mathscr{L} \leq \mathscr{K}$.

Mostremos, portanto que $\lim _{n \rightarrow+\infty} f(n)=\mathscr{L}$.

Note que para qualquer $\varepsilon>0$, sempre vai existir algum $m \in \mathbb{N} *$ tal que $f(m)>\mathscr{L}-\varepsilon$.

Temos que para todo $\varepsilon>0$ e $n>m$ vale: $\mathscr{L}-\varepsilon<f(m)<f(n)<\mathscr{L}<\mathscr{L}+\varepsilon$ ou ainda, $\mathscr{L}-\varepsilon<f(n)<\mathscr{L}+\varepsilon$ e portanto $-\varepsilon<f(n)-\mathscr{L}<\varepsilon$. Isto é, para todo $\varepsilon>0$, existe $m>0$ tal que para todo $n>m$ vale que $|f(n)-\mathscr{L}|<\varepsilon$.

Logo, podemos concluir de I, II e III que $f(n)=\left(1+\frac{1}{n}\right)^{n} \operatorname{com} n \in \mathbb{N}^{*}$ converge para $\mathscr{L}$.

Ele será, portanto o limite, o qual é denotado por e. Ou seja, convencionamos que o limite dessa função quando que $n \rightarrow+\infty$ é: $\lim _{n \rightarrow+\infty}\left(1+\frac{1}{n}\right)^{n}=e$.

Estamos agora em condições de provar três teoremas muito importantes que estenderão o domínio do exposto acima para $\mathbb{R}$.

Teorema 6.2.1. Seja a função $f(x)=\left(1+\frac{1}{x}\right)^{x}$ definida em $\{x \in \mathbb{R}$ tal que $x>0\}$, então temos que $\lim _{x \rightarrow+\infty}\left(1+\frac{1}{x}\right)^{x}=e$.

Demonstração. Sejam $n$ e $n+1$ dois naturais consecutivos e um $x$ real qualquer tal que $n \leq x<n+1$. Assim,

$$
n \leq x<n+1 \Rightarrow \frac{1}{n+1}<\frac{1}{x} \leq \frac{1}{n} \Rightarrow 1+\frac{1}{n+1}<1+\frac{1}{x} \leq 1+\frac{1}{n} .
$$


Levando em consideração o fato de $n \leq x<n+1$, obtemos:

$$
\left(1+\frac{1}{n+1}\right)^{n}<\left(1+\frac{1}{x}\right)^{x} \leq\left(1+\frac{1}{n}\right)^{n+1}
$$

Tomando então o limite das expressões, temos

$$
\begin{aligned}
\lim _{n \rightarrow+\infty}\left(1+\frac{1}{n+1}\right)^{n}<\lim _{x \rightarrow+\infty}\left(1+\frac{1}{x}\right)^{x} \leq \lim _{n \rightarrow+\infty}\left(1+\frac{1}{n}\right)^{n+1} \\
\lim _{n \rightarrow+\infty} \frac{\left(1+\frac{1}{n+1}\right)^{n+1}}{\left(1+\frac{1}{n+1}\right)}<\lim _{x \rightarrow+\infty}\left(1+\frac{1}{x}\right)^{x} \leq \lim _{n \rightarrow+\infty}\left(1+\frac{1}{n}\right)^{n} \cdot\left(1+\frac{1}{n}\right) \\
\frac{\lim _{n \rightarrow+\infty}\left(1+\frac{1}{n+1}\right)^{n+1}}{\left(1+\frac{1}{n+1}\right)}<\lim _{x \rightarrow+\infty}\left(1+\frac{1}{x}\right)^{x} \leq \lim _{n \rightarrow+\infty}\left(1+\frac{1}{n}\right)^{n} \cdot \lim _{n \rightarrow+\infty}\left(1+\frac{1}{n}\right) \\
\frac{e}{1}<\lim _{x \rightarrow+\infty}\left(1+\frac{1}{x}\right)^{x} \leq e \cdot 1 \\
e<\lim _{x \rightarrow+\infty}\left(1+\frac{1}{x}\right)^{x} \leq e .
\end{aligned}
$$

Nesse ponto, devemos nos lembrar do famoso Teorema do Confronto visto em qualquer curso de Cálculo 1, para concluir que:

$$
\lim _{x \rightarrow+\infty}\left(1+\frac{1}{x}\right)^{x}=e
$$

Teorema 6.2.2. Seja a função $f(x)=\left(1+\frac{1}{x}\right)^{x}$ definida em $\{x \in \mathbb{R}$ tal que $x<-1\}$, então temos que $\lim _{x \rightarrow-\infty}\left(1+\frac{1}{x}\right)^{x}=e$.

Demonstração. Tome $x=-(w+1)$, primeiro notemos que se $x \rightarrow-\infty$ então $w \rightarrow+\infty$, do 
qual

$$
\begin{aligned}
& \lim _{x \rightarrow-\infty}\left(1+\frac{1}{x}\right)^{x}=\lim _{w \rightarrow+\infty}\left(1-\frac{1}{w+1}\right)^{-(w+1)}=\lim _{w \rightarrow+\infty}\left(\frac{w}{w+1}\right)^{-(w+1)}=\lim _{w \rightarrow+\infty}\left(\frac{w+1}{w}\right)^{w+1}= \\
& =\lim _{w \rightarrow+\infty}\left(1+\frac{1}{w}\right)^{w+1}=\lim _{w \rightarrow+\infty}\left(1+\frac{1}{w}\right)^{w} \cdot\left(1+\frac{1}{w}\right)=\lim _{w \rightarrow+\infty}\left(1+\frac{1}{w}\right)^{w} \cdot \lim _{w \rightarrow+\infty}\left(1+\frac{1}{w}\right)= \\
& =e \cdot 1=e .
\end{aligned}
$$

Teorema 6.2.3. Seja a função $f(x)=(1+x)^{\frac{1}{x}}$ definida em $\{x \in \mathbb{R}$ tal que $-1<x<1$ com $x \neq 0\}$, então $\lim _{x \rightarrow 0}(1+x)^{\frac{1}{x}}=e$.

Demonstração. Tome $x=\frac{1}{y}$, obtemos então $(1+x)^{\frac{1}{x}}=\left(1+\frac{1}{y}\right)^{y}$. Perceba agora que se:

$$
\begin{aligned}
& x \rightarrow 0^{+} \quad \Rightarrow \quad y \rightarrow+\infty \\
& x \rightarrow 0^{-} \quad \Rightarrow \quad y \rightarrow-\infty
\end{aligned}
$$

do qual obtemos

$$
\begin{aligned}
& \lim _{x \rightarrow 0^{+}}(1+x)^{\frac{1}{x}}=\lim _{y \rightarrow+\infty}\left(1+\frac{1}{y}\right)^{y}=e \\
& \lim _{x \rightarrow 0^{-}}(1+x)^{\frac{1}{x}}=\lim _{y \rightarrow-\infty}\left(1+\frac{1}{y}\right)^{y}=e
\end{aligned}
$$

Portanto, $\lim _{x \rightarrow 0}(1+x)^{\frac{1}{x}}=e$.

Uma vez apresentados todos esses fatos para o número $e$, e já sabendo que uma aproximação com duas casas decimais seria 2,72, é provável que em algum momento venha a surgir uma dúvida muito pertinente e nada óbvia, a saber: será possível representar esse valor (não apenas sua aproximação) em forma de uma fração irredutível? Em outras palavras, seria o número $e$ um número racional?

Teorema 6.2.4. Não é possível, representar o número e em forma de uma fração irredutivel, ou seja, e é um número irracional.

Euler, em 1737, provara a irracionalidade de ambos e e e (Maor, 2006, p. 247).

Façamos então a prova de que $e$ é um número irracional, mas antes lembremos a partir do binômio de Newton que:

$$
\left(1+\frac{1}{n}\right)^{n}=2+\frac{1}{2 !}\left(1-\frac{1}{n}\right)+\frac{1}{3 !}\left(1-\frac{1}{n}\right)\left(1-\frac{2}{n}\right)+\ldots+\frac{1}{n !}\left(1-\frac{1}{n}\right) \ldots\left(1-\frac{n-1}{n}\right)
$$


E também que existe $\lim _{n \rightarrow \infty}\left(1+\frac{1}{n}\right)^{n}=e$, de sorte que tal limite resultará em

$$
\begin{aligned}
& \lim _{n \rightarrow \infty} 2+\frac{1}{2 !}\left(1-\frac{1}{n}\right)+\frac{1}{3 !}\left(1-\frac{1}{n}\right)\left(1-\frac{2}{n}\right)+\frac{1}{4 !}\left(1-\frac{1}{n}\right)\left(1-\frac{2}{n}\right)\left(1-\frac{3}{n}\right)+\ldots= \\
& =2+\frac{1}{2 !}(1-0)+\frac{1}{3 !}(1-0)(1-0)+\frac{1}{4 !}(1-0)(1-0)(1-0)+\ldots= \\
& =2+\frac{1}{2 !}+\frac{1}{3 !}+\frac{1}{4 !}+\ldots=\sum_{n=0}^{\infty} \frac{1}{n !}=e .
\end{aligned}
$$

Esta série infinita foi descoberta por Newton em 1665, e pode ser obtida da expansão binomial de $\left(1+\frac{1}{n}\right)^{n}$, deixando $n \rightarrow \infty$. Ela converge muito rapidamente, devido ao aumento rápido dos valores dos fatoriais nos denominadores. Por exemplo, a soma dos primeiros onze termos (terminando com 1/10!) é 2,718281801; o valor real, aproximado para nove casas decimais é 2,718281828 (Maor, 2006, p. 196).

Suponha então que $e$ seja racional, ou seja, $e=\frac{p}{q}$, onde $p, q \in \mathbb{N}^{*} \operatorname{com} \operatorname{mdc}(p, q)=1$.

Desse modo, $\frac{p}{q}-\left(1+\frac{1}{1 !}+\frac{1}{2 !}+\ldots+\frac{1}{q !}\right)=\sum_{n=q+1}^{\infty} \frac{1}{n !}$.

Note que $\sum_{n=q+1}^{\infty} \frac{1}{n !}=\frac{1}{q !}\left(\frac{1}{(q+1)}+\frac{1}{(q+1)(q+2)}+\frac{1}{(q+1)(q+2)(q+3)}+\ldots\right)$ do qual $\frac{1}{q !}\left(\frac{1}{(q+1)}+\frac{1}{(q+1)(q+2)}+\frac{1}{(q+1)(q+2)(q+3)}+\ldots\right)<\frac{1}{q !}\left(\frac{1}{(q+1)}+\frac{1}{(q+1)^{2}}+\ldots\right)$.

Acima à direita da desigualdade, a expressão entre parênteses é a soma dos infinitos termos de uma Progressão Geométrica com primeiro termo $a_{1}$ e razão $r$ iguais a $\frac{1}{(q+1)}$ com soma dada por $S_{n}=\frac{a_{1}}{1-r}$. Obtemos então que $\sum_{n=q+1}^{\infty} \frac{1}{n !}<\frac{1}{q !} \cdot \frac{1}{q}$, ou seja, as seguintes afirmações são verdadeiras:

$$
\begin{gathered}
\frac{p}{q}-\left(1+\frac{1}{1 !}+\frac{1}{2 !}+\ldots+\frac{1}{q !}\right)=\sum_{n=q+1}^{\infty} \frac{1}{n !}<\frac{1}{q !} \cdot \frac{1}{q} \\
0<\frac{p}{q}-\left(1+\frac{1}{1 !}+\frac{1}{2 !}+\ldots+\frac{1}{q !}\right)<\frac{1}{q !} \cdot \frac{1}{q} \\
\left(1+\frac{1}{1 !}+\frac{1}{2 !}+\ldots+\frac{1}{q !}\right)<\frac{p}{q}<\left(1+\frac{1}{1 !}+\frac{1}{2 !}+\ldots+\frac{1}{q !}\right)+\frac{1}{q !} \cdot \frac{1}{q} \\
q !\left(1+\frac{1}{1 !}+\frac{1}{2 !}+\ldots+\frac{1}{q !}\right)<p(q-1) !<q !\left(1+\frac{1}{1 !}+\frac{1}{2 !}+\ldots+\frac{1}{q !}\right)+\frac{1}{q} .
\end{gathered}
$$

Perceba que $q !\left(1+\frac{1}{1 !}+\frac{1}{2 !}+\ldots+\frac{1}{q !}\right)$ é inteiro, pois todos os denominadores se cancelarão após a distributiva. A fim de facilitar a notação, façamos $q !\left(1+\frac{1}{1 !}+\frac{1}{2 !}+\ldots+\frac{1}{q !}\right)=S$, obtendo então $S<p(q-1) !<S+\frac{1}{q}$. 
Note também que $\frac{1}{q}<1$ para todo $q \in \mathbb{N}^{*}$ de sorte que $S<p(q-1)$ ! $<S+1$.

Ora, conseguimos dessa forma exibir um inteiro $p(q-1)$ ! que jaz entre dois inteiros consecutivos. Um absurdo, portanto $e$ é irracional. 


\section{Capítulo 7}

\section{Logaritmos e exponenciais}

Uma vez que definimos uma função $L O G: \mathbb{R}_{+}^{*} \rightarrow \mathbb{R}$ como $L O G(x)=y$ pudemos concluir que $L O G(e)=1$. Baseando-nos na definição usualmente utilizada nos livros didáticos, em que, a base de um logaritmo corresponde ao valor $x$ para o qual a função resulta 1, inferimos que nosso logaritmo possui base $e$, também conhecido como logaritmo natural. Passaremos portanto, a adotar a partir de agora a notação $\ln (x)$ para a nossa função $L O G(x)$ definida pelas áreas das faixas de hipérbole.

A partir das propriedades demonstradas na seção 5.3, podemos encontrar os valores de $\ln (x)$ para todo $x$ da forma $e^{n}$, com $n$ número inteiro.

Com efeito, sabemos que: $\ln (1)=0, \ln (e)=1, \ln \left(e^{2}\right)=2 \cdot \ln (e)=2, \ldots, \ln \left(e^{n}\right)=n \cdot \ln (e)=$ $n$ e ainda, $\ln \left(e^{-1}\right)=-1 \cdot \ln (e)=-1, \ln \left(e^{-2}\right)=-2 \cdot \ln (e)=-2, \ldots, \ln \left(e^{-n}\right)=-n \cdot \ln (e)=$ $-n$.

Sabemos também que $\ln (x)$ é uma função estritamente crescente no seu domínio. Assim podemos, a partir dessas informações esboçar o gráfico da função logaritmo natural, como mostra a figura a seguir.

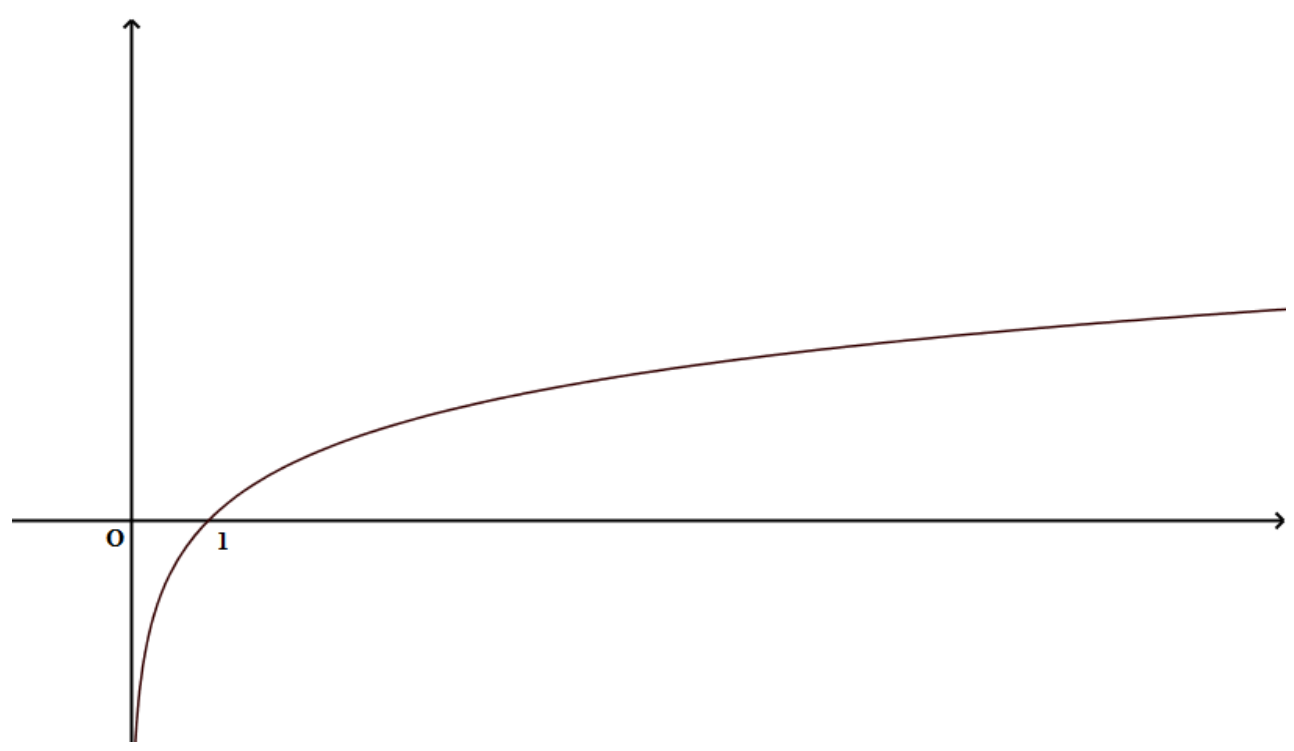

Figura 7.1: Gráfico função lnx.

Mostramos também na seção 5.3, que a função por nós definida é injetora (P1) e sobrejetora 
(Teorema 5.3.1), desse modo, podemos afirmar que ela possui uma inversa $l n^{-1}$ para a qual utilizaremos a notação $\ln ^{-1}(x)=\exp (x)$, ou seja, por definição temos que:

$$
\begin{gathered}
\exp : \mathbb{R} \rightarrow \mathbb{R}_{+}^{*} \\
y=\exp (x) \quad \Leftrightarrow \quad x=\ln (y)
\end{gathered}
$$

Por outro lado, sabemos que o gráfico de uma função inversa a outra é simétrico ao gráfico da função inicial em relação à reta de equação $y=x$ (por simetria de reflexão). Assim também podemos esboçar o gráfico de $\exp (x)$ obtendo a seguinte figura:

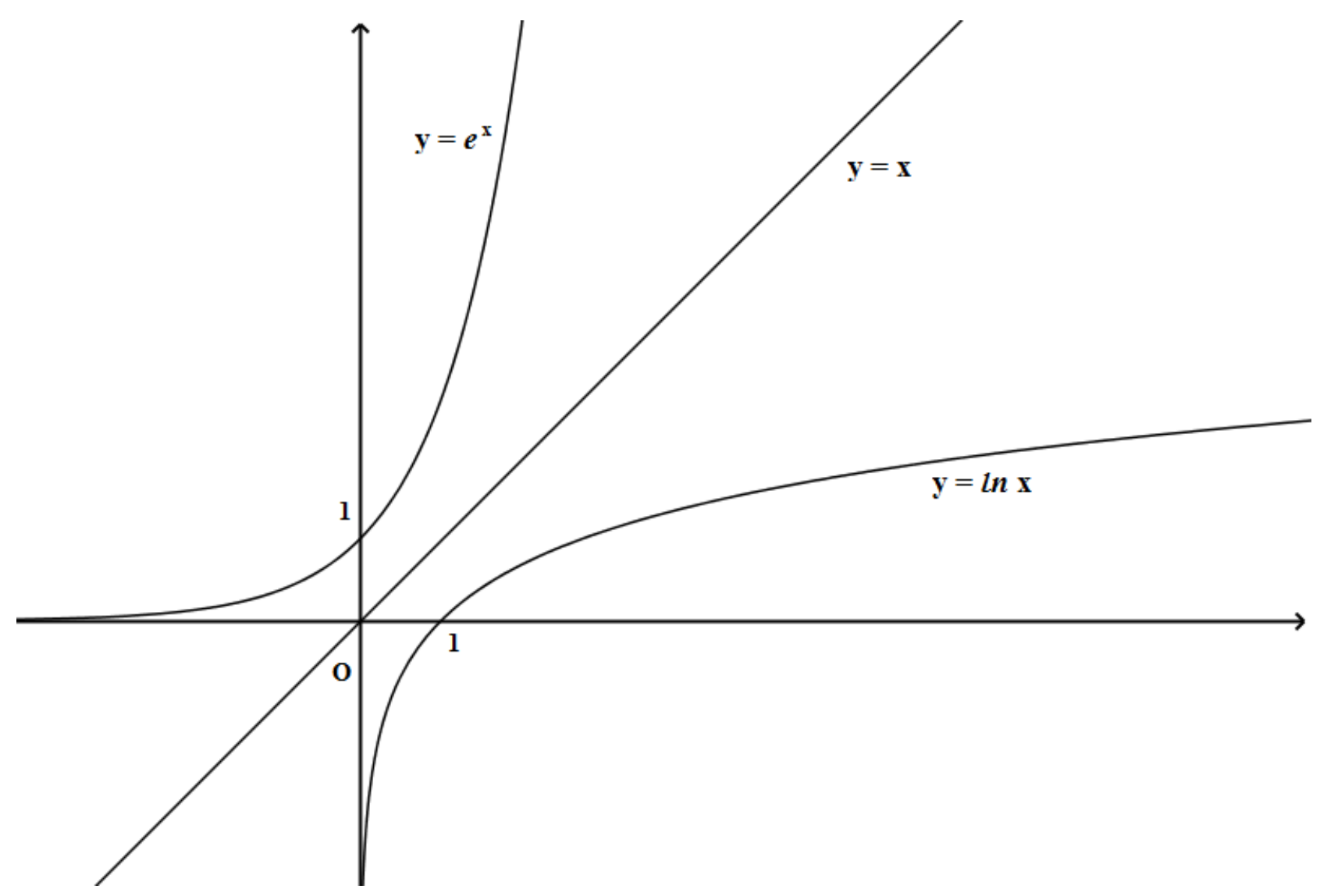

Figura 7.2: Gráfico Inversa.

Vamos provar algumas propriedades para essa função, observando antes que, do ponto de vista geométrico, podemos interpretar $y=\exp (x)$ como o valor da abscissa que devemos tomar para que a área $H_{1}^{y}=x$, se $y>1$ e $H_{1}^{y}=-x$, se $0<y<1$.

P8) Para todo $x, y \in \mathbb{R}$ e $a, b \in \mathbb{R}_{+}^{*}$ vale $\exp (x+y)=\exp (x) \cdot \exp (y)$.

Prova: $\operatorname{Sejam} \exp (x)=a \Leftrightarrow x=\ln (a)$ e $\exp (y)=(b) \Leftrightarrow y=\ln (b)$. Nessas condições temos que

$$
\exp (x) \cdot \exp (y)=a b
$$

Por outro lado, das equivalências $x+y=\ln (a)+\ln (b)=\ln (a b) \Rightarrow x+y=\ln (a b)$. 
Logo, por definição,

$$
\exp (x+y)=a b
$$

Por (7.1) e (7.2) concluímos que $\exp (x+y)=\exp (x) \cdot \exp (y)$.

P9) Para todo $x, y \in \mathbb{R}$ e $a, b \in \mathbb{R}_{+}^{*}$ vale $\exp (x-y)=\frac{\exp (x)}{\exp (y)}$.

Prova: $\operatorname{Sejam} \exp (x)=a$ e $\exp (y)=b$, o que equivale, por definição a $x=\ln (a)$ e $y=\ln (b)$. Nestas condições temos que:

$$
\frac{\exp (x)}{\exp (y)}=\frac{a}{b}
$$

Por outro lado, $x-y=\ln (a)-\ln (b)=\ln \left(\frac{a}{b}\right) \Rightarrow x-y=\ln \left(\frac{a}{b}\right)$.

Assim, por definição, vale então que

$$
\exp (x-y)=\frac{a}{b}
$$

Por (7.3) e (7.4) concluímos que $\exp (x-y)=\frac{\exp (x)}{\exp (y)}$.

P10) A função exp $: \mathbb{R} \rightarrow \mathbb{R}_{+}^{*}$ é crescente.

Sejam $x, y \in \mathbb{R}$ e $a, b \in \mathbb{R}_{+}^{*} \operatorname{com} x>y$, de modo que $a=\exp (x)$ e $b=\exp (y)$. Temos que $\exp (x)=a \Leftrightarrow x=\ln (a)$ e que $\exp (y)=b \Leftrightarrow y=\ln (b)$, portanto $x>y \Leftrightarrow \ln (a)>\ln (b)$.

Pelo fato da função $\ln$ ser crescente e injetora, podemos afirmar que $\ln (a)>\ln (b) \Leftrightarrow a>b$, ou seja, nas condições inicialmente dadas, vale que, $\exp (x)>\exp (y)$, ou seja, obtivemos a validade de:

$$
x>y \quad \Leftrightarrow \quad \exp (x)>\exp (y)
$$

P11) Vale sempre $\exp (0)=1$, pois partindo da definição $\exp (b)=y \Leftrightarrow b=\ln (y)$, obtemos a equivalência: $\ln (1)=0 \Leftrightarrow 1=\exp (0)$.

P12) Teremos sempre: $\exp (x)>0 \forall x \in \mathbb{R}, \exp (x)>1$ se $x>0$ e $\exp (x)<1$ se $x<0$.

De fato $\exp (x)>0$ para todo $x \in \mathbb{R}$ por definição, já que $\operatorname{Im}(\exp )=\operatorname{Dom}(\ln )$. Seja $x \in \mathbb{R}$ tal que $x>0$, por $\mathbf{P} \mathbf{1 0}$, temos que $\exp (x)>\exp (0)$.

Por outro lado, de $\mathbf{P 9}, \exp (0)=\exp (x-x)=\frac{\exp (x)}{\exp (x)}=1$, ou seja, $\exp (x)>1$. De modo análogo, para $0>x \Rightarrow \exp (0)>\exp (x)$, ou seja, $\exp (x)<\exp (0)=1$.

Note que, partindo das propriedades acima, não há dúvidas de que uma notação mais conveniente e usual para $\exp (x)$ seria $b^{x}$ uma vez que, exp atende às principais propriedades 
das funções exponenciais. Então a partir daqui, usaremos $b^{x}$ no lugar de $\exp (x)$. A pergunta natural que poderá surgir agora é: "A qual base $b$ especificamente, a função $\exp (x)$ corresponde?" A resposta se justifica facilmente partindo do seguinte fato: $\ln (e)=1 \Leftrightarrow e=\exp (1)$, ou seja, as duas notações equivalentes são:

$$
\exp (x)=e^{x}
$$

Perceba que essa última conclusão, em conjunto com P8, consolida de vez o fato de estarmos lidando com uma função exponencial de base $e$, como a que aprendemos habitualmente na escola. Entretanto, para continuar nosso estudo fazendo referência ao objeto primeiro de análise (logaritmo via área de faixas de hipérboles), usaremos a notação $e^{x}$ apenas quando a dificuldade técnica sobrepuser o ganho didático.

Notemos agora que, se tomarmos $\lim _{x \rightarrow 0}(1+k x)^{\frac{1}{x}}$, e fizermos a substituição $k x=u$ obtemos que $x=\frac{u}{k}$. Além disso, quando $x \rightarrow 0$, também $k x \rightarrow 0$ e, portanto:

$$
\lim _{u \rightarrow 0}(1+u)^{\frac{k}{u}}=\left[\lim _{u \rightarrow 0}(1+u)^{\frac{1}{u}}\right]^{k}=e^{k}
$$

como mostrado na seção 6.2 .

No teorema 6.2.3 também da seção 6.2 mostramos que os limites: $\lim _{x \rightarrow 0}(1+x)^{\frac{1}{x}}$ e $\lim _{x \rightarrow \infty}\left(1+\frac{1}{x}\right)^{x}$ são equivalentes. A partir disso, observemos que fazendo $x=\frac{1}{w}$ no limite $\lim _{x \rightarrow 0}(1+k x)^{\frac{1}{x}}$, quando $x \rightarrow 0$, teremos $w \rightarrow \infty$ resultando portanto $\lim _{w \rightarrow \infty}\left(1+\frac{k}{w}\right)^{w}=e^{k}$ em concordância com o esperado.

A partir do exposto, podemos dar um sentido mais claro à existência de um número que expresse o valor de $e^{x}$, mesmo quando $x$ for um número irracional. De fato do ponto de vista técnico, conseguimos aceitar sem grandes dificuldades uma operação com expoente irracional e uma base qualquer simplesmente ignorando os pormenores que a questão traz, porém, do ponto de vista didático, a tarefa pode não ser tão simples. Ao ensinar um conceito, é importante que ele próprio esteja claro ao locutor, e ai reside um grande problema ao tratar a exponenciação da maneira usual, pois não há uma justificativa aceitável para que um aluno do ensino básico realize tais operações (potência com expoente irracional). Em se tratando de base e expoente racionais, (não negativo para a base), contornamos o problema com a radiciação, porém uma operação que não se justifica, causa desconforto no momento de seu ensino. E é justamente nesta tentativa de justificar a operação que temos um ganho gigantesco com a abordagem das faixas de hipérbole, pois, uma vez que o valor numérico de uma determinada área pode ser um real qualquer, nada impede que se escolha um número irracional para a área, por exemplo, pode ganhar significado para o estudante a pergunta: Qual abscissa aproximada devo tomar para que a área de uma faixa seja 0,101001000100001 ou então $\pi$, ou ainda $\sqrt{2}$, enfim, qualquer irracional imaginável. 


\subsection{Limite exponencial fundamental via área da hipér- bole}

Ao pensar no estudante de ensino básico ou mesmo de início de graduação, (ainda que esses não sejam nosso público alvo), seria interessante oferecer argumentos menos técnicos, mas que fossem igualmente sólidos para convencer nosso leitor dos fatos que foram apresentados na seção 6.2. E aqui, fazemos menção ao terceiro inconveniente citado no capítulo 2. Para se provar a desigualdade $\ln (1+x)<x$ por meios algébricos, é necessário certo conhecimento sobre crescimento de funções, conceitos como derivadas, pontos de inflexão, máximo e mínimo entre outros. Porém do ponto de vista geométrico (ainda que de modo informal), não existe qualquer dificuldade em aceitar tal desigualdade, uma vez que, por uma simples análise da figura constatamos que $\ln (1+x)$ representada pela faixa de hipérbole no intervalo 1 a $(1+x)$, está abaixo do retângulo de base $x$ e altura 1, e evidentemente, acima do retângulo de base $x$ e altura $\frac{1}{1+x}$.

Dessa forma, podemos inferir que as respectivas áreas das figuras também obedecerão à desigualdade:

$$
x \cdot \frac{1}{1+x}<\ln (1+x)<x \cdot 1
$$

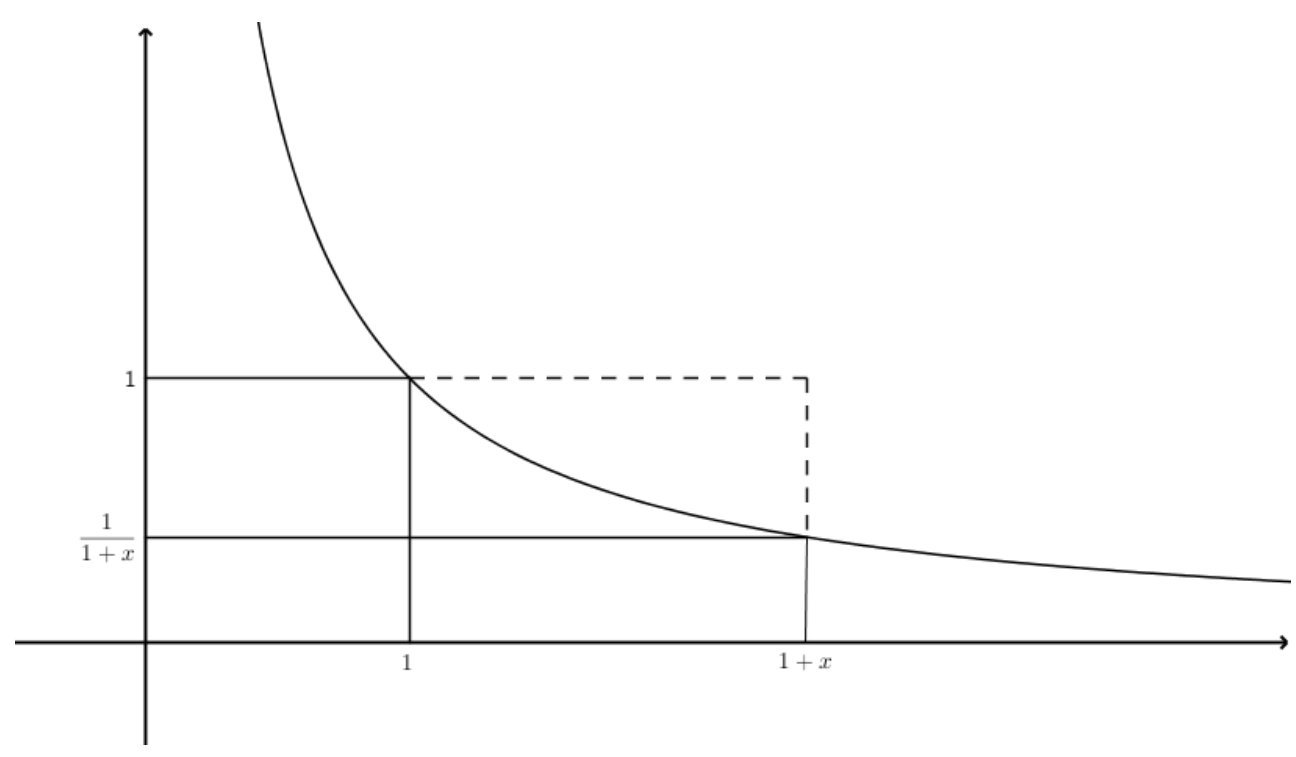

Figura 7.3: Hipérbole da desigualdade exponencial fundamental.

Multiplicando todos os termos da desigualdade pelo real positivo $\frac{1}{x}$ obtemos:

$$
\frac{1}{x} \cdot x \cdot \frac{1}{1+x}<\frac{1}{x} \cdot \ln (1+x)<\frac{1}{x} \cdot x \cdot 1
$$

o que implica

$$
\frac{1}{1+x}<\ln (1+x)^{\frac{1}{x}}<1
$$

Como a função exponencial é continua, podemos aplicar os valores aos expoentes:

$$
e^{\frac{1}{1+x}}<(1+x)^{\frac{1}{x}}<e .
$$


Tomando o limite para $x \rightarrow 0$, a desigualdade será:

$$
\lim _{x \rightarrow 0} e^{\frac{1}{1+x}}<\lim _{x \rightarrow 0}(1+x)^{\frac{1}{x}} \leq \lim _{x \rightarrow 0} e
$$

o que implica

$$
e<\lim _{x \rightarrow 0}(1+x)^{\frac{1}{x}} \leq e
$$

Pelo teorema do confronto, concluímos que $\lim _{x \rightarrow 0}(1+x)^{\frac{1}{x}}=e$.

Do qual concluímos facilmente que $\lim _{x \rightarrow \infty}\left(1+\frac{1}{x}\right)^{x}=e$. Para o caso em que $x<0$, o raciocínio é análogo, bastando fazer algumas adaptações. Seja $x<0$, podemos supor que $x>-1$, do qual obtemos $x+1>0$, dessa forma. faz sentido falar de $\ln (1+x)$. Como $-1<x<0$, então $-\ln (1+x)$ será a área da faixa da hipérbole $H_{1+x}^{1}$, o qual foi convencionado por nós ser um valor negativo (dessa forma, $-\ln (1+x)$ é positivo). A partir de uma análise na figura 7.4 a seguir, obtemos a desigualdade:

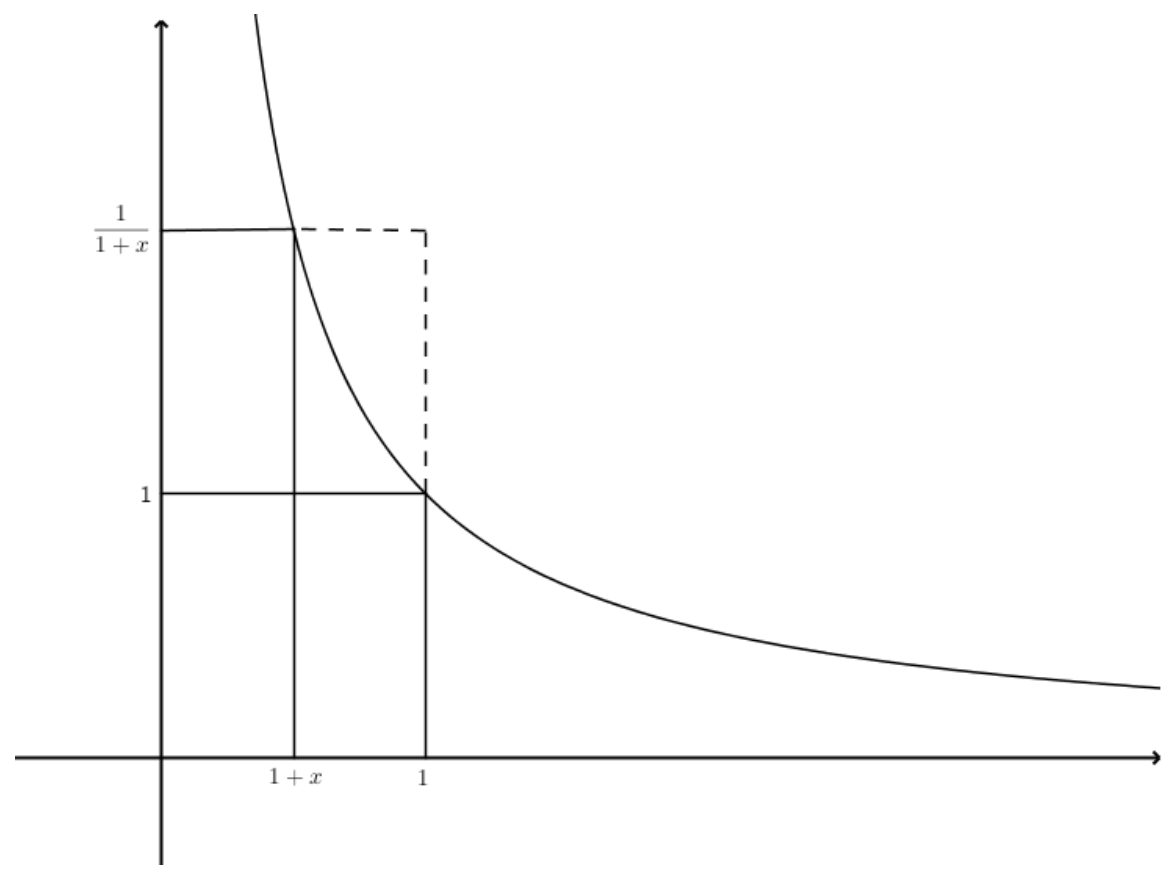

Figura 7.4: Hipérbole da desigualdade exponencial fundamental.

$$
-x \cdot 1<-\ln (1+x)<-x \cdot \frac{1}{1+x} .
$$

Multiplicando todos os termos da desigualdade pelo real positivo $-\frac{1}{x}$ obtemos:

$$
\frac{1}{x} \cdot x \cdot 1<\frac{1}{x} \cdot \ln (1+x)<\frac{1}{x} \cdot x \cdot \frac{1}{1+x} \quad \Rightarrow \quad 1<\ln (1+x)^{\frac{1}{x}}<\frac{1}{1+x} .
$$

E pelos mesmos argumentos apresentados anteriormente, partindo da desigualdade

$$
e<(1+x)^{\frac{1}{x}}<e^{\frac{1}{1+x}}
$$


obtemos

$$
e<\lim _{x \rightarrow 0}(1+x)^{\frac{1}{x}} \leq e \Rightarrow \lim _{x \rightarrow 0}(1+x)^{\frac{1}{x}}=e
$$

para $x<0$.

Dessa forma, por todo o exposto, concluímos por fim que $\lim _{x \rightarrow \infty}\left(1+\frac{1}{x}\right)^{x}=e$.

\subsection{Logaritmos e exponenciais em outras bases}

Vamos aqui, apresentar as funções logarítmicas em outras bases além do número irracional $e$, partindo da premissa que chamamos de base $a \neq 1$ da função ao único número que resulta $\log _{a} a=1$.

Provamos no teorema 5.3.2 da seção 5.3, que podemos obter qualquer função logarítmica, multiplicando uma particular por uma constante $c$ conveniente. Desse modo, partindo de $\ln (x)$, podemos reinterpretar o enunciado do teorema da seguinte forma: "Dada uma função logarítmica $M$ qualquer, existe uma constante $c>0$ tal que $M(x)=c \cdot \ln (x)$ para todo $x>0 "$.

Queremos, portanto, determinar uma constante $c$ que defina $\log _{a} x$ a partir de $\ln (x)$, ou seja, tal que valha: $\log _{a} x=c \cdot \ln (x)$ para todo $x>0$ e também $\log _{a} a=1$.

Tomando $x=a$ na primeira igualdade, obtemos $\log _{a} a=c \cdot \ln (a)$. Mas de $\log _{a} a=1$, decorre que $c \cdot \ln (a)=1$ ou ainda $c=\frac{1}{\ln (a)}$.

Desse modo, necessariamente obtemos a seguinte definição:

$$
\log _{a} x=\frac{\ln (x)}{\ln (a)}
$$

Claramente, o domínio e a imagem de $\ln$ e de $\log _{a}$ são os mesmos, o que nos fornece as igualdades $\operatorname{Dom}\left(\log _{a}\right)=\mathbb{R}_{+}^{*}$ e $\operatorname{Im}\left(\log _{a}\right)=\mathbb{R}$. Observemos que, como $\ln (a)>0$ se $a>1$, o "comportamento' de $\log _{a} x$ é semelhante ao de $\ln (x)$. Já, se a estiver entre 0 e 1 , como $\ln (a)<0$, para todo $x \in \mathbb{R}_{+}^{*}, \log _{a} x$ tem o sinal oposto ao de $\ln (x)$. Os gráficos a seguir ilustram tais situações:

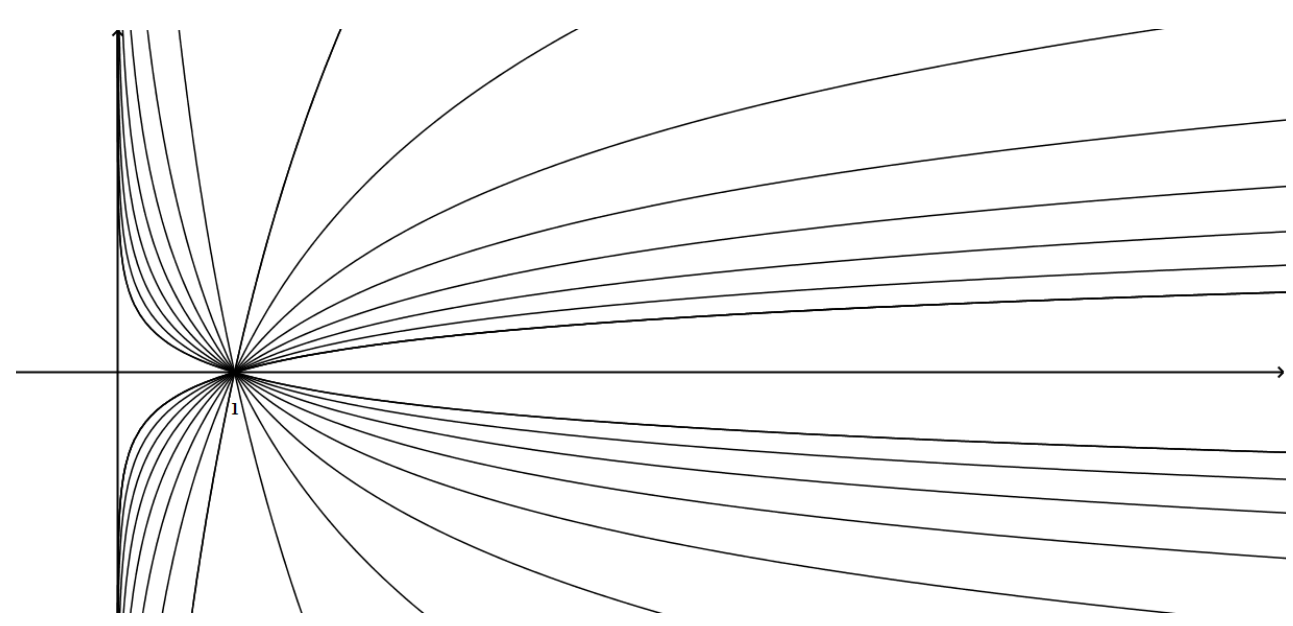

Figura 7.5: Feixe de gráficos. 
e

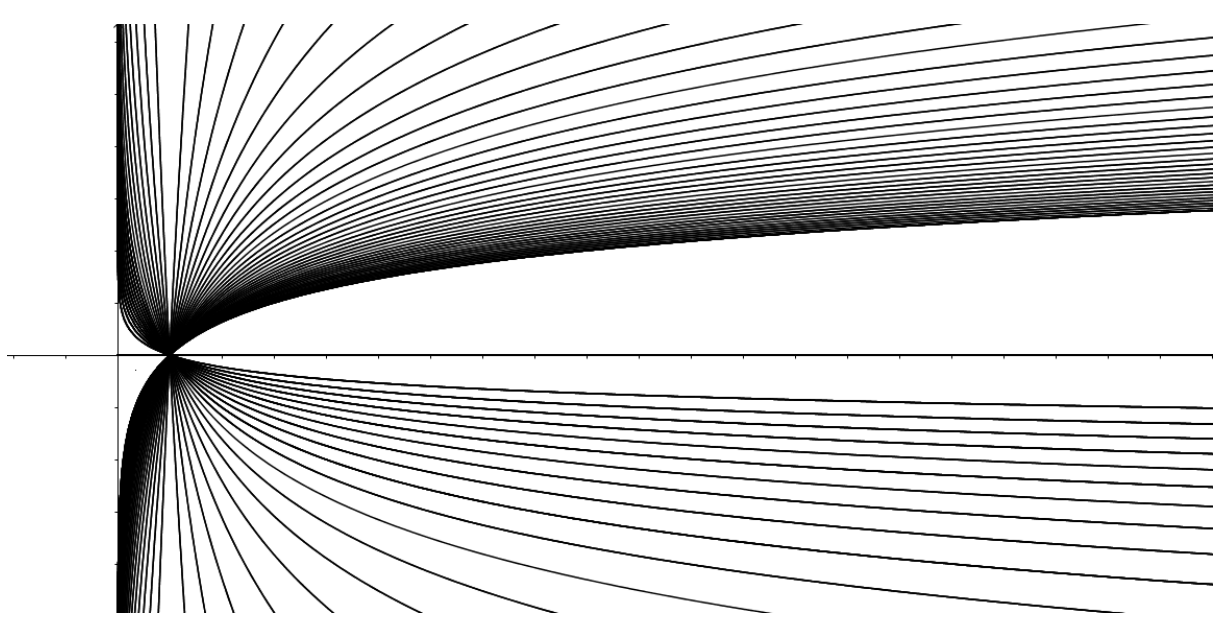

Figura 7.6: Feixe de gráficos 2.

P13) A função $\log _{a} x$ será crescente para $a>1$ e decrescente para $0<a<1$.

Sejam $\log _{a} x, \forall a \in \mathbb{R}_{+}^{*}$ com $a \neq 1$ e $\forall x, y \in \mathbb{R}_{+}^{*}$ com $x>y$, note primeiro que $x>y \Rightarrow$ $\ln (x)>\ln (y)$, como já visto em 5.3.

Para o caso em que $a>1$, já vimos que $\ln (a)>0$ e, de $\ln (x)>\ln (y) \Rightarrow \frac{\ln (x)}{\ln (a)}>\frac{\ln (y)}{\ln (a)}$, ou seja, $\log _{a} x>\log _{a} y$ e portanto crescente.

Para o caso em que $0<a<1$, vimos que $\ln (a)<0$ e, logo de $\ln (x)>\ln (y) \Rightarrow \frac{\ln (x)}{\ln (a)}<\frac{\ln (y)}{\ln (a)}$, ou seja, $\log _{a} x<\log _{a} y$ e portanto decrescente.

Vamos agora, definir exponenciais de base $a \neq 1$ em $\mathbb{R}_{+}^{*}$, da seguinte forma:

$$
\forall x \in \mathbb{R}, a^{x}=y \quad \Leftrightarrow \quad \log _{a} y=x .
$$

Já vimos que $\log _{a} y=\frac{\ln (y)}{\ln (a)}$. Desse modo, $\log _{a} y=x \Leftrightarrow \frac{\ln (y)}{\ln (a)}=x$, ou ainda, $\ln (y)=x \cdot \ln (a)$. Tomando a exponencial de base $e$ em ambos os lados da igualdade, obtemos:

$$
\ln (y)=x \cdot \ln (a) \quad \Leftrightarrow \quad y=e^{x \cdot \ln (a)}
$$

e portanto, necessariamente definimos:

$$
a^{x}=e^{x \cdot \ln (a)}
$$

\subsection{Logaritmos em outras bases por um viés geométrico}

Tomemos uma constante $k>0$. Em vez de partimos para a construção das faixas de hipérboles pela curva $x y=1$, podemos proceder de modo análogo, considerando a curva $x y=k$. Para cada valor escolhido, teremos um novo sistema de logaritmos. Nesse ponto, um comentário se faz pertinente. Dentre as infinitas possibilidades de escolha para $k$, existe uma 
que nos parece mais "natural", dado a familiaridade com a curva resultante. Esse valor é justamente $k=1$, o que resulta no logaritmo de base $e$, mais conhecido como "logaritmo natural". Vamos a algumas considerações para um $k$ arbitrário:

Dados dois pontos $a$ e $b$ quaisquer pertencentes ao eixo $x$, iremos indicar por $H(k)_{a}^{b}$ a faixa de hipérbole $y=\frac{k}{x}$ que estará compreendida entre as retas $x=a$ e $x=b$. Para o caso em que $k=1$, será indicado $H_{a}^{b}$, (como feito anteriormente). Vamos ver o exemplo das curvas $x y=1$ e $x y=2$, com valores $a$ e $b$ para as abscissas.

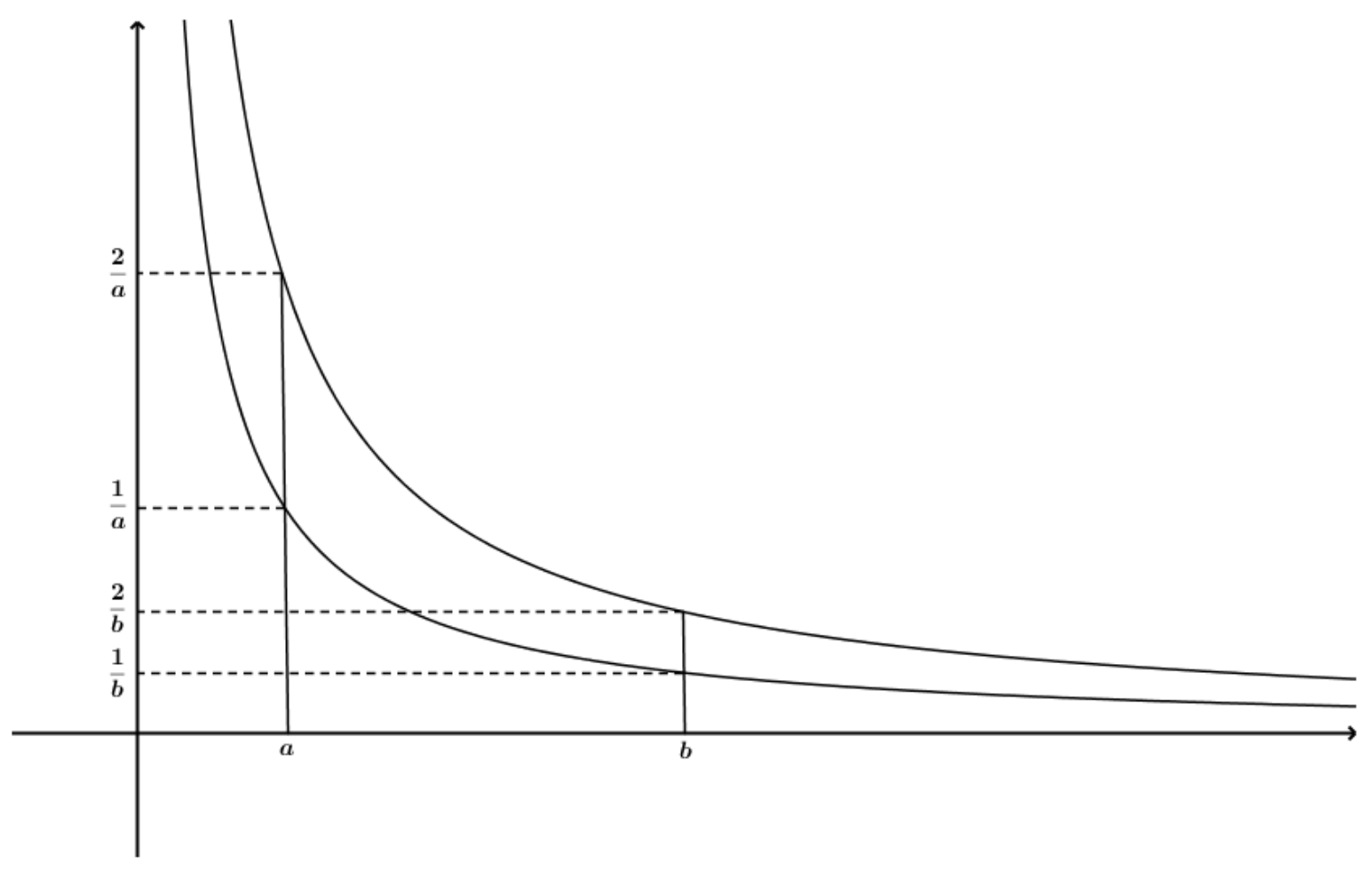

Figura 7.7: Gráficos das hipérboles $H(2)_{a}^{b}$ e $H_{a}^{b}$.

Vamos provar que a área de $H(k)_{a}^{b}$ é igual a $k \cdot H_{a}^{b}$.

Seja um segmento $[c, d]$ contido em $[a, b]$. Tomemos um retângulo de base $[c, d]$, inscrito na hipérbole $y=\frac{1}{x}$, ele terá altura $\frac{1}{d}$, enquanto que um retângulo, também de base $[c, d]$, inscrito na hipérbole $y=\frac{k}{x}$, terá altura $\frac{k}{d}$.

Por consequência, esse retângulo $R$ de base $[c, d]$, inscrito na hipérbole $y=\frac{1}{x}$, terá área $A=(d-c) \cdot \frac{1}{d}$, enquanto o retângulo $R(k)$, também de base $[c, d]$, inscrito na hipérbole $y=\frac{k}{x}$, terá área $A(k)=(d-c) \cdot \frac{k}{d}=k \cdot(d-c) \cdot \frac{1}{d}=k \cdot A$.

Logo, $\sum_{i=1}^{n} \operatorname{Área}\left(R(k)_{i}\right)=\sum_{i=1}^{n}=k \cdot \operatorname{Área}\left(R_{i}\right)=k \cdot \sum_{i=1}^{n} \operatorname{Área}\left(R_{i}\right)$.

Portanto definimos, $\log _{a} x=H(k)_{1}^{x}$ que é equivalente a $\log _{a} x=k \cdot \ln (x)$, com a mesma convenção anterior de atribuir "orientação às áreas", ou seja, sempre que $x<1$ o valor da função $\log _{a} x$ será o oposto do valor da área (negativo, portanto) e se $x>1$, a função assume o próprio valor da área da faixa correspondente. 
A base desse sistema de logaritmos será o número real positivo tal que:

$$
\begin{aligned}
\log _{a} x & =k \cdot \ln (x) \\
\frac{\ln (x)}{\ln (a)} & =k \cdot \ln (x) \\
\frac{1}{k}= & \ln (a) \Rightarrow e^{\frac{1}{k}}=a
\end{aligned}
$$

Então, $\log _{a} x$ será representado por:

$$
\begin{aligned}
& \log _{e^{\frac{1}{k}}} x=y \\
& e^{\frac{y}{k}}=x \Rightarrow \frac{y}{k}=\ln (x), \text { isto é, } \\
& y=k \cdot \ln (x) .
\end{aligned}
$$

Dessa forma, podemos interpretar $\log _{a} x$ como a área abaixo da hipérbole $y=k \cdot \ln x$ compreendida entre 1 e $x$. Entretanto, devemos notar que essa definição geométrica, torna a busca por uma base específica um tanto complicada e os cálculos trabalhosos, o que, de certa maneira, pode ser simplificado considerando $k=\frac{1}{\ln (a)}$ obtendo a igualdade

$$
y=\frac{1}{\ln (a)} \cdot \ln (x)
$$

Recaindo novamente na definição obtida anteriormente, ou seja, $\log _{a} x=\frac{\ln (x)}{\ln (a)}$.

\subsection{Logaritmo natural e sua inversa}

Nesta seção, trataremos de uma questão importantíssima envolvendo os conceitos apresentados anteriormente. Mostraremos algumas aplicações do chamado logaritmo natural ou neperiano. Vimos que um logaritmo será chamado assim, quando sua base for o número irracional $e$, assim, [...] os logaritmos de base e surgem naturalmente em problemas de origens as mais diversas, dai serem chamados de logaritmos naturais (Lima, 2009, p. IX). E de modo indissociável, também a função exponencial $e^{x}$ será frequente em modelos matemáticos, na descrição de fenômenos naturais.

Porém, antes de falar da exponencial de base $e$, vamos discutir um pouco mais o comportamento das funções exponenciais em geral. Tomemos o gráfico de $y=a^{x}$ para um $a>1$ qualquer.

Já vimos que seu comportamento é de uma função crescente, ou seja, conforme o valor de $x$ aumenta, também aumenta o valor de $y$. Entretanto, mais do que isso, é possível perceber que à medida que o valor de $x$ avança, partindo de menos infinito, $y$ cresce lentamente $\mathrm{e}$ depois cada vez mais rápido, tendendo depressa ao infinito no primeiro quadrante. De modo inverso, à medida que o valor de $x$ diminui, $y$ se aproxima cada vez mais de zero, porém a uma taxa cada vez mais lenta, de modo que nunca chegará efetivamente a esse valor. Será tão próximo do eixo $x$ quanto quisermos, mas nunca o tocará. Em uma linguagem mais técnica, 
podemos afirmar que o eixo das abscissas é uma assíntota horizontal para essa função, ou ainda, que o limite para a função quando $x$ tende a menos infinito é zero.

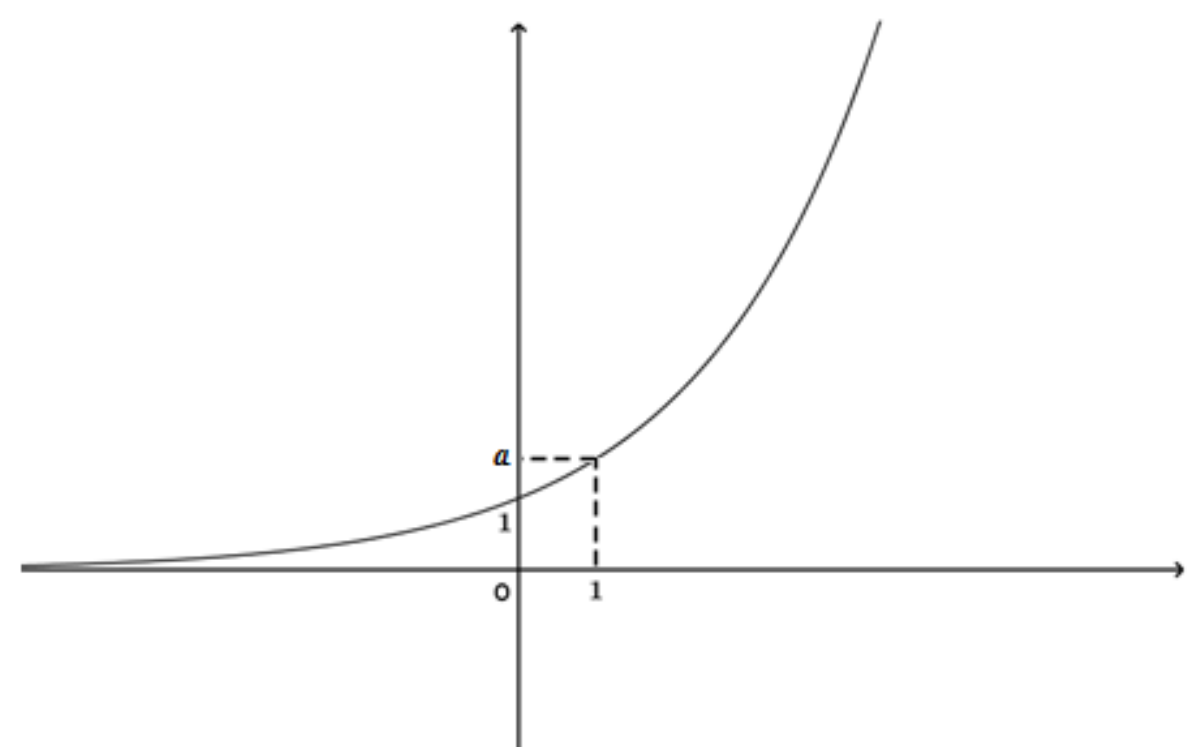

Figura 7.8: Gráfico de $y=a^{x}$ para $a>1$.

A curva acima, apresenta o comportamento de todos os gráficos exponenciais independentemente da base, bastando que seja maior que 1. É nítida sua "simplicidade", uma vez que não possui nenhuma das principais características dos gráficos de funções algébricas, tais como zeros (intersecção do gráfico com o eixo $x$ ), pontos de máximo e mínimo, pontos de inflexão ou assíntota vertical. Ainda mais, ocupa apenas "metade" do plano cartesiano. Por conta de tal "simplicidade", poderíamos, erroneamente, considerar ser ela, uma função de pouco interesse didático e científico. Entretanto, sua taxa de variação (isto é, a maneira como a curva cresce ou decresce, à medida que $x$ varia no seu domínio) possui uma peculiaridade muito interessante. Tomando a taxa de variação instantânea de uma função $y$, também conhecida como derivada (representado por $\frac{d y}{d x}$ ) chegamos a uma conclusão fascinante, a seguir comentada. (Para tanto, vamos partir do pressuposto que o leitor já tenha conhecimento do conceito de derivada, caso contrário, recomendamos a leitura das obras Simmons e Stewart usadas como referencias nesse trabalho).

Podemos definir a derivada de uma função como $\lim _{\Delta x \rightarrow 0} \frac{\Delta y}{\Delta x}$. Vamos encontrar essa taxa para a função $y=a^{x}$ nas condições estabelecidas. Se fizermos um acréscimo de $\Delta x$ ao valor $x$, então $y$ sofrerá um aumento de $\Delta y=a^{(x+\Delta x)}-a^{x}$. Tomando a definição acima, e usando algumas propriedades, obtemos:

$$
\lim _{\Delta x \rightarrow 0} \frac{\Delta y}{\Delta x}=\lim _{\Delta x \rightarrow 0} \frac{a^{(x+\Delta x)}-a^{x}}{\Delta x}
$$




$$
\begin{aligned}
& \lim _{\Delta x \rightarrow 0} \frac{\Delta y}{\Delta x}=\lim _{\Delta x \rightarrow 0} \frac{a^{x} \cdot a^{\Delta x}-a^{x}}{\Delta x} \\
& \lim _{\Delta x \rightarrow 0} \frac{\Delta y}{\Delta x}=\lim _{\Delta x \rightarrow 0} \frac{a^{x}\left(a^{\Delta x}-1\right)}{\Delta x}
\end{aligned}
$$

Fazendo $\Delta x=h$, para tornar a notação mais "limpa", obtemos:

$$
\lim _{\Delta x \rightarrow 0} \frac{\Delta y}{\Delta x}=\lim _{h \rightarrow 0} \frac{a^{x}\left(a^{h}-1\right)}{h} \quad \text { ou ainda } \quad \lim _{\Delta x \rightarrow 0} \frac{\Delta y}{\Delta x}=a^{x} \cdot \lim _{h \rightarrow 0} \frac{a^{h}-1}{h} .
$$

Neste ponto, não temos qualquer garantia de que o limite do resultado obtido exista de fato. Vamos, porém, tomar uma licença matemática e, admitir sua existência antes mesmo de prová-la. Denotando o limite pela letra $k$ temos o seguinte resultado:

Sendo $y=a^{x}$, teremos como derivada $\frac{d y}{d x}=k \cdot a^{x}$, ou seja, $\frac{d y}{d x}=k y$.

Esse resultado torna explícita a peculiaridade fundamental das funções exponenciais, a saber, que sua taxa de variação em cada ponto é proporcional ao próprio valor da função no ponto. Partindo disso, podemos levantar uma nova questão: Quanto vale essa constante de proporcionalidade? Ou mais interessante, existe alguma base $a$ que torne essa constante igual a 1 ?

Em outras palavras, queremos:

$$
\begin{aligned}
\lim _{h \rightarrow 0} \frac{a^{h}-1}{h} & =1 \\
\lim _{h \rightarrow 0} a^{h} & =\lim _{h \rightarrow 0}(1+h) \\
\left(\lim _{h \rightarrow 0} a^{h}\right)^{\frac{1}{h}} & =\left(\lim _{h \rightarrow 0}(1+h)\right)^{\frac{1}{h}} \\
a & =\lim _{h \rightarrow 0}(1+h)^{\frac{1}{h}}=e
\end{aligned}
$$

Como mostramos no teorema 6.2.3 da seção 6.2.

Sendo assim, se tomarmos a constante irracional $e$ para base de uma função exponencial, teremos um fato interessantíssimo, a taxa de variação de uma função exponencial de base $e$ é igual à própria função, em símbolos, sendo $y=e^{x}$, teremos como derivada $\frac{d\left(e^{x}\right)}{d x}=e^{x}$, ou seja, $\frac{d y}{d x}=y$.

Mas podemos ir além nessa conclusão, Não apenas a função e é igual à sua própria derivada, como é a única função (descontando-se uma constante multiplicativa) que tem essa propriedade (Crease, 2011, p. 136). Existem numerosos fenômenos naturais nos quais sua taxa de variação em relação ao tempo é proporcional à própria quantidade. Portanto, todo fenômeno deste tipo pode ser representado por uma equação diferencial do tipo $\frac{d y}{d x}=m y$, 
cuja solução será da forma $y=C e^{x m}$, onde as constantes $m$ e $C$ estão relacionadas às condições particulares de cada fenômeno. Um modelo matemático é a descrição de algum fenômeno do mundo real, por meio de ferramentas matemáticas. Uma equação diferencial é um modelo matemático que estabelece uma relação entre uma função e sua taxa de variação. Funções são as ferramentas matemáticas utilizadas para a descrição dos fenômenos que relacionam grandezas de variação interdependentes. Muitos desses fenômenos são descritos por proposições que envolvem uma taxa de variação de certa grandeza ao longo do tempo. Como apontam Boyce e DiPrima:

[...] para compreender e investigar problemas envolvendo o movimento de fluidos, o fluxo de corrente elétrica em circuitos, a dissipação de calor em objetos sólidos, a propagação e a deteç̧ão de ondas ou o aumento ou a diminuição de populações, entre muitos outros, é necessário saber alguma coisa sobre equações diferenciais (Boyce e Diprima, 2010, p. 01).

Os fenômenos que podem ser estudados por meio das equações diferenciais vão muito além dos apontados acima. Alguns deles podem até ser mais "fáceis de aceitar" como os fenômenos físicos ou químicos. Mas, tal ramo da Matemática é usado nas mais diversas áreas do conhecimento humano, como por exemplo, na psicologia [...] aqueles interessados na teoria do aprendizado estudam a chamada curva do aprendizado, que é o gráfico do desempenho $P(t)$ de alguém aprender alguma coisa como função do tempo de treinamento $t$ (Stewart, 2006, p. 206). Podemos ainda citar: Em sociologia, o cálculo diferencial é usado na análise do espalhamento do boato (ou inovações, ou modismos, ou padrões) (Ibidem).

\subsection{Aplicações envolvendo $\ln x$ e $e^{x}$ na modelagem de fenômenos}

Vamos agora discorrer sobre alguns modelos matemáticos que envolverão a constante $e$. Começaremos por um problema relacionado à Lei do resfriamento extraído e adaptado de um exemplo encontrado em Lima (2009):

- Em um dia cuja temperatura é de $30^{\circ}$ certa quantidade de água fervia em uma panela. Após ter passado cinco minutos do momento em que o fogo foi apagado, a temperatura da água era $65^{\circ}$. Quanto tempo depois de apagado o fogo a água atingirá a temperatura de $38^{\circ}$, sabendo que a lei matemática que expressa essa variação de temperatura é dada por $D(t)=D_{0} e^{-\alpha t}$ onde a constante $\alpha$ depende do material a qual a superfície do objeto é constituída. (Essa relação é conhecida como Lei do resfriamento de Newton, onde $D_{0}$ expressa o valor da diferença da temperatura do objeto exposto ao resfriamento e a temperatura ambiente no momento zero, e consequentemente $D(t)$ será a diferença no instante $t$ ).

No exato momento em que o fogo foi apagado $(t=0)$, a temperatura da água era $100^{\circ} \mathrm{e}$ a do ambiente $30^{\circ}$, logo, $D_{0}=100^{\circ}-30^{\circ}=70^{\circ}$. Após passar $t$ minutos, a diferença da temperatura da água para com a do ambiente é dada por $D(t)=70 \cdot e^{-\alpha t}$. Para determinar 
a constante $\alpha$, usamos o fato de que após 5 minutos a temperatura da água era $65^{\circ}$, ou seja:

$$
\begin{aligned}
35=65-30 & =D(5)=70 \cdot e^{-5 \alpha} \\
\frac{35}{70} & =e^{-5 \alpha} \\
\frac{1}{2} & =e^{-5 \alpha} \\
\ln \left(\frac{1}{2}\right) & =-5 \alpha \\
-\ln (2) & =-5 \alpha \\
\frac{\ln (2)}{5} & =\alpha \\
\alpha & =0,1386 .
\end{aligned}
$$

Temos, portanto a relação, $D(t)=70 \cdot e^{-0,1386 t}$ e desse modo, estamos aptos a responder ao problema inicial, ou seja, quanto tempo a água levará para atingir a temperatura de $38^{\circ}$ após apagado o fogo?

$$
D(t)=70 \cdot e^{-0,1386 t}=38-30=8 \quad \Rightarrow \quad e^{-0,1386 t}=\frac{8}{70}
$$

tomando $\ln$ em ambos os lados da igualdade, $-0,1386 t=\ln \left(\frac{8}{70}\right)$ ou ainda $-0,1386 t=$ $-\ln \left(\frac{70}{8}\right) \Rightarrow 0,1386 t=2,169$ e finalmente $t=\frac{2,169}{0,1386}=15,65$ minutos.

Agora um problema referente a crescimento populacional adaptado de um exemplo cujo original está em Simmons (1987):

- Considere uma cultura de bactérias, criadas em laboratório, com alimento ilimitado e sem inimigos. Se $N=N(t)$ representa o número de bactérias no instante $t$, é natural aceitar que a taxa de variação de $N$ é proporcional ao próprio $N$. Se o número de bactérias presentes no início é $N_{0}$, e esse número dobra após 2 horas, qual será a população após 6 horas?

A lei de crescimento neste caso pode ser escrita como: $\frac{d N}{d t}=k N(k>0)$, rearranjando os termos: $\frac{d N}{N}=k d t$ e integrando em ambos os lados, temos:

$$
\int \frac{d N}{N}=\int k d t \quad \Rightarrow \quad \ln N=k t+C
$$

Como inicialmente (em $t=0$ ) temos $N=N_{0}$, substituímos em $\ln N_{0}=k \cdot 0+C$, para concluir que $\ln N_{0}=C$. Logo, nossa equação (7.5) é expressa por $\ln N=k t+\ln N_{0}$ ou ainda, $\ln N-\ln N_{0}=k t$ o que implica $\ln \frac{N}{N_{0}}=k t$ do qual obtemos:

$$
\frac{N}{N_{0}}=e^{k t} \Rightarrow N=N_{0} e^{k t}
$$

Precisamos agora descobrir a constante $k$, para isso, vamos usar o fato de que o número de bactérias dobra após 2 horas, ou seja, $2 N_{0}=N_{0} e^{2 k} \Rightarrow 2=e^{2 k}$ e pela propriedade dos logaritmos, obtemos $\ln 2=2 k$ ou ainda rearranjando os termos, $k=\frac{1}{2} \ln 2$. 
Do qual finalmente concluímos que a função necessária para obter a população de bactérias após 6 horas é $N(t)=N_{0} e^{(t \cdot \ln 2) / 2}$. Agora basta fazer $t=6$ para obter a proporção desejada, ou seja:

$$
N(6)=N_{0} e^{(6 \cdot \ln 2) / 2}=N_{0} e^{3 \cdot \ln 2}=N_{0} e^{\ln 8}=8 N_{0} .
$$

Logo, passadas 6 horas a população de bactérias será 8 vezes a inicial.

Vamos agora conhecer um novo problema, esse adaptado e extraído de Stewart (2006) referente a crescimento populacional mundial (1987):

- Use o fato de que a população mundial em 1950 era 2560 milhões e em 1960 de 3040 milhões para modelar a população do mundo na segunda metade do século XX. (Suponha que a taxa de crescimento seja proporcional ao tamanho da população.) Qual é a taxa de crescimento relativa? Use o modelo para estimar a população do mundo em 1993 e no ano de 2020.

Medimos o tempo $t$ em anos e fazemos $t=0$ no ano 1950. Medimos a população $P(t)$ em milhões de pessoas. Então $P(0)=2569$ e $P(10)=3040$. Uma vez que estamos supondo que $\frac{d P}{d t}=k P$, da mesma forma que no problema anterior, obtemos: $P(t)=P(0) e^{k} t=2560 \cdot e^{k t}$. Assim, $P(10)=2560 \cdot e^{10 k}=3040 \Rightarrow e^{10 k}=\frac{3040}{2560}$ e aplicando $\ln$ em ambos lados, temos $10 k=$ $\ln \left(\frac{3040}{2560}\right) \Rightarrow k=\frac{1}{10} \cdot \ln \left(\frac{3040}{2560}\right)$ ou ainda $k \approx 0,017185$ o qual podemos inferir que a taxa de crescimento relativa é aproximadamente 1,7\% ao ano, e também que o modelo matemático que descreve esse crescimento é dado por: $P(t)=2560 \cdot e^{0,017185 t}$. Para estimar a população mundial em 1993, basta calcular $P(t)$ para $t=43$, ou seja, $P(43)=2560 \cdot e^{0,017185 \cdot 43} \approx 5360$ milhões.

Fazendo uma previsão da população mundial para o ano de 2020 teremos $P(70)=2560$. $e^{0,017185 \cdot 70} \approx 8525$ milhões.

Vamos por fim conhecer um problema, adaptado e extraído de Boyce e Diprima (2010) referente à mistura de compostos:

- Em um instante $t=0$, um tanque contém $Q_{0}$ lb de sal dissolvido em cerca de 100 gal de água. Uma torneira despeja no tanque uma mistura de $\frac{1}{4} \mathrm{lb}$ de sal por galão de água a uma taxa de $r$ galões por minuto. Ao mesmo tempo esse líquido, já bem misturado, sai do tanque por outra mangueira com a mesma taxa de entrada. Encontre a quantidade de sal $Q(t)$ no tanque em qualquer instante t e a quantidade limite $Q_{L}$ após um período muito longo de tempo.

Partindo do pressuposto que o sal não é criado nem destruído no tanque, as variações nas quantidades estão apenas relacionadas à entrada e saída. Mais precisamente essa taxa $\frac{d Q}{d t}$ será igual à razão de entrada do sal menos a razão de saída, ou seja:

$$
\frac{d Q}{d t}=\text { taxa de entrada }- \text { taxa de saída. }
$$

Como as quantidades de entrada e saída são iguais, o volume de água no tanque é constante em 100 galões. Portanto, a taxa em que o sal deixa o tanque é $[r Q(t) / 100] \mathrm{lb} / \mathrm{min}$. Desse modo, a equação diferencial que rege esse processo é:

$$
\frac{d Q}{d t}=\frac{r}{4}-\frac{r Q}{100} \Rightarrow \frac{d Q}{d t}+\frac{r Q}{100}=\frac{r}{4}
$$


Obtemos uma equação diferencial linear que pode ser facilmente resolvida por meio de um fator integrante, nesse caso $e^{r t / 100} \mathrm{e}$, portanto temos:

$$
\begin{aligned}
& e^{r t / 100}\left(\frac{d Q}{d t}+\frac{r Q}{100}\right)=e^{r t / 100} \frac{r}{4} \\
& e^{r t / 100} \frac{d Q}{d t}+e^{r t / 100} \frac{r Q}{100}=e^{r t / 100} \frac{r}{4} \\
& \frac{d}{d t}\left(e^{r t / 100} Q\right)=e^{r t / 100} \frac{r}{4} \\
& \int \frac{d}{d t}\left(e^{r t / 100} Q\right) d t=\int e^{r t / 100} \frac{r}{4} d t \\
& e^{r t / 100} Q(t)=\frac{r}{4} \int e^{r t / 100} d t \\
& e^{r t / 100} Q(t)=25 e^{r t / 100}+C \\
& Q(t)=25+C e^{-r t / 100}
\end{aligned}
$$

Aplicando a condição inicial $Q(0)=Q_{0}$ obtemos $Q(0)=25+C e^{-r \cdot 0 / 100}$, ou seja, $Q_{0}=25+C$ ou ainda $C=Q_{0}-25$. Portanto, $Q(t)=25+\left(Q_{0}-25\right) e^{-r t / 100}$.

Para encontrar o valor limite $Q_{L}$, basta observar que a parcela $\left(Q_{0}-25\right) e^{-r t / 100}$ ira se anular para valores muito grandes de $t$, isto é, $Q(t) \rightarrow 25$ quando $t \rightarrow \infty$, logo o valor limite para essa situação é $Q_{L}=25$. 


\section{Capítulo 8}

\section{Problemas interessantes e curiosidades envolvendo $e$}

Neste capítulo, vamos conhecer alguns problemas que envolvem de modo direto ou indireto a constante $e$. Eles diferem dos apresentados no capítulo anterior, por possuírem um caráter menos técnico/teórico e mais lúdico. De fato, eles se apresentam sob a forma de desafios e situações que aos poucos vão revelando suas intenções e conclusões. A ideia, é que eles possam ser utilizados pelo professor para instigar a curiosidade dos alunos e posteriormente, no momento em que puder formalizar tais ideias, remeta o conteúdo a esses problemas. Acredito que o primeiro possa ser trabalhado com alunos do Ensino Fundamental II, por exigir um conhecimento técnico menos avançado. Por sua vez, os três últimos, se utilizam de um ferramental teórico mais avançado e talvez seja mais indicado para alunos de Ensino Médio, Licenciatura ou na formação continuada. De qualquer modo, penso que independente do uso que fará o professor, esses conhecimentos são essenciais para sua melhor compreensão dos assuntos e consequentemente, para a sua prática docente.

\subsection{Problema do moleiro e do burro}

Um moleiro era alguém que trabalhava nos moinhos de água ou de vento na moedura de grãos e cereais, em especial do trigo e milho utilizados na fabricação de farinha. É uma profissão muito antiga e que já gozou de muito prestígio na sociedade. Hoje, porém, graças ao desenvolvimento tecnológico e processos industriais, essa profissão se tornou bastante rara. Talvez somente seja possível encontrar algum moleiro ou moinho em funcionamento em pequenas cidades, afastada dos grandes centros urbanos, mas por hora, basta-nos saber o que é para conhecermos o clássico problema que leva o nome de "Problema do moleiro e do burro":

Um moleiro armazenou 10 sacas de trigo, cada uma contendo $100 \mathrm{~kg}$ de trigo. Como ele precisava transportar a carga de sua casa até o moinho, que fica a $100 \mathrm{~km}$ de distância, pediu emprestado um burrinho para seu compadre. Mas foi logo advertido por ele dos seguintes pormenores:

- Ele faz todo tipo de carreto, desde que, quando carregando, precisa ser alimentado constantemente por grãos de trigo. Quando se encontra sem peso, anda o quanto necessário sem apresentar problema;

- O burrinho suporta transportar no máximo $100 \mathrm{~kg}$ por viagem. 
O moleiro achou as condições justas e partiu com o burrinho para transportar suas sacas de trigo. Acontece que já na primeira viagem percebeu que ele comia o equivalente a $1 \mathrm{~kg}$ de trigo por quilômetro percorrido, de modo que ao fim do percurso, ele tinha comido todo o trigo. Desse modo, devemos responder:

Respeitando os termos propostos, é possível transportar todo o trigo da casa do moleiro até o moinho?

E se o moleiro dividir o caminho fazendo varias viagens menores?

Por fim, existe algum modo de maximizar a quantidade de trigo que realmente chega ao moinho?

À primeira vista, parece ser um problema sem solução, dado que a cada viagem o burrinho consome toda a carga que esta transportando. Entretanto, há uma estratégia que o moleiro pode adotar. Vamos ver o que acontece se o caminho for dividido em dois trechos de $50 \mathrm{~km}$.

De inicio o moleiro transportará todo o trigo até a metade do caminho e, portanto, o burrinho consumirá metade de cada carga, ou seja, restarão 10 sacas de $50 \mathrm{~kg}$ cada. Na segunda etapa, poderão ser juntadas duas metades para formar uma carga de $100 \mathrm{~kg}$, restando, portanto, 5 sacas de $100 \mathrm{~kg}$ cada. No final do segundo percurso, restarão 5 sacas de $50 \mathrm{~kg}$ cada. Desse modo, dividindo o percurso em dois trechos iguais de $50 \mathrm{~km}$ cada, conseguiremos "salvar" ao final do processo o equivalente à metade da metade, ou em outras palavras, a quarta parte da carga, isto é, $250 \mathrm{~kg}$. A pergunta que surgirá naturalmente é se existe alguma forma de "salvar" uma carga maior que $250 \mathrm{~kg}$ a partir da situação descrita? E a resposta é sim, vamos ver o que ocorre se dividirmos o percurso em 5 trechos de igual tamanho:

Na primeira etapa, transportaremos toda a carga para $20 \mathrm{~km}$ de distância da casa, mas "perderemos" 1/5 da carga, ou seja, nos restará apenas 4/5 (10 sacos de $80 \mathrm{~kg}$ cada), o que pode ser arranjado de modo a formar 8 sacos de $100 \mathrm{~kg}$. Na segunda etapa, transportaremos toda a carga para $40 \mathrm{~km}$ de distância da casa, mas "perderemos" novamente $1 / 5$ dessa carga, ou seja, nos restará apenas $4 / 5$ de $4 / 5$ ( 8 sacos de $80 \mathrm{~kg}$ cada), o que pode ser arranjado de modo a formar 6 sacos de $100 \mathrm{~kg}$ e um de $40 \mathrm{~kg}$. Poderíamos continuar esse procedimento até transportar toda a carga pelos $100 \mathrm{~km}$. Teríamos, portanto (em uma situação teórica) o equivalente a " $4 / 5$ de $4 / 5$ de $4 / 5$ de $4 / 5$ de $4 / 5$ ", isto é, $(4 / 5)^{5}$ da carga inicial que equivale a $327,68 \mathrm{~kg}$.

Generalizando esse procedimento para $\mathrm{n}$ intervalos igualmente espaçados, teremos a expressão $\left(\frac{n-1}{n}\right)^{n}$ indicando a proporção da carga inicial. Se tomarmos um número de paradas muito grande, nossa expressão se aproximará cada vez mais de um número relacionado ao irracional $e$. Podemos dizer então, para fins teóricos que, tomando $n$ tendendo ao infinito, obtemos $\lim _{n \rightarrow \infty}\left(\frac{n-1}{n}\right)^{n}$ que pode ser reescrito como $\lim _{n \rightarrow \infty}\left(1-\frac{1}{n}\right)^{n}$ que resulta $e^{-1}$ ou o equivalente a 0,3678 da carga inicial, que no nosso exemplo será $367,8 \mathrm{~kg}$.

\subsection{Problema do amigo secreto (Permutação Caótica)}

Uma permutação de $n$ números, com $n \in \mathbb{N}$ é chamada caótica, quando nenhum número estiver em seu lugar primitivo. Desse modo, tomando a lista 1234 de números naturais, temos que 3412 e 2341 são permutações caóticas, enquanto 2431 não é (o 3 está em seu lugar primitivo). A fim de calcularmos o número $D_{n}$ de permutações caóticas de determinada lista 
de $n$ números, devemos definir o conjunto $A_{i}$ que contém todas as permutações de $123 \ldots n$ em que o número $i$ ocupa exatamente a i-ésima posição, com o valor $i \in\{1,2, \ldots, n\}$.

Podemos relacionar esse problema à tão famosa brincadeira chamada "amigo secreto", muito comum nas festas de fim de ano. Nela um determinado número de participantes coloca seu nome em um papel e posteriormente cada um sorteia um desses papeis para presentear sem que ninguém saiba quem sorteou quem. Muito provavelmente, todos já brincaram ou pelo menos já ouviram falar dessa brincadeira, mas vale à pena destacar que, uma situação que não pode ocorrer, é quando um (ou mais participantes) pega $(\mathrm{m})$ o próprio nome na hora do sorteio, pois desse modo ele(s) deve(m) presentear a si mesmo(s), o que foge ao espírito da brincadeira. E, justamente essa situação em que alguém sorteia o próprio nome é que podemos chamar de permutação não caótica (pois ao menos um nome acabou em seu lugar primitivo). No caso em que isso ocorre, são feitos tantos sorteios quanto necessário, até que ninguém pegue o próprio nome. A fim de facilitar a descrição, vamos chamar as situações em que um ou mais participantes sorteiam seu próprio nome de situações com "ponto fixo".

Vamos descobrir como calcular o número de permutações caóticas de $(1,2, \ldots, n)$ e posteriormente a probabilidade de permutações $A_{1}, A_{2}, \ldots, A_{n}$ da mesma sequência, mas tendo $i$ como ponto fixo, partindo da seguinte ideia:

Calculemos o número total de permutações possíveis $\Omega$ de $(1,2, \ldots, n)$ e depois vamos eliminando os casos desfavoráveis, ou seja, com ponto fixo.

$$
\begin{aligned}
& S_{0}=\#(\Omega)=n ! ; \\
& S_{1}=\sum_{i=1}^{n} \#\left(A_{1}\right)=\sum_{i=1}^{n}(n-1) !=n(n-1) !=n ! ; \\
& S_{2}=\sum_{1 \leq i<j \leq n} \#\left(A_{i} \cap A_{j}\right)=\sum_{1 \leq i<j \leq n}(n-2) !=C_{n, 2} \cdot(n-2) !=\frac{n !}{2 !} ; \\
& S_{3}=\sum_{1 \leq i<j<k \leq n} \#\left(A_{i} \cap A_{j} \cap A_{k}\right)=\sum_{1 \leq i<j<k \leq n}(n-3) !=C_{n, 3} \cdot(n-3) !=\frac{n !}{3 !} ; \\
& \vdots \\
& S_{n}=C_{n, n} \cdot(n-n) !=\frac{n !}{n !} .
\end{aligned}
$$

Agora basta tomar o total de permutações e subtrair os casos em que ocorre ponto fixo. Apesar de parecer trivial essa tarefa, é preciso ter cuidado, pois ela necessita de uma análise minuciosa, caso contrário podemos cometer o equívoco de contar duas vezes algum caso ou eliminar algum que deveria ser considerado.

Apenas a título de exemplo, note o caso $n=3$. Vamos encontrar $A_{1}$ :

Fixando o primeiro elemento: (1223), (132);

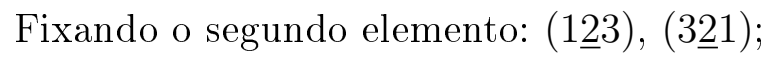

Fixando o terceiro elemento: (12י), (21ㅍ); 
Partindo disso, deveríamos subtrair 6 do resultado total, mas é claro que isso não é verdade, uma vez que o caso (123) foi contado 3 vezes. Como contornar isso então? Podemos usar o princípio da Inclusão e Exclusão, e o problema ficará simples. Não iremos abordá-lo aqui para não sobrecarregar sobremaneira o texto, mas para o leitor interessado, Santos e Morgado (utilizados em nossa bibliografia) trazem o assunto de modo completo. Entretanto, partindo dessas ideias, podemos observar o seguinte:

Tomando um caso genérico com n elementos, devemos observar o seguinte:

Ao fixar o primeiro elemento, teremos certo número de permutações, mas dentre todas elas, em algum momento ocorrerão as do tipo $(\underline{1} 2 \ldots)$. Por outro lado, ao fixar o segundo elemento, em certo momento ocorrerão as permutações do tipo (1… .). Ora, serão justamente as mesmas permutações computadas duas vezes cada. Não precisamos nos preocupar em descontar cada uma duas vezes se, em vez de subtrairmos, nós somarmos as do tipo (12 ...), resolvendo assim o problema da dupla subtração.

Em símbolos, o que queremos é o seguinte:

$$
\begin{aligned}
D_{n} & =S_{0}-S_{1}+S_{2}-S_{3}+\ldots+(-1)^{n} \cdot S_{n} \\
& =n !-n !+\frac{n !}{2 !}-\frac{n !}{3 !}+\ldots+(-1)^{n} \cdot \frac{n !}{n !} \\
& =n !\left[1-1+\frac{1}{2 !}-\frac{1}{3 !}+\ldots+(-1)^{n} \cdot \frac{1}{n !}\right] \text { ou ainda } \\
& =n !\left[1-\frac{1}{1 !}+\frac{1}{2 !}-\frac{1}{3 !}+\ldots+(-1)^{n} \cdot \frac{1}{n !}\right]
\end{aligned}
$$

Na seção 3.4, dissemos que Euler passou a representar a função $e^{x}$ utilizando a série:

$$
e^{x}=1+\frac{x}{1 !}+\frac{x^{2}}{2 !}+\frac{x^{3}}{3 !}+\frac{x^{4}}{4 !}+\frac{x^{5}}{5 !}+\frac{x^{6}}{6 !}+\frac{x^{7}}{7 !}+\frac{x^{8}}{8 !}+\frac{x^{9}}{9 !}+\frac{x^{10}}{10 !}+\frac{x^{11}}{11 !}+\frac{x^{12}}{12 !} \ldots
$$

Note que se tomarmos para $x$ o inteiro $(-1)$, obtemos:

$$
e^{-1}=1-\frac{1}{1 !}+\frac{1}{2 !}-\frac{1}{3 !}+\frac{1}{4 !}-\frac{1}{5 !}+\frac{1}{6 !}-\frac{1}{7 !}+\frac{1}{8 !}-\frac{1}{9 !}+\frac{1}{10 !}-\frac{1}{11 !}+\frac{1}{12 !} \ldots
$$

Limitando o número de termos (por exemplo para 9), podemos afirmar então que, para algum real $\varepsilon>0$ temos:

$$
e^{-1}=1-\frac{1}{1 !}+\frac{1}{2 !}-\frac{1}{3 !}+\frac{1}{4 !}-\frac{1}{5 !}+\frac{1}{6 !}-\frac{1}{7 !}+\frac{1}{8 !}+\varepsilon
$$

ou ainda

$$
e^{-1}=\frac{D_{n}}{n !}+\varepsilon
$$

Perceba que esse $\varepsilon$ (o qual chamaremos de erro), se tornará tão menor, quanto mais termos n utilizarmos. 
Podemos desse modo, calcular a probabilidade de obtermos permutações caóticas em um dado número de lançamentos. Mas perceba que dividindo o número de casos favoráveis pelo número total de casos, obtemos justamente:

$$
P\left(D_{n}\right)=\frac{D_{n}}{n !}=e^{-1}-\varepsilon
$$

Em outras palavras, obtemos uma aproximação para $\frac{1}{e}$ com uma precisão tão boa quanto desejarmos. No momento em que quisermos obter uma aproximação melhor, basta aumentar o número $n$.

Podemos então concluir a partir do exposto que a probabilidade de se realizar um sorteio de amigo secreto e ele "dar certo", isto é, ninguém tirar seu próprio nome, é algo em torno de $\frac{1}{e}$ ou ainda, aproximadamente $36 \%$. Pode parecer bem contra intuitivo se pensarmos por outra ótica, isto é, a probabilidade de alguém tirar o próprio nome é algo em torno de $64 \%$ e, portanto maior do que a probabilidade de ninguém sortear a si mesmo.

\subsection{Matematizando as sensações}

No ano de 1825 o fisiologista alemão Ernst H. Weber $(1795$ - 1878) fez uma série de experiências envolvendo sensações humanas. Em uma delas um homem vendado deveria segurar uma espécie de peso ao qual, gradualmente, eram acrescentadas cargas menores. O homem deveria avisar quando sentisse, pela primeira vez, que houve um aumento de peso. Foi descoberto que a percepção da mudança de peso não era proporcional ao aumento absoluto da carga, mas sim, ao aumento relativo. Ou seja, se em um momento a pessoa submetida ao teste estivesse segurando um peso com $10 \mathrm{~kg}$ e a ele fosse acrescentado $1 \mathrm{~kg}$ (aumento de dez por cento), para fornecer a mesma sensação à pessoa quando estivesse segurando um peso de $20 \mathrm{~kg}$ seria necessário acrescentar um peso de $2 \mathrm{~kg}$, isto é, um aumento proporcional a dez por cento. Analisando por outra ótica, podemos dizer que a sensação transmitida ao acrescentar um peso de $2 \mathrm{~kg}$ a alguém que já esteja segurando um peso de $10 \mathrm{~kg}$ seria diferente se essa mesma pessoa estivesse segurando um peso de $20 \mathrm{~kg}$. Isso pode ser expresso matematicamente pela expressão:

$$
d s=k \cdot \frac{d W}{w}
$$

em que $d s$ é o menor aumento perceptível de peso, $d W$ o aumento do peso correspondente, $W$ é o peso já existente e $k$ é uma constante de proporcionalidade.

Essa lei foi generalizada para todo tipo de sensação fisiológica, tais como dor sentida por uma pressão física, percepção de brilho causado por fonte de luz ou de volume causado por uma fonte sonora etc. Posteriormente essa lei foi muito utilizada e popularizada pelo médico alemão Gustav T. Fechner (1801 - 1887) e ficou conhecida como "lei de Weber-Fechner".

Interpretando do ponto de vista matemático essa lei, temos uma equação diferencial que após ser integrada resultará:

$$
s=k \ln W+C
$$

Se tomarmos $W_{0}$ como o maior peso que não causa estímulo físico (um nível limite exatamente antes de provocar uma resposta), teremos $s=0$ para $W=W_{0}$ o qual resulta que $C=-k \ln W_{0}$. 
Substituindo esse valor na expressão anterior, obtemos por fim:

$$
s=k \ln W-k \ln W_{0} \quad \Rightarrow \quad s=k \ln \frac{W}{W_{0}} .
$$

Podemos concluir então que a resposta para um estímulo obedece a uma lei logarítmica de base $e$. Desse modo, para que a resposta aumente em iguais proporções, o estímulo correspondente deve aumentar a uma taxa constante, ou seja, em progressão geométrica.

Apesar da lei de Weber-Fechner ter sido aplicada a uma grande variedade de situações em que se media uma resposta fisiológica, hoje sua validade universal é discutível. Enquanto os estímulos físicos podem ser perfeitamente mensurados, por se tratarem de medidas objetivas, a resposta humana ao estímulo será algo subjetivo e totalmente sujeito a características próprias de cada situação e pessoa submetida ao teste. Entretanto, existe uma sensação que se mostrou extremamente precisa no que diz respeito à possibilidade de mensurá-la. A mudança de volume ou tonalidade musical. O ouvido humano é um órgão extremamente sensivel, capaz de notar uma mudança de tonalidade causada por uma alteração de frequência de apenas 0,3 por cento (Maor, 2006, p. 149). Um músico possui uma habilidade ainda maior para identificar essas mudanças, dado que treina essa capacidade constantemente e, um ouvido bem treinado capta facilmente mudanças na faixa de 20 ciclos por segundo até algo próximo de 20 mil (variando com a idade). Em termos de tonalidade, essa diferença corresponde a cerca de dez oitavas (é raro uma orquestra usar mais que sete).

Ao tomarmos um conjunto de notas separadas por oitavas, ou seja, com proporção 2:1, a frequência dessas notas aumenta na progressão $1,2,4,8, \ldots$ e assim sucessivamente. Por essa razão, a pauta onde são escritas as notas musicais é na verdade uma escala logarítmica em que a distância vertical (tom da nota) é proporcional ao logaritmo da frequência.

Para finalizar, podemos ainda citar a escala de brilho de magnitude estelar, a escala Richter (que mede a intensidade dos tremores de terra), a escala de espectro visível pelo olho humano, a escala decibel de ruído, entre várias outras que seguem uma escala logarítmica.

\subsection{Problema do paraquedista}

Suponha que um paraquedista salte de um avião e em dado momento $t=0$ abra seu paraquedas. É possível estimar a velocidade em que ele chegará ao solo?

Esse problema será apresentado dentro de hipóteses que o simplificam, como admitir que a queda se dê em movimento vertical e desconsiderando uma análise dimensional mais detalhada das grandezas envolvidas. Nessa situação ideal é possível considerar a força de resistência que o ar exerce proporcional à velocidade da queda, para velocidades relativamente pequenas. Chamemos de $k$ a constante de proporcionalidade e $m$ a massa do paraquedista. Teremos duas forças opostas agindo sobre ele, o peso $m g$ (sendo $g$ a aceleração da gravidade, cerca de $9,8 \mathrm{~m} / \mathrm{s}^{2}$ ) e a resistência do ar $k v$ (no qual $v=v(t)$ é a velocidade de queda no instante $t$ ).

A força resultante será

$$
F=m g-k v
$$

O sinal negativo na equação indica que são forças agindo em direções opostas. 
De acordo com a segunda lei do movimento de Newton

$$
F=m a
$$

onde $a=\frac{d v}{d t}$ representa a aceleração ou taxa de variação da velocidade em relação ao tempo, e desse modo, igualando (8.1) e (8.2), obtemos

$$
m \frac{d v}{d t}=m g-k v \quad \Rightarrow \quad \frac{d v}{d t}=g-\frac{k v}{m}
$$

Interpretando a expressão $\frac{d v}{d t}$ como uma proporção entre duas diferenciais, e substituindo a fração $\frac{k}{m}$ por $a$, podemos reescrever a equação anterior de modo a isolar as variáveis $v$ e $t$, e posteriormente resolver a equação diferencial obtendo, portanto:

$$
\frac{d v}{g-a v}=d t \quad \Rightarrow \quad \frac{-1}{a} \ln (g-a v)=t+c .
$$

É possível determinar a constante de integração $c$ que apareceu na igualdade a partir da condição inicial desse problema, isto é, chamando a velocidade no instante em que o paraquedas se abre de $v_{0}$, teremos $v=v_{0}$ quando $t=0$. Substituindo na equação obtida temos $c=\frac{-1}{a} \ln \left(g-a v_{0}\right)$, ou seja,

$$
\begin{gathered}
\frac{-1}{a} \ln (g-a v)=t-\frac{1}{a} \ln \left(g-a v_{0}\right) \\
\frac{-1}{a}\left[\ln (g-a v)-\ln \left(g-a v_{0}\right)\right]=t \\
\ln (g-a v)-\ln \left(g-a v_{0}\right)=-a t \\
\ln \left(\frac{g-a v}{g-a v_{0}}\right)=-a t
\end{gathered}
$$

Por fim, resolvendo essa equação para $v$ em função de $t$, ficaremos com:

$$
\begin{gathered}
\ln \left(\frac{g-a v}{g-a v_{0}}\right)=-a t \\
\frac{g-a v}{g-a v_{0}}=e^{-a t} \\
g-a v=e^{-a t}\left(g-a v_{0}\right) \\
a v=g-e^{-a t}\left(g-a v_{0}\right) \\
a v=g-g e^{-a t}+a v_{0} e^{-a t}
\end{gathered}
$$




$$
\begin{aligned}
& a v=g\left(1-e^{-a t}\right)+a v_{0} e^{-a t} \\
& v=\frac{g}{a}\left(1-e^{-a t}\right)+v_{0} e^{-a t}
\end{aligned}
$$

Dessa equação, podemos inferir uma conclusão interessantíssima:

Se o paraquedas for aberto imediatamente após o salto, teremos $v_{0}=0$, desse modo, o último termo da equação é eliminado e, portanto, se resume a $v=\frac{g}{a}\left(1-e^{-a t}\right)$. Por outro lado, mesmo caindo livremente antes de abrir o paraquedas, o efeito "velocidade inicial nula" aumenta com o passar do tempo, isto é: para $t \rightarrow \infty$, a expressão $e^{-a t}$ tende a zero e, portanto, a velocidade limite $v_{\infty}$ depende unicamente do peso $m g$ e do coeficiente de resistência $k$, ou seja, $v=\frac{g}{a}$, mas como $a=\frac{k}{m}$, resulta em $v=\frac{m g}{k}$. Justamente esse fato que propicia um pouso suave e seguro em um vôo de paraquedas. Podemos ver o comportamento descrito através do seguinte gráfico:

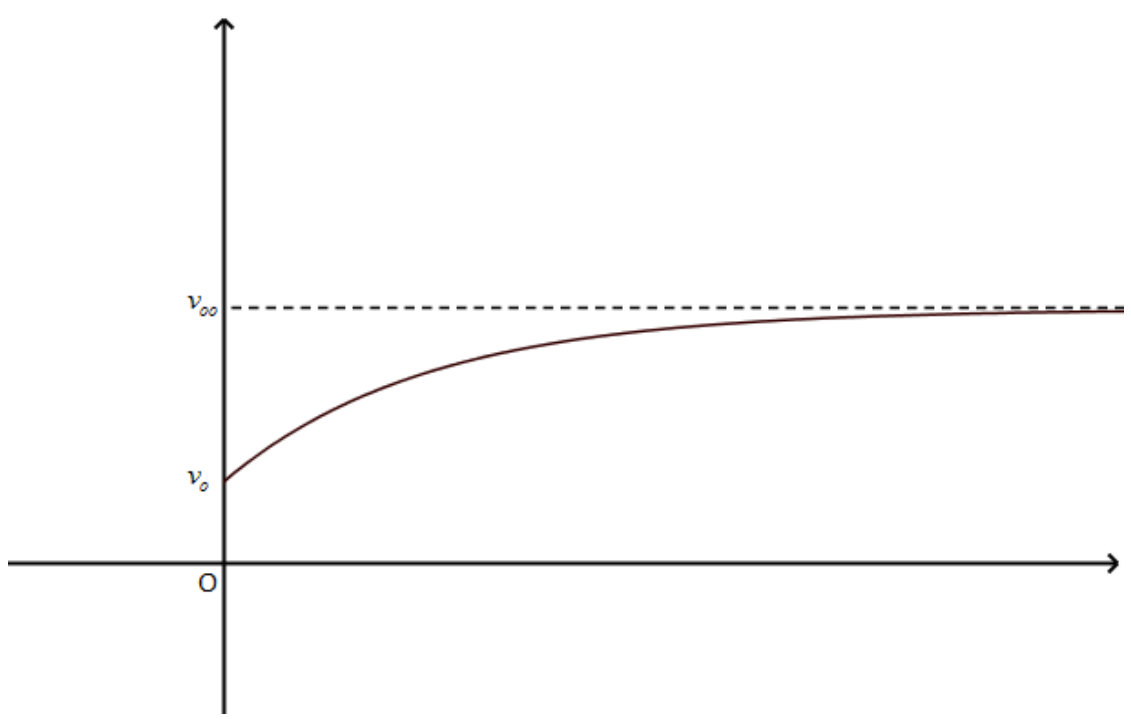

Figura 8.1: Gráfico Paraquedas. 


\section{Capítulo 9}

\section{Considerações finais}

Se por um lado, já é consenso entre os profissionais da educação que o professor necessita de um conhecimento que vai além do oferecido em sua formação, por outro não se tem estabelecido qual deve ser esse conhecimento. Dentro das concepções existentes, há os que defendem que apenas um saber matemático aprofundado pode dar conta da tarefa de ensinar e existem os que acreditam ser a prática suficiente para atingir o objetivo esperado. Neste trabalho, no capítulo 2, apresentamos um terceiro ponto de vista. Compreendemos que a sala de aula é um espaço complexo de troca de informações, onde convivem diferentes pessoas, as mais variadas concepções, pré-requisitos, habilidades físicas e intelectuais. Dessa forma, acreditamos que nenhuma dessas convicções deva ser descartada, mas sim, que se estabeleça um amálgama entre o que cada uma delas tem de melhor a oferecer.

Baseados no artigo de Ball et al. (2008), mais especificamente no conceito de conhecimento matemático especializado, e na questão "Qual matemática o professor necessita para realizar seu trabalho de modo satisfatório?", esperamos que esta dissertação contribua para a reflexão e o desenvolvimento profissional do professor, tanto em formação, quanto em atuação. Buscamos oferecer elementos que complementem os conhecimentos pedagógicos, epistemológicos e matemáticos do educador por meio de uma abordagem completa e atual de conceitos relativos ao tema. Devemos salientar que o referencial teórico utilizado merece, por si só, uma profunda análise e reflexão, por ser um campo novo e rico de estudos que tem influenciado uma série de pesquisas na área da educação de modo geral. Acreditamos que as questões históricas e epistemológicas aqui apresentadas, podem desempenhar um papel importante nas aulas, (inclusive corroborados por recomendações de documentos oficiais que regulamentam a educação) uma vez que, nada surge por acaso, e a Matemática, como qualquer outro corpo do saber, não é isenta de influências sociais. É importante que o aluno também se aproprie dessa concepção a fim de tornar o conhecimento mais legítimo e natural. Por fim, cabe destacar a relevância do próprio tema matemático aqui abordado, dado que:

A função logaritmo, porém, nunca morrerá, pela simples razão de que as variações exponenciais e logarítmicas são partes vitais da natureza e da análise. Consequentemente, um estudo das propriedades da função logaritmo e de sua inversa, a função exponencial, permanecerá sempre uma parte importante do ensino da matemática (Eves, 2004, p. 351). 
CONSIDERAÇÕES FINAIS 


\section{Referências Bibliográficas}

Ávila(2006) Geraldo Ávila. Análise Matemática para licenciatura. Edgard Blucher, São Paulo, 3 edição. Citado na pág.

Ball et al.(2008) Deborah Ball, Mark Thames e Geoffrey Phelps. Content knowledge for teaching: What makes it special? Journal of Teacher Education, 59:389-407. Citado na pág. xi, $9,10,11,12,13,14,15,17,18,97$

Boyce e Diprima(2010) William E. Boyce e Richard C. Diprima. Equações diferenciais elementares e problemas de valores de contorno. LTC, Rio de Janeiro. Tradução: Valéria de Magalhães Iório. Citado na pág. 85, 87

Boyer(1974) Carl Benjamin Boyer. História da Matemática. Edgard Blucher, São Paulo, 4 edição. Tradução: Elza F. Gomide. Citado na pág. 19

Carneiro(1995) José Paulo Carneiro. O problema do amigo oculto. Revista do Professor de Matemática, (28). Citado na pág.

Crease(2011) Robert P. Crease. As grandes Equações: a história das fórmulas matemáticas mais importantes e os cientistas que as criaram. Zahar, Rio de Janeiro. Tradução: Alexandre Cherman. Citado na pág. 28, 29, 39, 84

de Freitas Druck(1995) Iole de Freitas Druck. Um pouco da história de potências, exponenciais e logaritmos. Relatório Técnico 24 do Departamento de Matemática. IME-USP, São Paulo. Citado na pág.

Edwards(1979) C. H. Edwards. The historical development of the Calculus. SpringerVerlag, New York. Citado na pág. 36

Eves(2004) Howard Eves. Introdução à História da Matemática. Editora da Unicamp. Tradução: Hygino H. Domingues. Citado na pág. 20, 97

Figueiredo(2011) Djairo Guedes Figueiredo. Números irracionais e transcendentes. SBM, Rio de Janeiro, 3 edição. Citado na pág.

Iezzi et al.(2014) Gelson Iezzi, Osvaldo Doce, David Degenszajn, Roberto Périgo e Nilze de Almeida. Matemática: ciência e aplicações, volume 1. Saraiva, São Paulo, 8 edição. Citado na pág. 5, 7, 8

Jakubovic(1980) José Jakubovic. Das Porcentagens aos Logaritmos. CENP. Subsídios para a implementação da proposta curricular de matemática para o $2 \hat{A}^{o}$ grau, 1(6):31-45. Citado na pág. 22, 25

Lima(2009) Elon Lages Lima. Logaritmos. SBM, Rio de Janeiro, 4 edição. Citado na pág. 1, $6,8,19,20,33,82,85$ 
Maor(2006) Eli Maor. e: A história de um número. Record, Rio de Janeiro, 3 edição. Tradução: Jorge Calife. Citado na pág. 21, 22, 27, 28, 69, 70, 94

MEC(2001) Guia de Orientações Metodológicas Gerais. MEC. Ministério da Educação, MEC. Secretaria de Ensino Fundamental. Programa de Formação de Professores Alfabetizadores, PROFA , Brasília, DF, 2001. Citado na pág. 9

Morgado et al.(1991) Augusto Cezar Morgado, Paulo Cezar Pinto Carvalho, Pedro Fernandez e Jo ao Bosco Pitombeira. Análise Combinatória e Probabilidade, Coleção do Professor de Matemática. Sociedade Brasileira de Matemática, Rio de Janeiro. Citado na pág.

Paiva(2013) Manuel Paiva. Matemática, volume 1. Moderna, São Paulo, 2 edição. Citado na pág. 5,7

Roque() Tatiana Roque. História da Matemática. Uma visão crítica, desfazendo mitos e lendas. Zahar, Rio de Janeiro. Citado na pág.

Santos et al.(1995) J. P. O. Santos, M. P. Mello e I. T. C Murari. Introdução à Análise Combinatória. Editora da UNICAMP, Campinas. Citado na pág.

Simmons(1987) George F. Simmons. Cálculo com geometria analítica, volume 1. McGrawHill. Tradução: Seiji Hariki. Citado na pág. 1, 6, 28, 86

Smole e Diniz(2013) Katia Stocco Smole e Maria Ignez Diniz. Matemática: Ensino Médio, volume 1. Saraiva, São Paulo, 8 edição. Citado na pág. 5, 6

Stewart(2006) James Stewart. Cálculo, volume 1. Pioneira Thomson Learning, São Paulo, 5 edição. Citado na pág. 85,87 